\title{
Demand for Irrigation Water from Depleting Groundwater Resources:
}

\section{An Econometric Approach}

\author{
Dissertation \\ to obtain the Ph. D. degree
}

in the International Ph. D. Program for Agricultural Sciences in Goettingen (IPAG)

at the Faculty of Agricultural Sciences,

Georg-August-University Göttingen, Germany

\author{
presented by \\ Tinoush Jamali Jaghdani \\ born in TEHRAN / IRAN \\ Göttingen, December 2011
}





\section{D7}

1. Name of supervisor: Prof. Dr. Bernhard Brümmer

2. Name of co-supervisor: Prof. Dr. Stephan v. Cramon-Taubadel

Date of dissertation: 09.02.2012 



\section{Contents}

$\begin{array}{ll}\text { 1. Introduction } & 1\end{array}$

1.1. The importance of groundwater and economic studies . . . . . . . . . . 1

1.2. Research motivation ...................... 3

1.3. Outline of the chapters ................... 6

2. Demand for Irrigation Water from Depleting Groundwater Resources in Pistachio Production 9

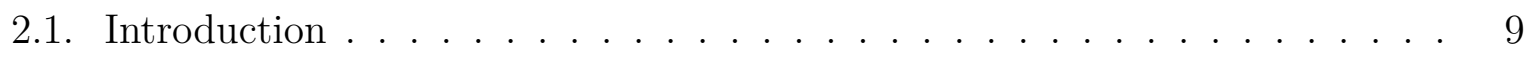

2.1.1. Groundwater scarcity rent and Gisser-Sanchez Paradox . . . . . . . 11

2.1.2. Water demand estimation in industry and agriculture . . . . . . 13

2.1.3. Groundwater resources demand and influential factors . . . . . . . . 16

2.1.4. Groundwater demand estimation in Iran . . . . . . . . . . . . . 18

2.2. The conceptual framework . . . . . . . . . . . . . . . 19

2.3. Field study and data . . . . . . . . . . . . . . . . . . 23

2.3.1. Study area . . . . . . . . . . . . . . . . 23

2.3.2. Pistachio production . . . . . . . . . . . . . 28

2.3.3. Field work . . . . . . . . . . . . . . . . . 30

2.3.4. Description of data . . . . . . . . . . . . . 34

2.4. Empirical model and estimation . . . . . . . . . . . . . . . . 46

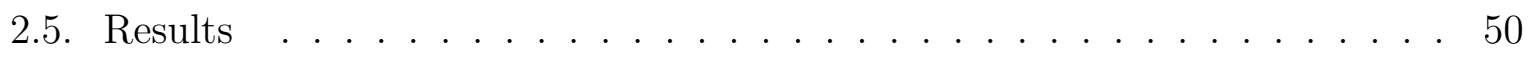

2.6. Discussion . . . . . . . . . . . . . . . . . 6 64

2.7. Conclusion . . . . . . . . . . . . . . . . . . . 67 
3. Participation of Tree-crop Farmers in Spot Water Markets in Semiarid Areas 69

3.1. Introduction . . . . . . . . . . . . . . . . . . . . . . . 69

3.2. Literature review . . . . . . . . . . . . . . . . . . . 72

3.3. Methodology . . . . . . . . . . . . . . . . . 74

3.4. Study area and data . . . . . . . . . . . . . . . . . . 76

3.5. Results . . . . . . . . . . . . . . . . . . . 80

3.5.1. Description of results . . . . . . . . . . . . . . 80

3.5.2. Analysis of results . . . . . . . . . . . . . . . 80

3.6. Discussion . . . . . . . . . . . . . . . . . . . . 85

3.7. Conclusion . . . . . . . . . . . . . . . . . . 87

4. Willingness to Pay for Irrigation Water from Groundwater in Spot Water $\begin{array}{ll}\text { Market by Self Selectivity } & \mathbf{8 8}\end{array}$

4.1. Introduction . . . . . . . . . . . . . . . . . . . . . . . 88

4.1.1. Water valuation and water pricing . . . . . . . . . . 88

4.1.2. Water market and water property rights . . . . . . . . . . . 91

4.2. Literature Review . . . . . . . . . . . . . . . . . . . . . . . 94

4.3. Methodology . . . . . . . . . . . . . . . . . 98

4.4. Study area and data . . . . . . . . . . . . . . . . . 101

4.5. Results . . . . . . . . . . . . . . . . . . . . 104

4.6. Discussion and conclusion . . . . . . . . . . . . . . . . 108

$\begin{array}{ll}\text { 5. Summary } & 110\end{array}$

$\begin{array}{ll}\text { Bibliography } & 116\end{array}$

$\begin{array}{ll}\text { A. Appendix } & 130\end{array}$ 


\section{List of Tables}

1.1. The top 20 groundwater irrigating countries . . . . . . . . . . . 4

2.1. Demographic structure and agricultural operating units structure in the area covering Rafsanjan aquifer . . . . . . . . . . . . . . . . . 24

2.2. Area of planted crops in Rafsanjan aquifer (ha) . . . . . . . . . . . 25

2.3. General information about the Rafsanjan aquifer . . . . . . . . . . . 26

2.4. The land and water ownership pattern in the 157 farm sample . . . . . . 33

2.5. Descriptive summary of the variables . . . . . . . . . . . . . 34

2.6. Parameter estimates of translog cost function in SUR and SAR . . . . . . 54

2.7. SUR and SAR estimation of Shephard's lemma equation for sand-manure-

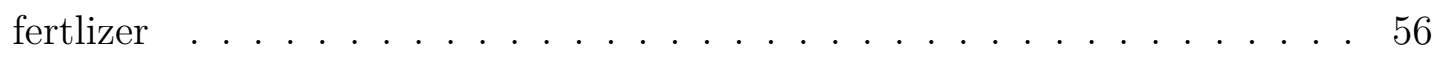

2.8. SUR and SAR estimation of Shephard's lemma equation for water . . . . 56

2.9. SUR and SAR estimation of Shephard's lemma equation for pesticide de-

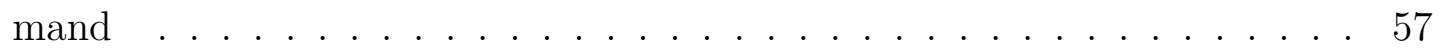

2.10. SUR and SAR estimation of Shephard's lemma equation for machine de-

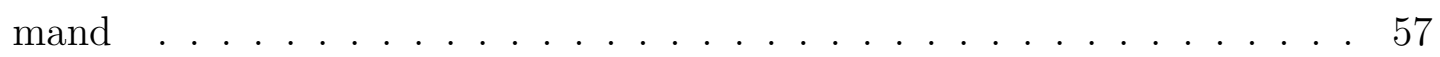

2.11. SUR and SAR estimation of demand elasticities on the mean of sample cost shares . . . . . . . . . . . . . . . . . . . . 5 58

2.12. SUR and SAR estimation of shadow prices for the average of sample . . . . 59

2.13. SUR and SAR estimation of shadow prices for the average of positive and

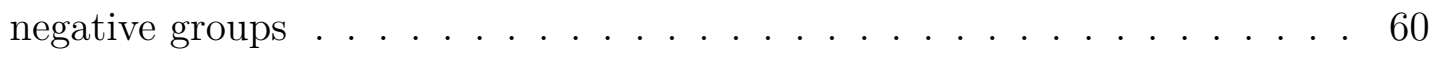

3.1. General information about the Rafsanjan aquifer region . . . . . . . . . . 77

3.2. Pumping unit and farm participation in water market . . . . . . . . 78 
3.3. Descriptive summary of variables . . . . . . . . . . . . . . . 79

3.4. Land ownership status of study participants in spot water market . . . . . 82

3.5. Water quota per hectare and participation in water market . . . . . . . . . 82

3.6. Logistic regression coefficients of factors affecting the decision to buy ground-

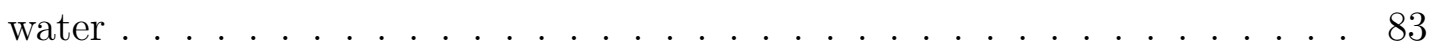

3.7. Calculated probabilities of factors affecting the outcome according to the logit model (percent) . . . . . . . . . . . . . . . . . . . 84

4.1. Pumping unit and farm participation in spot water market . . . . . . . . 101

4.2. Descriptive summary of variables . . . . . . . . . . . . . . 104

4.3. Heckman model . . . . . . . . . . . . . . . . . . . . . . . . . . . 107 


\section{List of Figures}

1.1. Share of groundwater from total irrigation water and all water uses . . . 5

2.1. The map of study area . . . . . . . . . . . . . . . . . 23

2.2. Rafsanjan Hydrograph (1984-2009) . . . . . . . . . . . . . . 26

2.3. Rafsanjan aquifer water quality EC graph . . . . . . . . . . . . 27

2.4. Global top five pistachio producers . . . . . . . . . . . . . . . 29

2.5. Geographical position of wells and farms . . . . . . . . . . . . . . . 32

2.6. Histogram of the ownership pattern of pumping units and EC of ground-

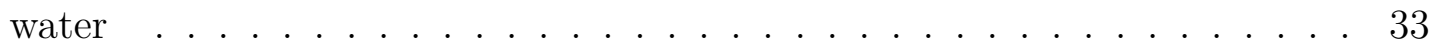

2.7. Irrigation water use and water quota per hectare for the sample $\ldots . .36$

2.8. Electricity tariffs for normal hours in different sectors . . . . . . . . . . . . 37

2.9. Electricity tariffs for off-peak hours in different sectors . . . . . . . . 38

2.10. Electricity tariffs for peak hours in different sectors . . . . . . . . . 38

2.11. The histogram of pistachio production per hectare as an average of bearing and non-bearing years . . . . . . . . . . . . . . . . . 40

2.12. the average pistachio production per hectare for the bearing year 2008 and the non-bearing year $2007 \ldots \ldots$. . . . . . . . . . . . . . . 41

2.13. The relation between the age of the wells and the number of well repositioning up to 2008 in the sample . . . . . . . . . . . . . . . . . 44

2.14. Histogram of the average age of the trees on sampled farms and tree density per hectare . . . . . . . . . . . . . . . . . . . . . . 45

2.15. Spatial neighborhood . . . . . . . . . . . . . . . . . . 48

2.16. Boxplot of the share of variable costs . . . . . . . . . . . . . . 51 
2.17. Boxplot of the energy share of the variable pumping costs $\ldots \ldots \ldots$. . . 52

2.18. The difference between the depth of water levels and the depth of the wells 52

2.19. Moran's I test results on the residuals of the water equation and translog cost function . . . . . . . . . . . . . . . . . . . 5 55

2.20. The relation between shadow price for extra water in farm to the water quota per hectare in SUR and SAR . . . . . . . . . . . . . . . . 61

2.21. The relation between the shadow price for extra tree in farm and tree density per hectare . . . . . . . . . . . . . . . . . 61

2.22. The plot of the relation between the available stock of capital for well and estimated shadow price for extra unit investment in well repositioning in

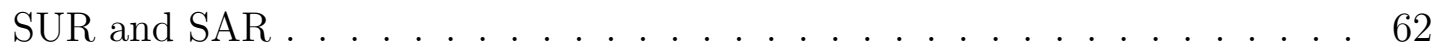

2.23. Relation between EC level, and shadow price for EC . . . . . . . . . . 63

2.24. Relation between EC level, and shadow price for EC larger than 6000 . . . 63

3.1. Geographical position of wells and farms . . . . . . . . . . . . . 78

3.2. Irrigation water quality at water pumping units $\ldots \ldots . . . . . .80$

3.3. Relative shares of bought water as a percentage of water used, water quota and related to farm size f . . . . . . . . . . . . . . 81

4.1. Histogram of the variable pumping costs and the price paid within the spot water market during 2007-2008 agricultural year in the sample of observations 102

4.2. Spatial distribution of water prices $\left(\right.$ rials $/ \mathrm{m}^{3}$ ) in the aquifer during 20072008 agricultural year in the sample of observations . . . . . . . . . . 103 


\section{List of Abbreviations}

\begin{tabular}{|c|c|}
\hline CGE & Computable General Equilibrium \\
\hline CVM & Contingent Valuation Method \\
\hline DEA & Data Envelopment Analysis \\
\hline EC & Electric Conductivity \\
\hline FMS & Fertiliser-Manure-Sand \\
\hline GLM & Generalised Linear Model \\
\hline GM & Generalised Method \\
\hline GSE & Gisser and Sánchez Effect \\
\hline IWRM & Integrated Water Resources Management \\
\hline IWRMC & Iran Water Resources Management Company \\
\hline KRW & Kerman Regional Water Corporation \\
\hline $\mathrm{kWh}$ & Kilowatt hours \\
\hline LPM & Linear Probability Model \\
\hline MLE & Maximum Likelihood Estimation \\
\hline MOE & Ministry of Energy \\
\hline
\end{tabular}

NKEPD Co. North Kerman Electrical Power Distribution Company

OLS Ordinary Least Square 
RIWA Rafsanjan Irrigation Water Authority

SUR Seemingly Unrelated Regression

USDA United States Department of Agriculture

VMP Value Marginal Products

WFD Water Framework Directive

WRS Basic Water Resources Studies

WTP Willingness to Pay 


\section{Acknowledgments}

Many thanks especially to Prof. Dr. Bernhard Brümmer for supervising me as a PhD student. It is a great honor for me to have him as my primary supervisor and it is a great pleasure for me to do the $\mathrm{PhD}$ study with his guidance. I am very grateful for his comments, assistance, support, and patience during the development of this research and my PhD study in the past years. I have benefited a lot from his wide methodological and theoretical knowledge and guidance. Many thanks go to Prof. Dr. Stephan v. Cramon-Taubadel for being the second supervisor of this thesis and his support during the past years. Thanks to Prof. Dr. Meike Wollni for being the examiner of my dissertation. I thank the Iran Water Resources Management Company (IWRMC) for providing piezometric data. I gratefully acknowledge the help of Mr. A. N. Esfandiari, the Head of Economics Desk in IWRMC and Mr. A. G. Alizadeh, Director General of Amin Padidar Pistachio Co. during the field research. Thanks to Mrs. Tayebeh Aryan, the Head of Economics Section of Mahabghodss Consulting Engineers Co. for her cooperation and help. Thanks also go to the Rafsanjan Irrigation Water Authority (RIWA) for their cooperation, especially Mr. Abbas Darvishi, who is responsible for Statistics and Information in RIWA. I am very grateful to local people for their patience and cooperation during field surveys. I recognise the financial support from the Lichtenberg Foundation and Georg-August-Universität Göttingen during my PhD study and this research. I am thankful to all colleagues in the chair of Agricultural Market Analysis and the chair of Agricultural Policy at Göttingen University for all their support and help. Special thanks go to my colleague and friend Dr. Rico Ihle for his encouragement and support. Finally heartfelt thanks to my parents and family members for their unending support for all my endeavours. I am truly grateful to all. 



\section{Introduction}

"At this stage of history either one of two things is possible. Either the general population will take control of its own destiny and will concern itself with community interests, guided by values of solidarity and sympathy, and concern for others; or alternatively there will be no destiny for anyone to control"

(Manufacturing Consent: Noam Chomsky and the Media 2:40:53).

\subsection{The importance of groundwater and economic studies}

During the second half of the 20th century, groundwater withdrawals have increased up to the point that they now supply water to half of the world's population (UNICEF, 1998). It is said that groundwater is the world's most extracted raw materials (Jaroslav and Annukka, 2007). This extra use has caused water table drawdowns and depletion of groundwater resources (aquifer ${ }^{1}$ ) in many parts of the world, and this highlights the importance of groundwater management. Intensive use of groundwater leads to a wide array of social, economic and environmental consequences such as land subsidence, increases in the vulnerability of agriculture and other uses of the water to climate change, increases in pumping costs, etc. (Burke, 2003, p.70). The open-access nature of natural resources such as groundwater and the accompanying externalities, in combination with

\footnotetext{
${ }^{1}$ In hydrology, rock layer that contains water and releases it in appreciable amounts. The rock contains water-filled pore spaces, and, when the spaces are connected, the water is able to flow through the matrix of the rock. An aquifer may also be called a water-bearing stratum, lens, or zone (Britannica On-line Encyclopedia)
} 
the failure to treat natural resources as capital has made this an attractive research area (Brown, 2000, p.895), with a view toward the development of rules for efficient water allocation among competing uses over time and space (Xepapadeas and Koundouri, 2004, p.1). While groundwater has always been important to humankind, both technical and institutional management of the resource tend to be fairly primitive relative to surface water. Perhaps this is due to the physical characteristics of groundwater. Its sources are usually hidden below ground, and only the often sophisticated networks for its distribution to the final place of use are clearly visible, so that groundwater management is often underestimated in terms of relevance (and complexity). Even as technical understanding has grown, institutional arrangements have lagged behind (Garrido and Livingston, 2003, p.218).

An economist thinks of groundwater as something that can be treated as a potentially valuable resource like many others such as gold or silver (Shaw, 2005, p.202). Economic studies on groundwater resources have focused mainly on comparisons of quantity-based management between two regimes: optimal control and competitive pumping. In order to do such a comparison, variables affecting groundwater use must be defined. As a result, the study of groundwater demand or willingness to pay (WTP) for groundwater is part of a strategy for the management of this resource, in the sense that it provides information about the effects of control variables on groundwater use (Koundouri, 2004b, p.716). Understanding the economics of water can help inform decision makers of the full social costs of water use in agriculture and the full social value or benefits that agriculture's use of water can provide (Hanemann, 2006). Economic incentives, such as using water pricing, taxes and fees for demand management and allocation of water, have proved to be effective in domestic and industrials sectors (UNWWAP, 2009, p.156). However, the empirical analysis of the economics of groundwater management is often hampered by a lack of data access. Availability of groundwater data with acceptable quality is a major problem in many studies (Koundouri, 2004b, p.716) as aquifers are wide and pumps are dispersed over a large area. The specific pattern of groundwater abstraction for irrigation has not been mapped consistently at any national, regional or global scale. The same is true of hydrological mapping and groundwater occurrences (Burke, 2003, p.68). 
Irrigated agriculture is the main user of the major sedimentary aquifers of the Middle East, North Africa, and North America as well as the Asian alluvial plains of the Punjab and Terai (Björklund et al., 2009, p.132). Irrigation is the most important water use sector accounting for about $70 \%$ of the global freshwater withdrawals and $90 \%$ of consumptive water uses (Siebert et al., 2010, p.1863). Globally, area equipped for irrigation is currently about 301 million ha, of which $38 \%$ is equipped for irrigation with groundwater. Total annual consumptive groundwater use for irrigation is estimated at $545 \mathrm{~km}^{3}$, or $43 \%$ of the total annual consumptive irrigation water use of $1277 \mathrm{~km}^{3}$ (Siebert et al., 2010, p.1863). As agriculture is the biggest groundwater user in many parts of the world, factors affecting agricultural demand for water is of high interest.

\subsection{Research motivation}

In developed countries and in many other places in the world, the easiest investments for exploiting water resources have already been made. The cost of new water supplies is and has been rising. With available dam sites decreasing, water tables falling and the distances between the point of water abstraction and water use increasing, the costs of exploitation and supply are rising. Costs are also pushed up by the growing need to treat water before use (UNWWAP, 2009, p.59). The economic challenge is to establish a management regime that is both efficient and equitable. This applies to change institutional arrangements from an unmanaged to a managed system (Garrido and Livingston, 2003, p.207). Public investment in groundwater development and protection has been smaller and more dispersed than for surface water resources (UNWWAP, 2009, p.131). There is an evolutionary pattern of resource management policy. As resource stocks are drawn down, management agencies dominated by non-economists are restricting overall harvest, thus reducing the domain of common property to just the harvestable quota. No particular economic purpose is served by this policy but it could achieve biological, ecological or physical goals if the agencies were resolute and immune from the pressures for greater quotas exerted by harvesters (Brown, 2000, p.890). Generally speaking, application of economic principles to groundwater management to date is very limited (Garrido and 
Table 1.1.: The top 20 groundwater irrigating countries

\begin{tabular}{|c|c|c|c|c|c|c|}
\hline \multirow[b]{2}{*}{ Country } & \multirow[b]{2}{*}{$\begin{array}{l}\text { Cultivated } \\
\text { land per } \\
\text { agricul- } \\
\text { tural } \\
\text { worker } \\
\text { (hectares) }\end{array}$} & \multirow[b]{2}{*}{$\begin{array}{l}\text { Area under } \\
\text { groundwater } \\
\text { irrigation } \\
\text { (thousands } \\
\text { of hectares) }\end{array}$} & \multirow[b]{2}{*}{$\begin{array}{c}\text { Share of } \\
\text { global } \\
\text { groundwater- } \\
\text { irrigated } \\
\text { area } \\
\text { (percent) }\end{array}$} & \multicolumn{2}{|c|}{ Groundwater-irrigated area } & \multirow[b]{2}{*}{$\begin{array}{l}\text { Groundwater- } \\
\text { irrigated } \\
\text { area } \\
\text { (percent of } \\
\text { total area) }\end{array}$} \\
\hline & & & & $\begin{array}{l}\text { Share of } \\
\text { irrigated } \\
\text { area } \\
\text { (percent) }\end{array}$ & $\begin{array}{l}\text { Share of } \\
\text { total } \\
\text { cultivated } \\
\text { area } \\
\text { (percent) }\end{array}$ & \\
\hline India & 0,6 & 26538 & 38,6 & 53 & 15,6 & 8,1 \\
\hline United States & 63,8 & 10835 & 15,8 & 45,5 & 6,1 & 1,1 \\
\hline China & 0,3 & 8863 & 12,3 & 16 & 5,5 & 0,9 \\
\hline Pakistan & 0,8 & 4871 & 7,1 & 30,8 & 22 & 6,1 \\
\hline Iran & 2,6 & 3639 & 5,3 & 50,1 & 21,3 & 2,2 \\
\hline Bangladesh & 0,2 & 2592 & 3,8 & 69,1 & 30,8 & 18 \\
\hline Mexico & 3,2 & 1689 & 2,5 & 27 & 6,2 & 0,9 \\
\hline Saudi Arabia & 6 & 1538 & 2,2 & 95,6 & 40,5 & 0,7 \\
\hline Italy & 11,2 & 865 & 1,3 & 27,2 & 7 & 2,9 \\
\hline Turkey & 1,9 & 672 & 1 & 16 & 2,4 & 0,9 \\
\hline Syria & 3,3 & 610 & 0,9 & 60,2 & 11,3 & 3,3 \\
\hline Brazil & 5,9 & 545 & 0,8 & 19 & 0,8 & 0,1 \\
\hline Libya & 22,9 & 464 & 0,7 & 98,7 & 21,6 & 0,3 \\
\hline Morocco & 2,4 & 430 & 0,6 & 29 & 4,6 & 1 \\
\hline Argentina & 24,1 & 403 & 0,6 & 27,7 & 1,2 & 0,1 \\
\hline Cuba & 5,2 & 393 & 0,6 & 45,1 & 10,4 & 3,5 \\
\hline Yemen & 0,6 & 383 & 0,6 & 79,6 & 23 & 0,7 \\
\hline Afghanistan & 1,2 & 367 & 0,5 & 11,5 & 4,6 & 0,6 \\
\hline Egypt & 0,4 & 361 & 0,5 & 10,6 & 10,6 & 0,4 \\
\hline Algeria & 3 & 352 & 0,5 & 61,8 & 4,3 & 0,1 \\
\hline
\end{tabular}

Source : Shah et al. (2007)

Livingston, 2003, p.211). Therefore, economic analysis that can improve the understanding of groundwater use is of interest.

According to FAO data (AQUASTAT), Iran is fifth on the list of the top 20 countries for using groundwater for irrigation (Shah et al., 2007, p.400). Table 1.1 shows the top 20 groundwater irrigating countries. There are 629 aquifers which are recognized throughout Iran; however $35.2 \mathrm{~km}^{3}$ from the total extraction (68 percent) comes from 176 aquifers which have negative balances. From this group, 88 aquifers are already in the red zone ${ }^{1}$ (Jamab, 2004, p.4). There are differences among the estimations of the total water use and the share of the groundwater use in Iran. Figure 1.1 shows groundwater and surface

\footnotetext{
${ }^{1}$ If the natural recharge of the aquifer remains far behind the intensive use of groundwater, the aquifer is called red zone in hydro-geological literature. In this condition the water table drops dramatically.
} 


\section{Share of groundwater from total irrigation water and all water uses $\left(\mathrm{km}^{3}\right)$}

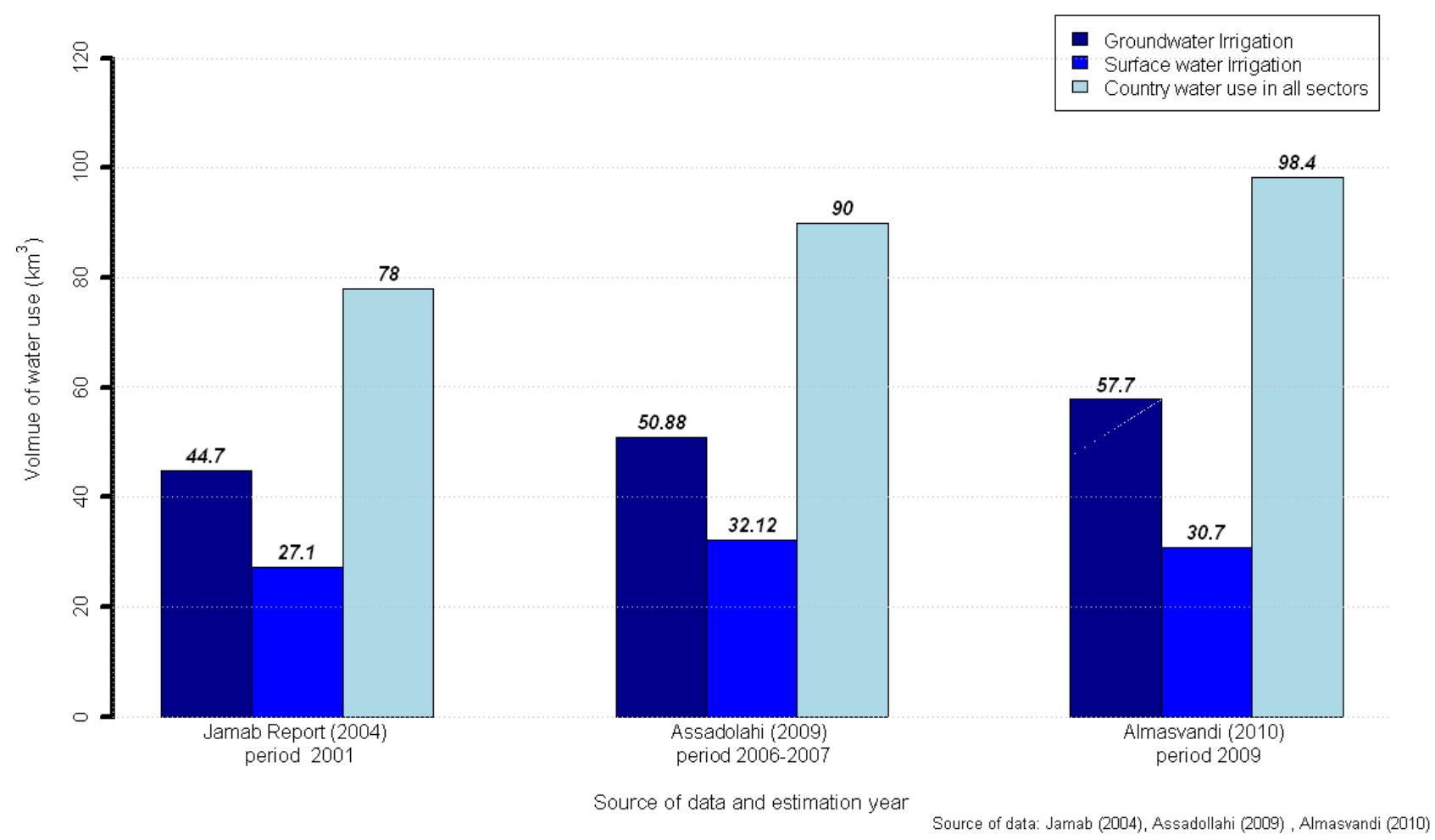

Figure 1.1.: Share of groundwater from total irrigation water and all water uses

water withdrawals for irrigation from the whole water withdrawal. Figure 1.1 has been made with the help of three different data sources. Based on Assadollahi (2010), irrigation water accounts for $90 \%$ of groundwater withdrawal in Iran. This accounts for more than $50 \mathrm{~km}^{3}$ of water ${ }^{2}$. This shows the importance of the groundwater resources in Iran and the necessity of economic instruments for resource management, especially in the agricultural sector.

As we can see, groundwater plays an important role for general water supply in Iran. In spite of its importance, its management is mainly technical, which is not so different from many other parts of the world. Groundwater is administrated under common property rights and managed by the government. The lack of econometric studies for analysing different aspects of the groundwater demand at the size of specific aquifer was the main motivation of this research. The importance of groundwater irrigation in Iran and the minor role of economic management of it were incentives to test and analyse the demand

\footnotetext{
${ }^{2}$ Based on Almasvandi (2010), approximately $65 \%$ of irrigation water is provided from groundwater and $35 \%$ is provided from surface water (figure 1.1).
} 
for groundwater from different aspects. This research is a contribution to the few studies on the econometric estimation of scarcity rents of groundwater and the groundwater market from different aspects. Field research and statistical analysis can help recognise the unknown aspects of groundwater demand in depleting groundwater resources. Knowing these aspects can help the local administration to develop better economical and political solutions for groundwater management. Rafsanjan aquifer in Southeaster part of Iran is selected for this study. The main reasons for selecting Rafsanjan are its unique agricultural production pattern, high-value pistachio production, and its size. Pistachio is one of the main Iran's non-oil export commodities and Rafsanjan is the main region of pistachio production.

\subsection{Outline of the chapters}

This dissertation is divided to three essays that summarise groundwater demand studies in pistachio production of the Rafsnajan aquifer in southeastern Iran. The field study was done from November 2008 - February 2009. In these essays, groundwater demand is analysed from three different methodological approaches. These essays that shape chapters $2-4$ are as follows:

- Chapter 2: Demand for irrigation water from depleting groundwater resources in pistachio production ${ }^{1}$

- Chapter 3: Participation of tree-crop farmers in spot water markets in semiarid $\operatorname{areas}^{2}$

- Chapter 4: Willingness to pay for irrigation water from groundwater in spot water markets by self-selectivity ${ }^{3}$

\footnotetext{
${ }^{1}$ The earlier version of this chapter was accepted for poster presentation in "XIIIth Congress of the European Association of Agricultural Economists", ETH in Zurich (Switzerland), August 29 - September 2, 2011 and for an oral presentation in the "Inaugural Conference on Iran's Economy", SOAS, University of London (England), December 7-8, 2011.

${ }^{2}$ The earlier version of this chapter was accepted for oral presentation in "Tropentag Conference 2011", Bonn, October $5-7,2011$

${ }^{3}$ The advanced version of this chapter was accepted for oral presentation in "Tropentag Conference 2012”, Göttingen, September 19 - 21, 2012
} 
Chapter 2 This chapter starts by reviewing the main literature and studies on groundwater management and demand studies. We analysed the economic factors and the groundwater quality as influencing variables on the derived demand function for irrigation water in the pistachio production of the Rafsanjan aquifer in southeastern Iran. The field study was conducted from November 2008 - February 2009. The details of the data and study area are given in this chapter. A translog cost function has been applied for the estimation of the derived demand function for groundwater in pistachio production and its shadow price. Spatial econometrics has been applied to correct the results. Results show that demand for groundwater is inelastic for changes in pumping costs. It also shows that spatial correlation affects the estimated demand function.

Chapter 3: A logit model for the binary participation variable is used to test the factors affecting farmers' decisions to buy groundwater from neighbours who share the same pump. Both farmer characteristics and technical variables are considered as explanatory variables. The results show that the technical variables contribute substantially to the participation decision. For example, a decrease in water quality, an increase in the age of the garden, and an increase in the size of the water quota reduce the probability of participation. In contrast, more scattered plots and a deeper water table increase the probability of participation in spot water markets. Additionally, the application of the spatial Moran's I test on the residuals of regression shows no spatial effects inside the model in the residuals. The results suggest that in this area participation in water markets is motivated more by profit-increasing factors than by farmer characteristics.

Chapter 4: This chapter looked at the self-selectivity issue of willingness to pay for irrigation water and the price dispersion available in these sorts of markets. The results show that two distinct groups with different WTP are available in the sample area and the participants in the spot water market have a much higher WTP for extra water than the non-participants. 
Finally chapter 5 is a general conclusion with recommendations for future policies and further research. Two questionnaires are included in the appendix. 


\section{Demand for Irrigation Water from}

\section{Depleting Groundwater Resources in}

\section{Pistachio Production}

"Nothing at all takes place in the universe in which some rule of maximum or minimum does not appear"

Leonhard Euler

\subsection{Introduction}

In the past, hydrologic challenges were mainly managed by manipulating the hydrologic cycle with engineering solutions, such as building new dams and canal networks. Increasingly, however, emphasis is being placed by many countries to improve the economic and environmental performance of the water system by providing economic incentives to take into account the cost, value, price and demand for water in agriculture (Molle and Berkoff, 2007, ch.1). There are many shortcomings that characterise how water is managed today in a context of increased scarcity: low efficiency, environmental degradation, and inequity. Despite some improvements, competition is increasing and water use efficiency remains low in most sectors. But the answer is not just more efficient allocation mechanisms and more emphasis on greater yields and productivity, because these alone may lead to further losses in equity and environmental sustainability. Rather, a combination of supply and demand management measures is needed (UNWWAP, 2009, p.154). Water demand management can be defined as any method (whether technical, economic, administrative, 
financial or social) that will accomplish one (or more) of the following five objectives (Brooks, 2006, p.524):

1. Reduce the quantity or quality of water required to accomplish a specific task.

2. Adjust the nature of the task or the way it is undertaken so that it can be accomplished with less water or with lower quality water.

3. Reduce the loss in quantity or quality of water as it flows from source through use to disposal.

4. Shift the timing of use from peak to off-peak periods.

5. Increase the ability of the water system to continue to serve society during times when water is in short supply.

In the absence of supply augmentation, the only way to ease the strain on aquifer systems adequately may be to reduce irrigated areas, improve farming practices, and shift to watersaving crops. But this could be difficult to be implemented in socioeconomic and political terms in developing countries (Shah et al., 2007, p.397). Demand management is more than only imposing charges on users. For the general case of renewable natural resources, the charge captures only the technological stock externality because the resource is not growing (Brown, 2000, p.892).

Demand-side management needs an understanding of the demand structure for groundwater. In most of the literature on optimal use of groundwater, the focus is on the optimal path of the groundwater supply with the help of dynamic optimisation. Sometimes these results are compared to the competitive pumping approach. This group of research has mostly simplified the demand structure for the depleting resources and assume that a saving policy on water consumption can be defined and implemented. The elasticity pattern of groundwater use and the possibility of the policy change, which ends in the reduction of consumption or more efficient use of the resource, were not often the focus of empirical studies in this field. Moreover, the groundwater extraction cost is simplified to its relation to water depth and energy consumption. Therefore, the more realistic case where other costs appear because of the depths of the well or adjustment cost of the pumps was not 
a discussion in this area of groundwater economics literature. In our research, we have tried to test the other factors that may affect the demand and pumping cost patterns of the depleting aquifer.

This study models the factors which affect the demand for groundwater in the pistachio production of the Rafsanjan aquifer in the southeastern part of Iran with the help of a translog cost function. Additionally, we estimate the shadow price of groundwater use in irrigation. In particular, specific attention is devoted to groundwater quality as an influencing factor in addition to water quantity, input prices, output level and pistachio garden structure. A field study was conducted in Rafsanjan from November 2008 February 2009. As groundwater is a hydrogeological variable and some level of spatial correlation regarding farmers' water use per hectare can be observed, the model has been checked for spatial correlation, and the results are corrected for that. Finally, groundwater shadow price and pumping costs elasticities are calculated in SUR and spatially-corrected SUR models.

In the next section, the literature on the demand estimation and other relevant former studies will be reviewed. In section three, the conceptual framework will be presented. Section four reviews the study area, the field study and structure of data which are used in the study. Section five presents the empirical model developed for this research. Finally the results are presented and discussed.

\subsubsection{Groundwater scarcity rent and Gisser-Sanchez Paradox}

Shadow price, accounting price or scarcity rent are various terms used in the literature for the same phenomenon (Brown, 2000, p.882). Shadow price/accounting price of the stock of a natural resource reflects the changes in the discounted value of the future flows in the welfare associated with the use of natural resources ${ }^{1}$. This shadow price, along with extraction costs, determines the resource's full cost. Full cost pricing is one of the

\footnotetext{
${ }^{1}$ The term shadow price which will be used in the rest of the text can be interpreted in another simpler way. In optimization literature the shadow price is define as instantaneous change per unit of the constraint in the objective value of the optimal solution of an optimization problem obtained by relaxing the constraint. Scarcity rent or accounting prices which are more used for natural resources can simply defined as the marginal opportunity cost imposed on future generations by extracting one more unit of a resource today. As it is mentioned above, these terms can be used interchangeably.
} 
main policy approaches in the economic management of water resources (advised also by Water Framework Directive (WFD) of the EU (Directive 2000/60/EC of the European Parliament and of the Council, 2000, Paragraph.38)), and it can be used as base for establishing taxes, which is one approach to mitigate the external effects of groundwater use (Howe, 2002, p.629). The shadow price of groundwater would be determined at the high end by what prospective buyers are willing to pay and at the low end by what sellers are willing to accept. Given the difficulty of establishing clear groundwater ownership rights, shadow prices frequently go unrecognized and are difficult to estimate. In the absence of optimal dynamic management of common-pool groundwater resources, or, alternatively, in the presence of a competitive extraction regime, ignoring shadow prices results in inefficient pricing and misallocation of the resource (Koundouri, 2004b, p.706). In the 'Optimal Control' literature, two different definitions for shadow prices are often used. One is the shadow price which is defined for the user of the groundwater (control variable) and the second is the shadow price which can be defined for the stock of the resource and its quantitative-qualitative depletion (state variable). This issue will be explained further in the theoretical section. But there is a empirical limitation for the above justification of the optimal dynamic management of common-pool groundwater resources. The analytical results in Gisser and Sánchez (1980, p.641), tested by empirical estimates of parameters in the Pecos River Basin in the US, gave rise to the prediction that temporal optimal control of groundwater would not enhance the welfare of farmers compared with the strategy of free markets. In other words, since 1980, Gisser and Sánchez effect (GSE) severely limited the role and scope of groundwater economic management. As a result, although serious depletion of aquifers is a major threat to many fresh water ecosystems all over the world, the social benefits from managing groundwater extraction are numerically insignificant (Koundouri, 2004a, p.1). Koundouri has summarised the existing empirical evidence on the robustness of GSE in Koundouri (2004b, p.715, table 1) and Koundouri (2004a, p.10, table 2). She concluded that management benefits are quite sensitive to the slope of the demand function and interest rate, moderately sensitive to aquifer storativity and size, and relatively insensitive to either parameters (Koundouri, 2004a, p.10). She has suggested a number of circumstances that have or may potentially 
allow groundwater management to significantly increase welfare. These include nonlinear extraction costs, heterogeneous land productivity, nonstationary demand, situation of near aquifer depletion and accounting for risk averse groundwater extracting agent (Koundouri, 2004a, p.10). In the dynamic optimization framework, the resource's shadow price is determined by the derivatives of the value function of the problem with respect to the resource's stock (Arrow et al., 2003, p.153). It must be added that the core focus of the comparison between optimal control and competitive pumping in the former studies was mainly done by using mathematical models. Mathematical models are mainly based on deductive reasoning and comparing the scenarios. Koundouri and Xepapadeas (2004) developed an econometric framework to estimate the shadow price of the groundwater stock (state variable) and irrigation water (control variable) on one hand and to test the GSE by comparing the two values on the other hand. Their approach is followed in this study and will be explained in detail later in the section on conceptual framework (see 2.2 ). In the rest of this section, the literature on demand estimation of irrigation water and development of groundwater resources economic models is reviewed.

\subsubsection{Water demand estimation in industry and agriculture}

In crop production and other agricultural activities, especially in arid and semi arid areas, water is an important input which usually cannot be obtained through market activities. Therefore, it is categorized as a non-market good and its value has to be estimated through direct and indirect non-market valuation methods. Young (2005) divided all empirical economic valuation techniques of water into the two broad categories of inductive and deductive techniques. Inductive techniques employ inductive logic by statistical or econometric procedures in order to generalize from individual observations. In contrast, deductive methods use logical processes to draw a particular conclusion from a general idea. Deductive techniques are built on constructed models and empirical assumptions suitable for the proposed projects or policy. Inductive techniques are constructed from statistical analysis and are based on observed transactions, responses to questionnaires, or secondary data from government reports. Their accuracy depends on the representativeness of the samples, appropriate statistical distribution and the functional forms 
which are used to fit the data. Inductive methods have the advantage of reflecting actual economic behavior, but they are weak in predicting future behavior. Future behavior and valuation may need to be forecasted by developing conclusions based on sample parameters (Young, 2005, p.45). Moreover, inductive methods demand high statistical and computational skills. Some examples of inductive valuation methods are econometric estimations of production and cost functions, hedonic valuation methods, observations of water market transactions, and contingent valuation methods (CVM). In contrast, deductive techniques use empirical studies of production or consumption processes, published government reports and experts' opinions. The accuracy of the results of deductive reasoning depends on the validity of the model specification and database employed for the model. They are flexible and they can reflect any desired future economic and technical conditions. Although these methods are fast and inexpensive, caution must be used with their application as any simple process may result in conceptually incorrect results. These broad categorizations do not reject the fact that for any deductive method, there must be some initial empirical and inductive steps, just as an inductive approach needs some deductive reasoning to proceed (Young, 2005, p.44-46). Some examples of deductive valuation methods include residual imputation methods, changes in net rents, mathematical programming approaches, and computable general equilibrium (CGE) models. Since inductive reasoning has been followed in this study, the literature review focuses mainly on econometrical empirical studies.

As it was mentioned above, econometric models are one of the main tools for valuation of water and estimation of the demand for water when farm-level microeconomic data in agriculture or the same data for industrials enterprises are available. Three main methods for estimating the demand function for water are the reduced form approach, deriving demand function from the cost function (Shephard's lemma) or the profit maximizing input demand function (Hotelling's lemma).

Aggregated regional or district-level data have been regularly used for demand estimation. Nieswiadomy $(1985,1988)$ represent one of the first attempts to estimate irrigation water demand. In the latter of these two studies, the water demand elasticity was estimated at only -0,25 based on panel data from the period of 1970-1980 for cotton and 
grain sorghum production on the high plains of Texas. Ogg and Gollehon (1989) applied the reduced form approach to estimate the water demand elasticity for field crops with the help of county level data. The results showed that irrigation water was highly inelastic. Renzetti (1992) has done one of the most comprehensive studies on industrials water demand among Canadian manufactures using cost function approach. The results showed inelastic demand $(-0,38)$. One of the prominent irrigation water demands studies has been done by Moore et al. (1994) in the central plains of the United States. They checked three different models of short-run input use. These models were the allocatable fixed input model, the variable input model and the satisficing model. Profit maximization, and as a result Hotteling's lemma, was considered for direct estimation of irrigation water demand. They concluded that the fixed allocatable input model provides a better explanation for multi crop water use. Moore et al. (2000) estimated the supply functions for multioutput irrigators in Pacific Northwest of US by using a tobit model in order to analyse the economic welfare of the producers. Farm level survey data $(1986,1990)$ has been used for the study. This experiment predicted increases in the water pumping costs and decreases in the producers' surplus. One of the recent econometric studies on water demand is Schoengold et al. (2006). They estimated water demand by using a linear function. Water consumption was regressed on water price, wage, farm characteristics and fuel price without any discussion about underlying cost or profit functions. Water price was significant with a negative sign. They conclude that better management alone can result in significant water conservation. Mullen et al. (2009) used a Heckman model with profit function to analyse the demand structure for water and water decision issues for corn, cotton, peanut and soybean in Georgia, USA from panel data sets in 1988, 1994, 1998 and 2003 (USDA-Farm and Ranch Survey). Pumping costs were used as a proxy for water price. Results indicated that the water demand was modestly affected by water price (with elasticities between -0.01 and -0.17 ), but more so by crop price (with elasticities between 0.5 and 0.82 ). Results also suggest adoption of lower pressure irrigation systems does not necessarily lead to lower water application rates on corn, cotton, peanuts, and soybeans. The coefficient for the Mills Lambda Ratio was not statistically significant for any of the Heckman models, raising doubts over the applicability of this 
model to irrigated crop production in southwest Georgia. In other words, the first stage of the Heckman model, namely crop selection, does not appear to be significantly affected by water-related decisions. Finally, it must be mentioned that the possible lack of farm level data is the major issue with this approach.

\subsubsection{Groundwater resources demand and influential factors}

Few studies have focused on groundwater demand by considering characteristics specific to the aquifer. Kanazawa (1992) is one of the first econometric studies which analysed the economic and hydrogeologic factors that affect the marginal pumping cost. As pumping and extraction data were not available, regional-district aggregated data were used. He concluded that single-equation analysis is inappropriate when marginal pumping costs were endogenous to the amount of pumping. Koundouri and Xepapadeas (2004) checked the shadow price of groundwater in crop irrigation by considering cost function and the input distance function approaches. They considered water level as an explanatory variable in the demand function in order to estimate the shadow price of the control and state variables of groundwater simultaneously. They used panel data of agricultural production over three periods on Cyprus Island. They concluded that non-internalized costs of currently observed myopic groundwater were significant. Thus, benefits from optimally managing these resources could be substantial. As Koundouri and Xepapadeas (2004) stated, it can be recognized that analyzing groundwater demand systems with a focus on aquifer structure and economic aspects has not been given much attention. But slowly its importance and usage is gaining the interest of researchers in the fields of economics and water resource management.

Not only has the consideration of quantitative aspects of aquifers in the empirical estimation of the demand function not developed much, but their qualitative aspects have also been neglected. The literature has extensively covered water quantities and quality, but usually separately, as illustrated by the apparent gap between joint quantity and quality management in these two branches of literature (Hellegers et al., 2001, p.303). Considering quality change as an economic aspect with external effects plays a big role in decision making and optimal management of the resource (Koundouri, 2004a, p.11). 
Groundwater quality degradation is another external effect of intensive groundwater use (Verba, 2003, p.113). The economic literature on the internalisation of externalities from agricultural groundwater extraction is rather sparse. The emphasis was either on the comparison of optimal pumping pathways to competitive pumping, or on water quality and analyses concerning contamination in a pollution-control prospective. The latter gives special emphasis to non-point pollution as an externality imposed by agricultural production activities.

Knapp and Dinar (1988) is one of the first major studies on water salinity and its affects on agricultural production. With the help of mathematical programming, they concluded that net return was reduced significantly by increases in the price of irrigation water, while ending soil salinities increases. Kan et al. (2002) analysed the microeconomics of irrigation water with saline water. They developed a production function by considering electric conductivity (EC) as an influencing factor. Simulation was used to check the effect of saline water on cotton and tomato production with the help of data from experimental fields. While the results suggested increases in salinity and decreases in profits regardless of crop type, there was ambiguity surrounding the relationship between changes in salinity and the optimal applied water usage. Regarding the conditions, water use could be increasing or decreasing. A groundwater quantity-quality optimal control theoretical model without empirical analysis has been developed by Hellegers et al. (2001) and later corrected by Rauscher (2007). Roseta-Palma (2002) developed another theoretical framework for an optimal control model by considering quality as an influential factor as quantity. She concluded that intervention may lower quantity while improving quality or vice versa. Therefore, the economic benefit of control might not be significant. Knapp and Baerenklau (2006) applied simulation for the Roseta-Palma (2002) theoretical model. They concluded that in a long run scenario of 500-1500 years, the benefits of control could be high but only a small share of the benefit was due to quality control. Brozovic et al. (2006) presented a theoretical framework for optimal management of groundwater by considering the spatial aspects of water pumping. They concluded that spatial factors may increase benefits from optimal control of groundwater resources. 


\subsubsection{Groundwater demand estimation in Iran}

Abdolahi-Ezzatabadi and Soltani (1996) estimated the different functions in order to forecast the external cost of water pumping and overdrafting of the Rafsanjan aquifer. Results showed that in the future, external costs would cover more than 70 percent of pumping costs. Mirzaei-Khallilabadi and Chizari (2004) estimated the optimal level of water use with the cost minimization assumption and data envelopment analysis (DEA). They concluded that if farmers behave as cost minimizing agents, water consumption would decrease. Khalilian and Mehrjardi (2005) applied the generalised quadratic function to find the groundwater elasticity for wheat producers in Kerman county. The results showed that irrigation water was an elastic input (-1.32). They used the average water table drop of the aquifer and computed the value of the marginal product in a production function framework in order to calculate the social welfare reduction of aquifer depletion. The result was a negligible impact of the water table drop on welfare. Sabohi et al. (2007) estimated an optimal control model for the Narimani aquifer in the Khorasan province. Results of the demand function showed that a tax policy was the best instrument for sustainable use of the groundwater resource. Asadi et al. (2007) analysed the irrigation water demand in a downstream network of the Taleghan dam with the help of mathematical programming. The results showed that the water elasticity is negative and in absolute terms less than one. Abdolahi-Ezzatabadi (2008) simulated the effect of policies on the welfare level and water resources. The results of the simulation show that instruments such as a tax will be successful with low discount rates and economic stability. When discount rates are high, regulatory instruments are efficient. Shajari et al. (2009) estimated the price elasticity for irrigation water of date production in Jahrom with the help of the Cobb-Douglas production function. They concluded that irrigation water demand was highly elastic for furrow (-2.095) and drip (-3.035) irrigation technologies.

As mentioned above, in this study, the quality of irrigation water and the spatial effect of water users are considered as factors which may play an important role in the size of economic demand for the irrigation water that has to be provided from groundwater. The objective of the study is to check the possible effect of market factors, spatial factors 
and water quality and quantity factors on the demand for groundwater resources with the help of an econometric model. Determining the size of these effects could also inform further policy decisions.

\subsection{The conceptual framework}

The theoretical model is based on the cost function approach (e.g., Nieswiadomy (1988), Halvorsen and Smith (1991), Roseta-Palma (2002), Koundouri and Xepapadeas (2004) and Knapp and Baerenklau (2006)). The starting point is a geophysical model for the change in the water table of an aquifer. Denote with $G_{i}(t)$ the level of water pumped by $i=1,2,3, \ldots, N$ agricultural firms with access to a common pool resource (Gisser and Sánchez, 1980, p.639):

$$
\dot{L(t)}=\frac{1}{A S}\left[R(t)+(\alpha-1) \sum_{i=1}^{N} G_{i}(t)\right]
$$

Here, $L(t)$ is the water table elevation above sea level and reflects the annual cumulative water extraction, $\dot{L(t)}$ is the annual change in the water table, $R(t)$ is the annual natural recharge into the aquifer, $\alpha$ is the return flow coefficient of percolation back to the aquifer, $A$ is the size of the aquifer $\left(m^{2}\right)$ and $S$ is a hydrological parameter which shows storativity capacity. Without loss of generality, we normalize $A S=1$.

If we can separate the input level used for the production of agricultural output from the input levels used in water extraction, the production technology can be defined as follows:

$$
Y_{i}=f_{i}\left(X_{i}^{p}, T, G_{i}\left(X_{i}^{g}, L, S, T\right)\right)
$$

where $Y_{i}$ denotes the output level, $X_{i}^{p}$ is a vector of agricultural inputs other than groundwater, $T$ is time, and $G_{i}()$ is firm specific groundwater extraction. The groundwater extraction depends on inputs used in the extraction process $X_{i}^{g}, L$ and $T$ (this model was first given in Halvorsen and Smith (1991, p.125) which was adapted for groundwater by Koundouri and Xepapadeas (2004, p.2)). Our contribution to this conceptual framework is to add water quality $(S)$ as an additional factor to the main model. 
In general, the structural cost function literature treats product quality as exogenous and it remains unobserved in the analysis because it is unobservable in most cases. Quality is usually assumed to be unrelated to the other endogenous variables in the analysis. This is often done because of the difficulties in collecting data on product quality, which can be quite costly. In many analyses, however, the assumption of exogenous, unobservable quality is incorrect because the products are differentiated on some attribute of quality. This creates biases in the parameter estimates, which can lead to inaccurate inferences (Boland and Marsh, 2006). Therefore, $S$ is considered as an index for water quality which affects the overall approach towards using other inputs and the level of output.

With a positive interest rate $r$, the wealth maximizing problem of a vertically-integrated agricultural firm is

$$
\max _{x_{i}^{p}, g_{i}} \int_{0}^{\infty} e^{-r t}\left[W_{Y_{i}} Y_{i}-W_{p_{i}} X_{i}^{p}-C_{i}^{g}\left(G_{i}, W_{g_{i}}, L, S, T\right)\right] d t
$$

subject to equations 2.1 and 2.2 and the initial condition $L(0)=L_{0} . W_{Y}$ is the output price, $W_{P}$ is the vector of agricultural input prices, $W_{g}$ is the vector of groundwater extraction input prices, and $C^{g}$ is the total cost function dual the groundwater extraction subproduction function given by

$$
C_{i}^{g}\left(G_{i}, W_{g_{i}}, L, S, T\right)=\min _{x^{g}}\left\{W_{g_{i}} X_{i}^{g}: G_{i} \geq G_{i}\left(X_{i}^{g}, L, T\right)\right\}
$$

The current Hamiltonian for farm $i$ is defined as:

$$
\mathcal{H}^{i}=W_{Y_{i}} Y_{i}-W_{p_{i}} X_{i}^{p}-C_{i}^{g}\left(G_{i}, W_{g_{i}}, L, S, T\right)+\mu^{i}\left[R+(\alpha-1)\left(G_{i}+\sum_{j \neq i}^{N} G_{j}\right)\right]
$$

where $\mu^{i}$ is the costate variable in the Hamiltonian. Based on Halvorsen and Smith (1991, p.125) and Koundouri and Xepapadeas (2004, p.3), the marginal value of the $j t h$ input, the shadow price of extracted groundwater and the shadow price of the water table can be defined as:

$$
W_{Y} \frac{\partial Y}{\partial x_{j}^{p}}=W_{p_{j}}
$$




$$
\begin{gathered}
W_{Y} \frac{\partial Y}{\partial G}-\frac{\partial C^{g}}{\partial G}=\mu \\
\dot{\mu}-r \mu=\frac{\partial C^{g}}{\partial L}
\end{gathered}
$$

where $r$ is the rate of interest. By considering the water quality index $(S)$ as a variable which reflects the annual cumulative deterioration of water quality because of water extraction, its shadow price can be defined in the same way as above:

$$
\ddot{\mu}-r \mu=\frac{\partial C^{g}}{\partial S}
$$

From the optimality conditions the costate $\mu$ is equivalent to the groundwater shadow price emerging from farmers' noncooperative behaviour with respect to water pumping. Equation 2.6 and 2.7 are static optimality conditions for reproducible inputs and natural resources input, respectively (Halvorsen and Smith, 1991, p.125). Equations 2.8 and 2.9 are dynamic optimality conditions while $\frac{\partial C^{g}}{\partial L}$ and $\frac{\partial C^{g}}{\partial S}$ reflects stock effects on water extraction function (Koundouri and Xepapadeas, 2004, p.3). When $\frac{\partial C^{g}}{\partial L}>0$ and $\frac{\partial C^{g}}{\partial S}>0$ the price of the resource in situ is predicted to increase at less than the rate of interest, and may decrease over the time.

As mentioned above (see 2.1.2), another factor is the non-market character of the groundwater which is owned in common. Because of this, no market price can be defined for this groundwater. Halvorsen and Smith (1991) used duality theory and derived the relationship between the gross and final resource indirect cost function for unextracted ore in the Canadian metal mining industry. Duality theory suggests that the wealth maximization problem of vertically-integrated agricultural firms (problem 2.3) corresponds to the following unrestricted cost minimization problem (Koundouri and Xepapadeas, 2004):

$$
\min W_{p} X^{p}+W_{g} X^{g}+\mu\left[G\left(X^{g}, L, S, T\right)\right] \text { s.t. } Y\left(X^{p}, G, T\right) \geq Y
$$

where $\mu$ is, as above, the costate variable in the Hamiltonian of problem 2.5 and takes the place of the shadow price of groundwater. Since information on $\mu$ can not be achieved from the market, Halvorsen and Smith (1991) considered the auxiliary problem of minimizing 
the total cost of all inputs used in the production process (excluding groundwater in our case) given $L, Y, G$ and $S$ each time. In this restricted auxiliary problem, $Y^{*}$ and $G^{*}$ are the solution to the firm's wealth maximizing problem.

$$
\min W_{p} X^{p}+W_{g} X^{g} \text { s.t. } G\left(X^{g}, L, S, T\right) \geq G^{*} \text { and } Y\left(X^{p}, G, T\right) \geq Y^{*}
$$

Each individual firm will not explicitly solve the equation 2.11. It will be solved simultaneously for the wealth maximizing quantities of output and the rate of groundwater extraction, together with the quantities of agricultural inputs that minimize the total costs. The solution to the equation 2.11 results in the restricted minimum cost function (Halvorsen and Smith, 1991; Koundouri and Xepapadeas, 2004, p.3):

$$
C=C\left(Y, G, L, S, W_{p}, W_{g}\right)
$$

where $C$ is variable cost. The shadow price of the groundwater stock of the renewable common pool aquifer used for agricultural irrigation is:

$$
\frac{\partial C}{\partial G}=-\mu
$$

and the stock effect associated with changes in aquifer quantity and quality defined as:

$$
\begin{aligned}
& \frac{\partial C}{\partial L}=\dot{\mu}-r \mu \\
& \frac{\partial C}{\partial S}=\ddot{\mu}-r \mu
\end{aligned}
$$

The econometric procedure for estimating the above conceptual model will be given in section 2.4 after a description of the data and study area. 


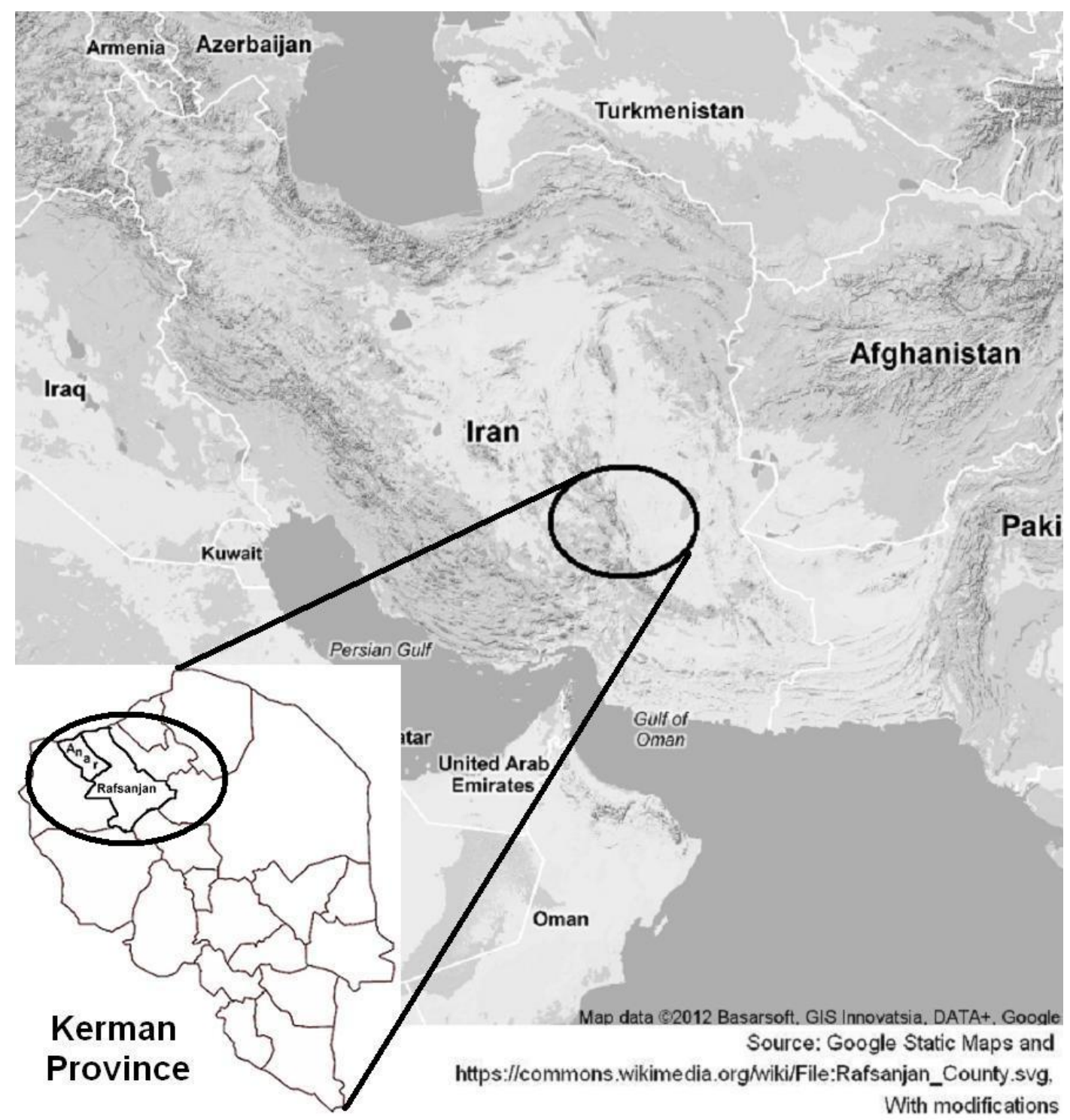

Figure 2.1.: The map of study area

\subsection{Field study and data}

\subsubsection{Study area}

Field work was conducted during November - February 2008-2009 in the Rafsanjan county in the southeastern part of Iran (figure $2.1^{1}$ ). The main reason for selecting Rafsanjan was its unique agricultural production pattern and its size.

Until May 2009 Rafsanjan aquifer was covered administratively by Rafsanjan County. In 2009 the northeastern part of the County was redesignated as the newly created Anar County. As the available official statistics refer to the former larger Rafsanjan County,

\footnotetext{
${ }^{1}$ ggmap and ggplot2 packages in R statistical software have been used to design this plot.
} 
Table 2.1.: Demographic structure and agricultural operating units structure in the area covering Rafsanjan aquifer

\begin{tabular}{|l|c|}
\hline Demographic data (2006 Census) \\
\hline Population & 295175 \\
Urban & 175372 \\
Rural & 119803 \\
Men & 152073 \\
Woman & 143102 \\
\hline Agricultural Operating Units (2003 Agricultural Census) \\
\hline Farm operating units & 43334 \\
Household farm with residence in the area & 14884 \\
Non resident farm operators & 28343 \\
Agro-companies & 107 \\
\hline
\end{tabular}

Source: Kerman Annual Statistical Book 2008

Website: http://amar.org.ir/Default.aspx?tabid=667\&fid=7666. last accessed 16.11.2012

the demographic and geographical features of both counties are given below together. Rafsanjan and Anar Counties lie within Kerman province in southeastern Iran and have a combined area of 10,266 $\mathrm{km}^{2}$. Geographically, these counties (equivalently Rafsanjan aquifer) lie between latitudes $55 \mathrm{deg}$ to $57 \mathrm{deg}$ E, and longitudes $29 \mathrm{deg} 53 \mathrm{~min}$ to 31 deg 15 min N. Rafsanjan and Anar counties contain 6 towns, 5 sections and 16 rural districts with 408 inhabited villages (Statistical Center of Iran, 2008). Table 2.1 shows some demographic aspects of the both counties.

There is some degree of ambiguity over the actual area of planted trees and orchards in the region. Based on the Statistical Centre of Iran 2003 Census on Agriculture, there are 72,856 hectares of tree crop plantations in the area. Table 2.2 shows the area of planted crops in both counties as obtained by the Kerman Provincial Agricultural Organization (Kerman Agrijahad Organization, 2012). There are 80-120 thousand hectare of pistachio orchards in the area where, in addition to pistachio production, related activities such as repairing pumps, pistachio trade, etc. are the main occupations.

Table 2.3 shows some general characters of the Rafsanjan aquifer ${ }^{1}$. This aquifer is divided into 3 parts which are connected at the bottom, but the storativity coefficients differ slightly between the parts. The western and northwestern of the aquifer is called Anar- Koshkoiyeh, the southern part is called Rafsanjan, and the eastern and northeastern

\footnotetext{
${ }^{1}$ The Office of Basic Water Resources Studies (WRS) is a subsection of Iran Water Resources Management Company (IWRMC).
} 


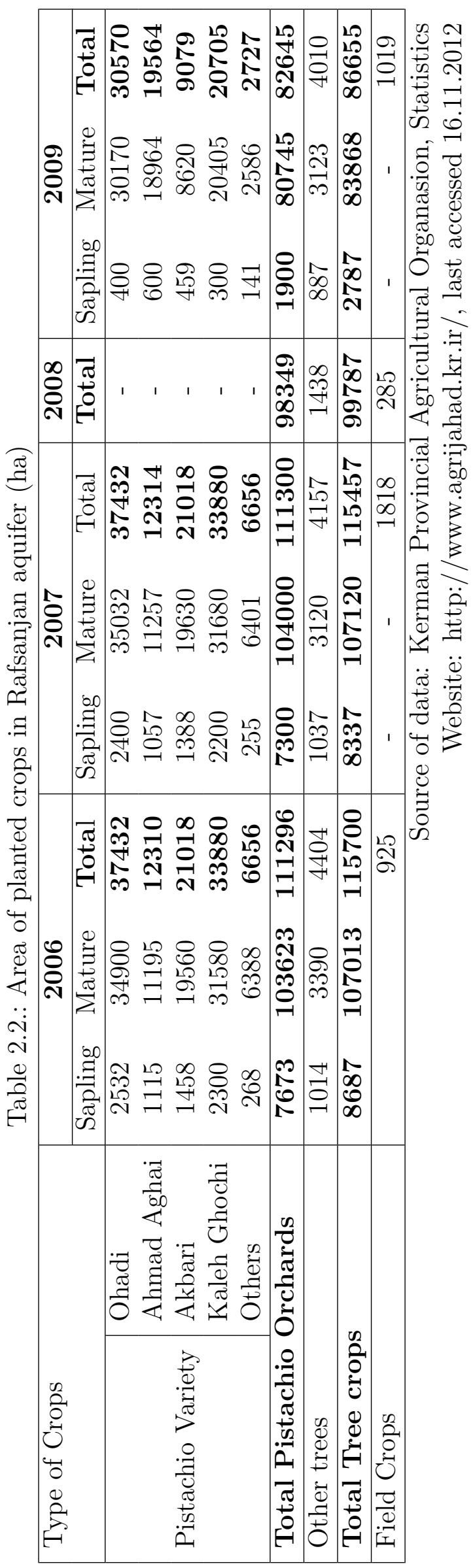


Table 2.3.: General information about the Rafsanjan aquifer

\begin{tabular}{|l|r|}
\hline Area of aquifer & $4108 \mathrm{~km}^{2}$ \\
Annual extraction & 693 million $\mathrm{m}^{3}$ \\
Share of agriculture & 666 million $\mathrm{m}^{3}$ \\
Storativity coefficient & $5 \%$ \\
Annual drop of water level & $72 \mathrm{~cm}$ \\
Aquifer condition & Red Zone \\
Average height from sea level & $1609 \mathrm{~m}$ \\
Average depth of water table (2010) & $55.5 \mathrm{~m}$ \\
\hline
\end{tabular}

Source of data: The Office of Basic Water Resources Studies last accessed 25.06.2011, http://wrs.wrm.ir/tolidat/ab-zirzamini.asp

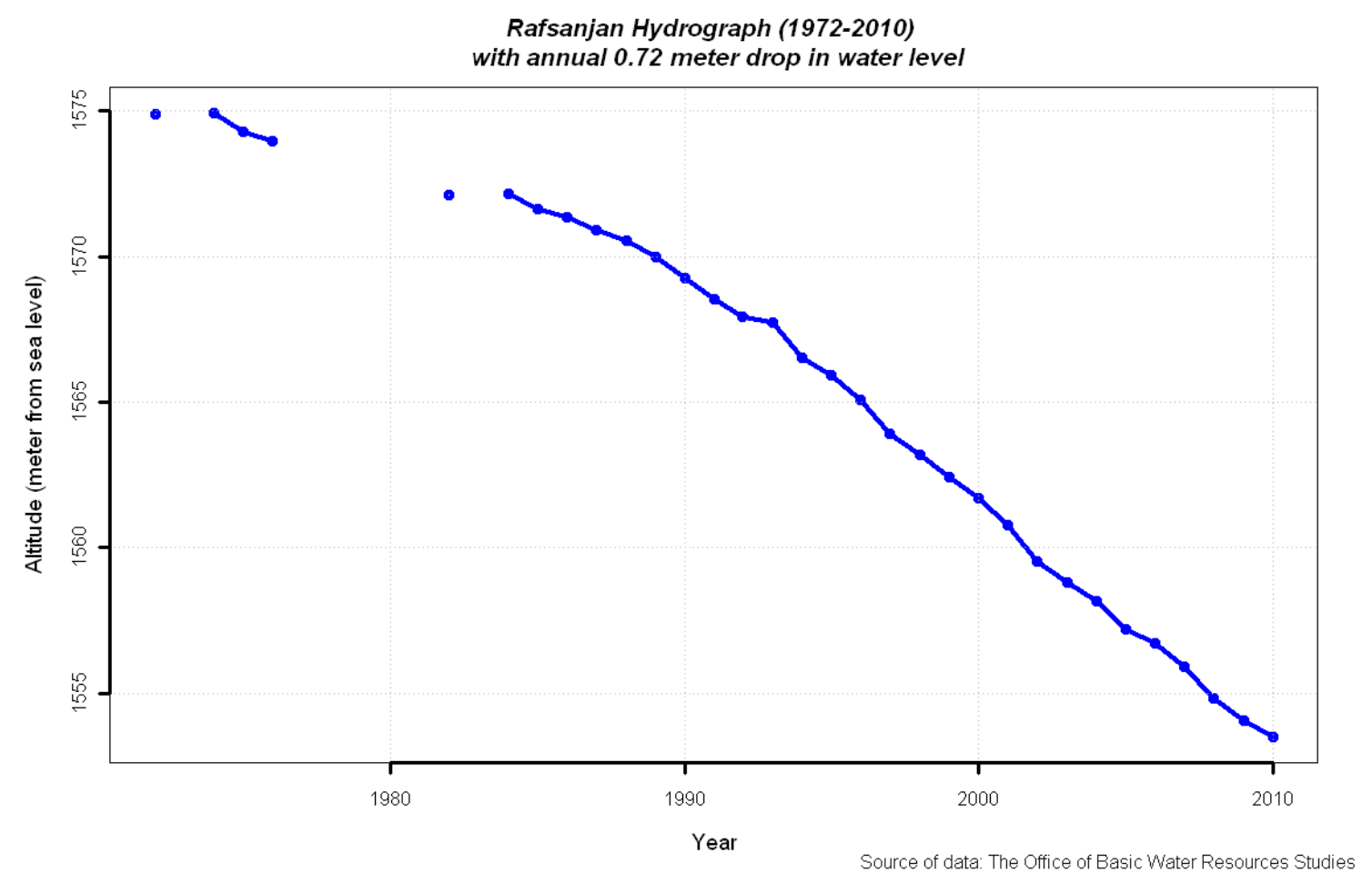

Figure 2.2.: Rafsanjan Hydrograph (1984-2009)

part is called Bahraman-Javadiyeh. In addition, there is an underground water flow from south to north. Back to the last hydro-geological report (Kawab, 2002), there has been an inflow of 136 million $\mathrm{m}^{3}$ and an outflow of 31 million $\mathrm{m}^{3}$ from the aquifer. The general hydrograph of Rafsanjan shows an annual drop of $72 \mathrm{~cm}$ on average (Figure 2.2 ). Additionally, the intensive use of groundwater has affected the aquifer's groundwater quality. Figure 2.3 shows the salinity control variable (EC) from 2000-2009.

There are more than 1300 active deep wells in the Rafsanjan plain, and most of them provide irrigation water for pistachio gardens while very few are used for other activities (WRS, 2011, form code: 420-042). 44\% of these deep wells are in Rafsanjan sub-section, 


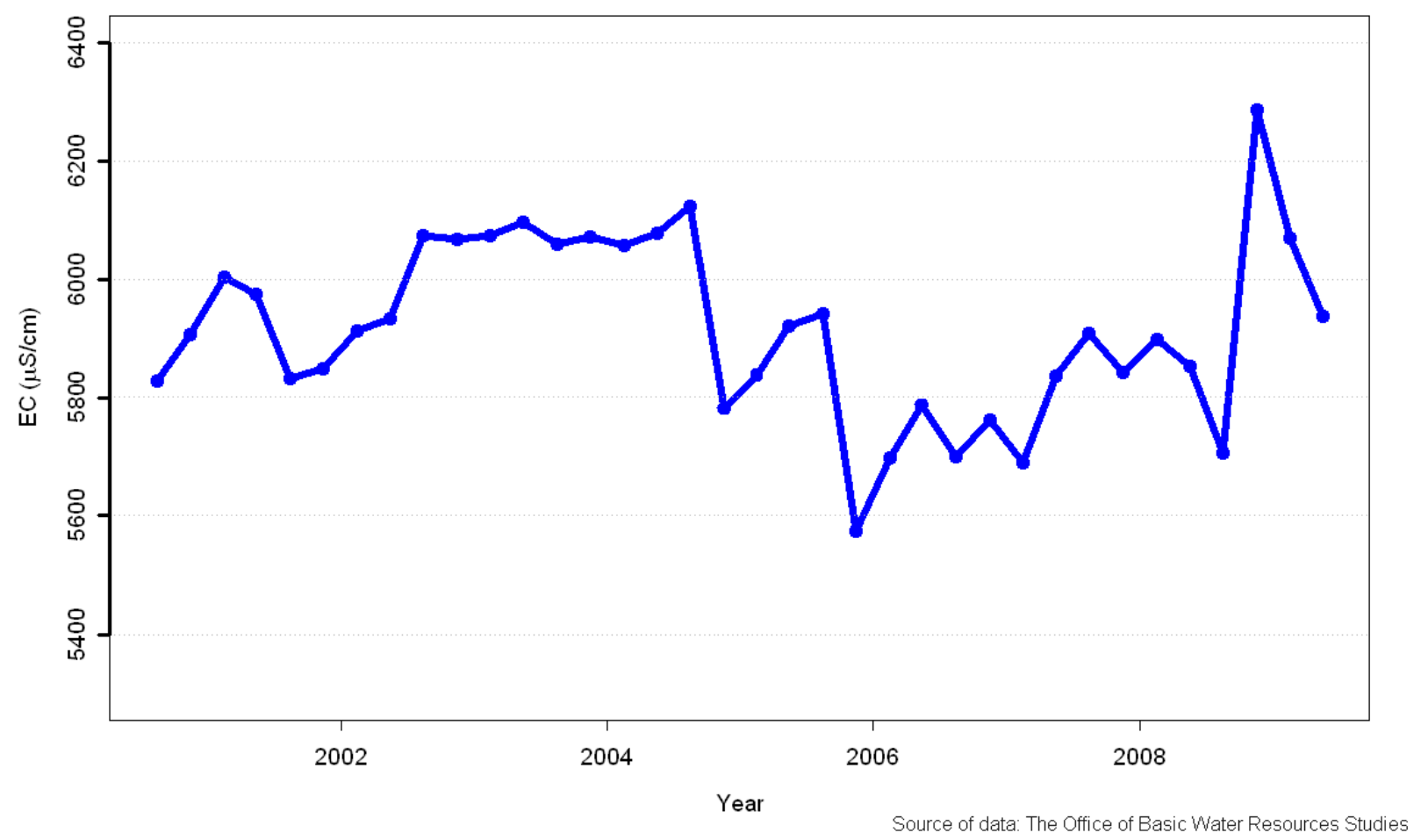

Figure 2.3.: Rafsanjan aquifer water quality EC graph

$31 \%$ are in Anar-Koshkoiyeh sub-section, and 25\% are in Bahraman-Javadiyeh sub-section (Rafsanjan Irrigation Water Authority). Over $83 \%$ of these wells use electro-pumps and the remainder use diesel pumps. Therefore, electricity is the major source of energy for the majority of the wells in this aquifer. Deep wells pump more than 612 million $\mathrm{m}^{3}$ water annually. There are 148 qanats and 61 semi-deep wells in the aquifer which play a smaller role in groundwater extraction, pumping more than 80 million $m^{3}$ annually (WRS, 2011, form code: 420-042). It is almost impossible to add new wells to the system, and the aquifer has been shared by almost the same operators for the last 20 years.

The first water pump was used in Rafsanjan in 1947, but it was not given much attention up until 1961 when it started to become popular. Very soon thereafter, the number of water pumps increased to such a high level that in 1974 the aquifer was designated as a red zone and establishing new wells and water pumps was forbidden. Nevertheless, by using legal and illegal tricks, the number of wells and pumps expanded gradually up until the 1979 revolution. As the official control decreased during the period of 1979-1980, many new allowances were granted and the number of wells expanded tremendously (Abtahi, 
1998$, p. 25$)^{1}$.

Increases in the price of pistachios after 1931 have motivated the expansion of pistachio farming in Rafsanjan. The development of water pumps and a land reform policy which did not affect Rafsanjan severely were the main reasons for gradually expanding this crop until the whole area was eventually devoted to pistachio production. Therefore, Rafsanjan has a monoculture cropping pattern (Abtahi, 1998, p.23). The ownership pattern in the area, however, is diverse. The 1960s land reform policy did not affect tree crops as severely as field crops agricultural land ownership. Therefore, large operational units remained in the hands of traditional landlords (Abtahi, 1998, p.57). As a result, this area has very heterogeneous farm and well ownership. The ownership pattern can be divided into 2 periods: before and after the revolution (1979). Most of the wells set up before the revolution are owned by large producers or a mix of large owners and smallholders. But all of the wells built during or after the revolution are characterized by smallholder ownership.

There is no permanent river in the area and irrigation depends solely on groundwater. This area borders the desert and has a very arid climate. According to the Kerman Regional Water Corporation (KRW), annual precipitation in Rafsanjan is close to $90 \mathrm{~mm}$ (KRW, 2009). Combining water-level data with satellite radar observations provides evidence for an annual land subsidence of $50 \mathrm{~cm}$ and land deformation around the Rafsanjan aquifer as a result of intensive groundwater use (Motagh et al., 2008).

\subsubsection{Pistachio production}

The pistachio (Scientific name: Pistacia vera L) is a small tree and its nut is the main non-oil agricultural export from Iran. At the moment, Iran and the USA are the biggest pistachio producers and exporters in the world (Economic Research Service (ERS), USDA, 2011, p.30). According to the FAO database (FAOSTAT for 2009), Iran, with 375,000

\footnotetext{
${ }^{1}$ Abtahi (1998, p.45) mentioned that the number of deep and semi deep pumps reached to 784 up to 1974. This number reached to 1000 in 1976 and now there are more than 1500 groundwater pumps active in this aquifer. Based on field research and my questions to experts, the number of pumps reached to a level of 800 before 1979 and since then, increase to a level of 1300 (study findings). The offical data shows that at the moment there are more than 1300 active registered deep and semi deep pumps in the area (WRS, 2011, form code: 420-042).
} 


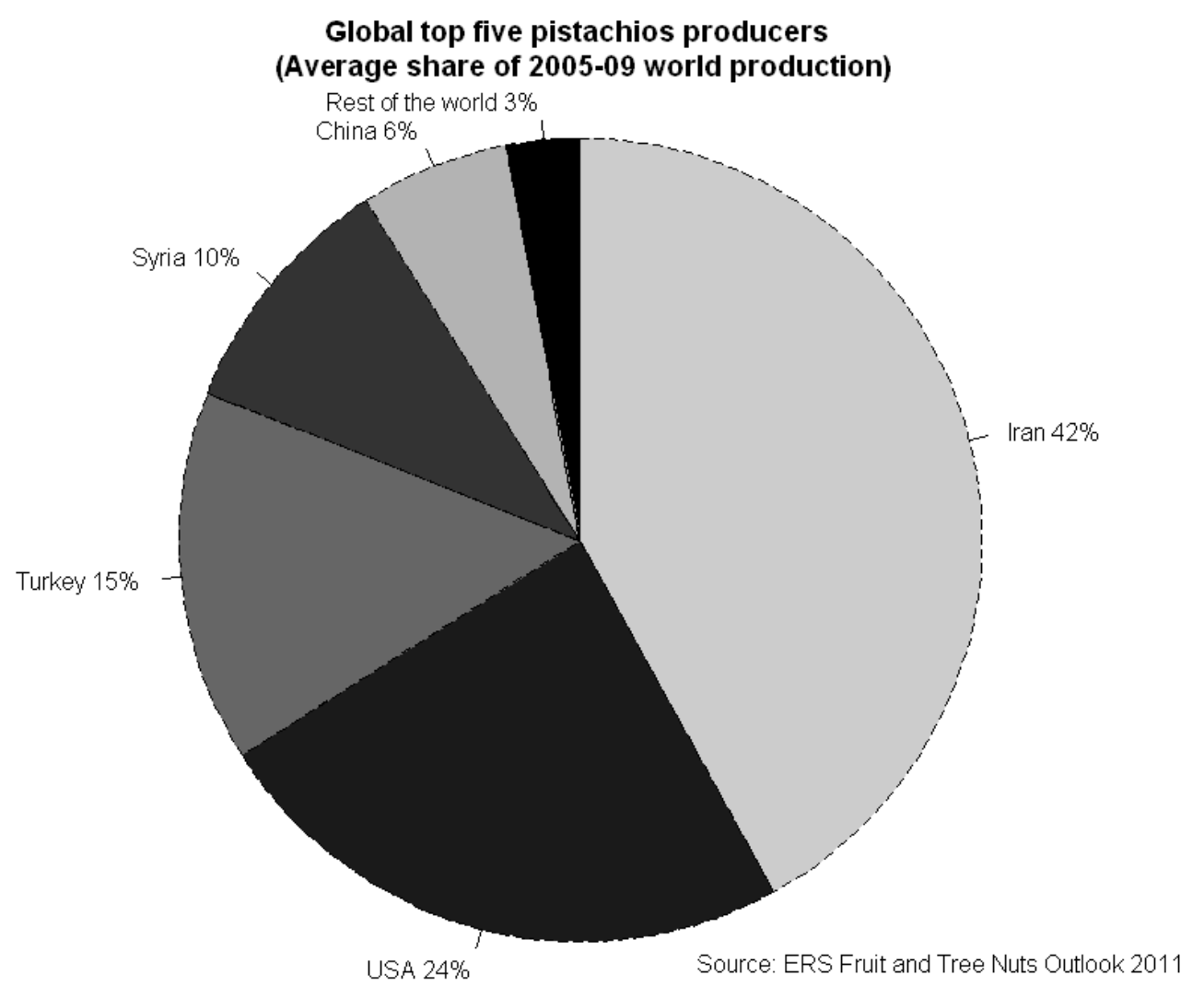

Figure 2.4.: Global top five pistachio producers

hectares of pistachio orchards, has the world's largest plantation area, followed by the USA with 50,991 hectares. American pistachio producers, with access to more sophisticated agricultural technology, are however much more productive than their Iranian counterparts (figure 2.4). Good-quality pistachios are a very special kind of nut and require very hot summers and very cold winters, which are the normal weather conditions in Rafsanjan. Increasing salinity can reduce pistachio harvest quantity and quality, however due to pistachio's salinity resistance there would be no significant reduction of crop production up to $8000 \mu \mathrm{S} / \mathrm{cm}$ (Iran Pistachio Association, 2011). Rafsanjan is the biggest pistachioproducing area in Iran and, as mentioned above, the whole area has become specialized in pistachio production during recent years to the point that there is almost no other agricultural production in the area ${ }^{1}$. Rafsanjan is named as "the city of green gold" by the residents of the area. Different types of pistachios can be found in the area which need different treatment and have different quality and prices in the market. However,

${ }^{1}$ Although the provincial agricultural office of Kerman has registered few other tree crops in their databases, the author did not find any other crops during the field survey. 
excluding saffron, pistachio is the most expensive agricultural crop in Iran. Since Iranian pistachio production is an export-oriented industry, many experts believe that the Government's currency policy of maintaining a strong Iranian rials against other currencies in the last few years has discouraged sustainable development of pistachio production in Iran, when faced with competition from a rapidly developing American industry. As the inflation rate in Iran is high $(13.2 \%$ for the year 2011 according to Central Bank of the Iran), production costs are increasing. However, as a result of rapid American production expansion lowering international pistachio prices, these costs are not matched by a corresponding increase in pistachio prices.

\subsubsection{Field work}

Data has been gathered using two-stage random sampling. Bearing in mind the difference in water quality that can be found in the study area, and the high cost of water quality studies, the readily available random sample of 60 wells which were seasonally controlled for water quality was used as the first-stage sample selection. To collect this data, the Rafsanjan Irrigation Water Authority (RIWA) selected 60 agricultural wells randomly around the aquifer and checks the chemical and quality factors of the water such as EC, $\mathrm{pH}$, etc. seasonally. So the factors related to the quality change of the aquifer can be observed. It was possible to obtain data for a period of 4 years.

The survey has been done using two different types of questionnaires, one concerning wells and the other concerning households. The questionnaire concerning wells has been designed and checked with irrigators, pumpers and well representatives. This questionnaire contained information covering the well ownership, technical aspects, historical trends, well management, labor force, energy consumption, maintenance, water charge, and property values. The household questionnaire contained questions about garden management, garden structure, the harvest value of crops, household socioeconomic structure, inputs, garden operational costs, processing costs, water provision costs and water trade. Cost items for a one-year period of agricultural production and two years of crop yield levels and selling prices were collected. The goal was to design a production-cost questionnaire which could cover both big and small farmers. As the sample of wells was random, 
both groups were included in the sample.

In order to carry out the survey, I contacted the wells' representatives first and interviewed them with the questionnaire concerning wells. I then contacted the farmers. Interviews with bigger farms owned by landlords were conducted with their representatives, usually in the office or in the field. It was sometimes the case that interviews lasted as long as one day as items had to be checked in the books. In the case of the smallholders, I interviewed some of the farmers who were using the same well. These farmers were chosen randomly based on the size of their farms. Orchard owners who lived and worked elsewhere were not mainly available for interview. Instead respondents mainly consisted of those who were actively involved in, and technically knowledgeable regarding, pistachio production. As mentioned above, the ownership pattern is very diverse. There were cases where 2-3 wells belonged to one landlord or where one well was owned by 200 people. Finally 57 wells' representatives were interviewed along with more than 157 farmers whose land is dispersed around the aquifer. This covers 52 pumping units. Each pumping unit refers to the number of wells which irrigate a specific farm area. There could be one well or several wells within one pumping unit. Usually, a pumping unit has one management pattern for all wells inside that pumping unit and its water is mixed for irrigation. Table 2.4 shows the land and water ownership pattern in the 157 farm sample. The ownership here covers only those farms which are irrigated by those specific pumping units. Many farmers owned other big or small piece of properties here and there but they were not focus of this survey as the sampling is based on the pumps. It must be added that in Iran due to the Law of Fair Distribution of Water (Majlis of Iran, 1983), people receive legal permission to use groundwater and it is a public good. However, this permission is a form of property ownership and has a very high value according to water charge levels of wells and water quality. Figure 2.5 shows the position of target wells in the study area. Figure 2.6 shows the histogram of the ownership pattern of pumping units and EC of the groundwater sampled. 
Geographic position of sample wells

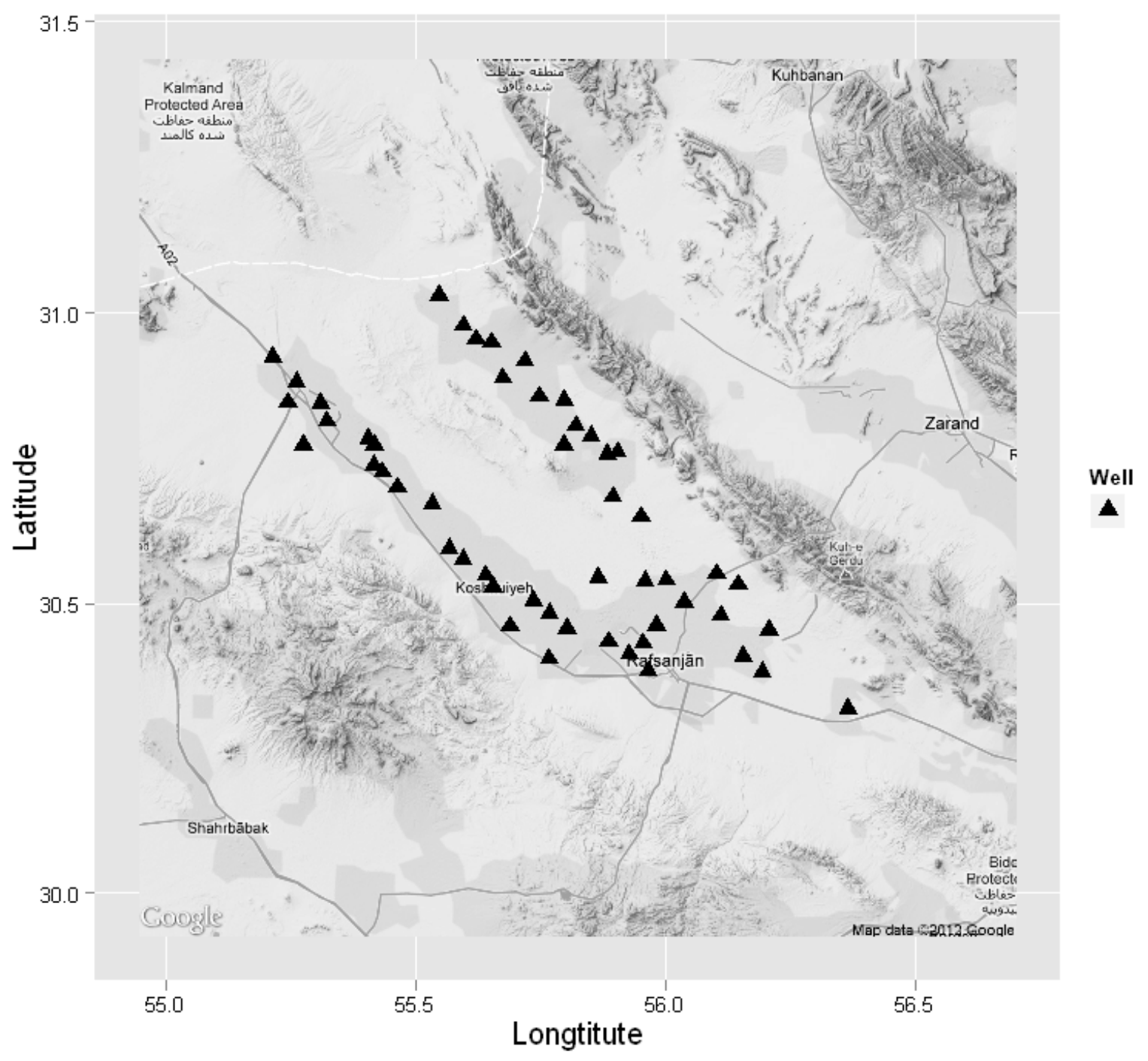

Source: Google Static Maps with the help of ggmap and ggplot2 packages in $\mathrm{R}$ statistical software

Figure 2.5.: Geographical position of wells and farms 
Table 2.4.: The land and water ownership pattern in the 157 farm sample

\begin{tabular}{|l|c|c|c|c|}
\hline \multirow{2}{*}{ Land ownership } & \multicolumn{3}{|c|}{ Regions } & \multirow{2}{*}{ Sum } \\
\cline { 2 - 4 }$\leq 5$ ha & Bahraman & Rafsanjan & Anar & 120 \\
$>5$ ha and $\leq 10$ ha & 39 & 38 & 43 & 8 \\
$>10$ ha and $\leq 15$ ha & 3 & 5 & 0 & 6 \\
$>15$ ha and $\leq 20$ ha & 1 & 4 & 2 & 4 \\
$>20$ ha and $\leq 25$ ha & 0 & 1 & 1 & 4 \\
$>25$ ha and $\leq 30$ ha & 4 & 0 & 0 & 4 \\
$>30$ ha and $\leq 35$ ha & 0 & 0 & 1 & 1 \\
$>35$ ha and $\leq 40$ ha & 1 & 0 & 0 & 1 \\
$>40$ ha and $\leq 45$ ha & 0 & 1 & 0 & 1 \\
$>45$ ha and $\leq 50$ ha & 1 & 0 & 0 & 1 \\
More than 50 ha & 1 & 2 & 4 & 7 \\
\hline Sum & 50 & 53 & 54 & 157 \\
\hline Water use per ha $\left(M^{3}\right)$ & 4 & 9 & 7 & 20 \\
\hline Less than 5000 & 20 & 37 & 26 & 83 \\
$5000-10000$ & 20 & 4 & 14 & 38 \\
$10000-15000$ & 6 & 3 & 7 & 16 \\
$15000-20000$ & 50 & 53 & 54 & 157 \\
\hline Sum
\end{tabular}

Source: Study findings

Histogram of ownership patterns of the pumping units in sample

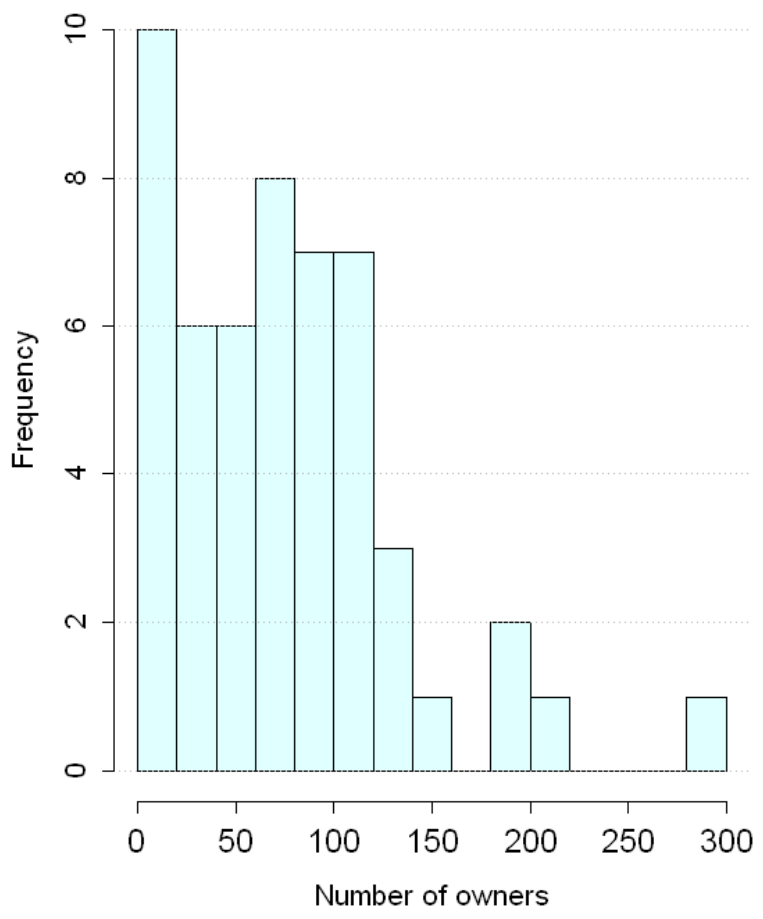

Histogram of electric conductivity (EC) at 52 pumping units

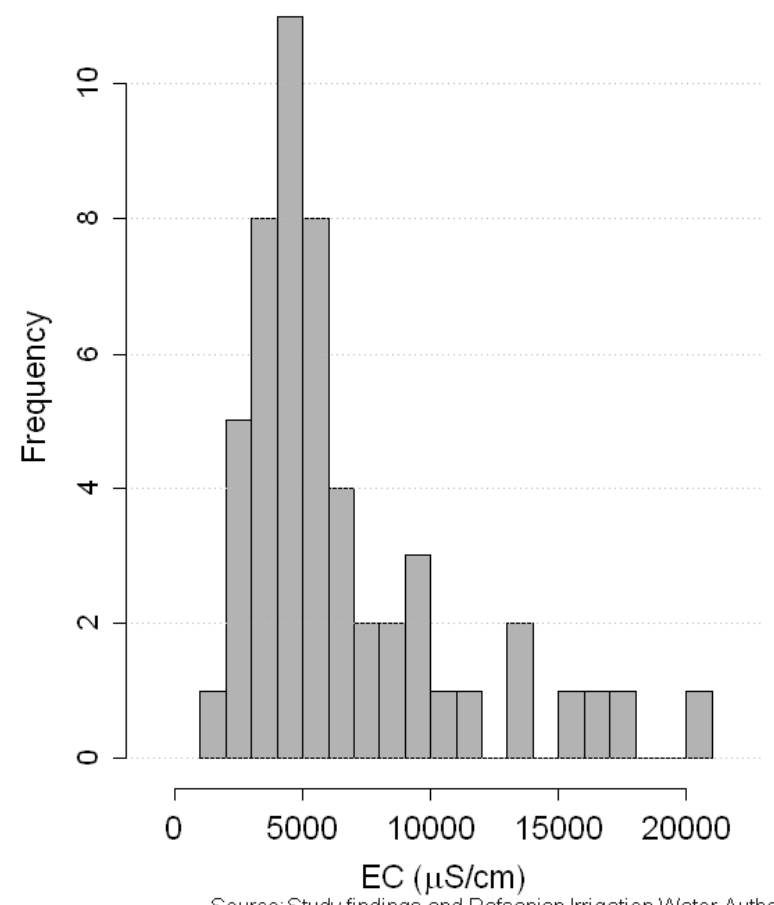

Source: Study findings and Rafsanjan Irrigation Water Authority

Figure 2.6.: Histogram of the ownership pattern of pumping units and EC of groundwater 


\subsubsection{Description of data}

The detailed cost data regarding the pumps and the farms were extracted from the questionnaires and entered into a database (MSACCESS 2003). Pumps and farms were dealt with separately. In the following paragraphs, the data structure and the variables used in the model for estimation are described. Table 2.5 shows a summary of variables used in the establishment of the model. Some additional variables which explain the conditions in the study area are also added to the table. Additionally, some modifications are considered for the model variables.

Table 2.5.: Descriptive summary of the variables

\begin{tabular}{lrrrr}
\hline Variables used in the model & Means & sd & Max & Min \\
\hline Fertilizer Manure sand Divisia price & 1018.60 & 1522.00 & 11007.30 & 23.70 \\
index (rials/kg) & & & & \\
Water pumping cost (rials/cubic & 357.90 & 318.30 & 1503.00 & 59.70 \\
meter) & & & & \\
Labor price index (rials/day) & 101833.80 & 16602.70 & 144383.00 & 58052.50 \\
Mashin price index (rials/hour) & 59926.70 & 43316.80 & 352214.60 & 14095.20 \\
Pesticide price index (rials/kg) & 124255.00 & 205923.10 & 1406325.30 & 19096.80 \\
Pistachio harvest (kg) & 11963.60 & 34045.30 & 285000.00 & 0.00 \\
Water quota (cubic meter) & 88084.80 & 255232.50 & 2126180.60 & 1002.90 \\
Well capital stock (million rials) & 169.00 & 397.40 & 2892.00 & 2.50 \\
Water salinity-EC & 6453.50 & 3885.00 & 21000.00 & 1314.00 \\
Density of trees in farm & 9362.70 & 26128.40 & 276840.00 & 112.50 \\
\hline Variables not used in the model & & & & \\
\hline Farm size (ha) & 9.60 & 25.20 & 224.90 & 0.10 \\
Age of gardens & 25.70 & 9.00 & 65.00 & 5.00 \\
No of frgmanted farms & 3.50 & 2.60 & 15.00 & 1.00 \\
Water quota per ha (cubic meter) & 8970.30 & 4272.40 & 22425.00 & 2307.40 \\
Water use per ha (cubic meter) & 9083.60 & 3970.60 & 20981.60 & 2325.90 \\
Water level (meter) & 62.20 & 30.60 & 138.70 & 8.10 \\
Well depth (meter) & 194.00 & 79.60 & 400.00 & 69.00 \\
Tree density per ha & 1216.60 & 863.80 & 5117.30 & 357.10 \\
\hline & & & Source: Study findings \\
\hline
\end{tabular}

Irrigation water and pumping costs The variable cost of pumping is calculated using the variable cost of wells. As the pumps do not have a water contour, the questionnaire asked about the flow rate of the pumps $(L i t / S)$ and this number was later checked. Then by considering the number of "off days", the total size of pumped water is calculated as 
follows for one year:

Water Flow $\times$ WorkingDays $\times 24$ Hours $\times 3600$ Second

By considering each farmer's share of the well, each farmer's annual share of the above pumped water is calculated and considered as the water input level of the farm. If the farmer bought, added or extracted any extra water to this amount, that is also considered in the water amount. Farmers have a specific quota for the amount of water they can take from each well. Their quota has been defined as a fixed factor and calculated as

Water Flow $\times$ WorkingDays $\times 24$ Hours $\times 3600$ Second $\times$ FarmerShareFromWell

The above formula shows the annual amount of water to which each farm is entitled. Actual water can differ from the entitlement as a result of buying water or transferring water between neighbouring pumps by farmers. Therefore, there are some differences between the water as an input and the water quota from the well, the latter of which can be seen as quasi-fixed factor. Figure 2.7 shows the histogram of water use and the water quota per hectare for the sample.

The variable cost of pumping is calculated in two different ways. As the absolute majority of the wells are shared among many owners, each share holder has to pay an annual bill to the well representant. For most of the pumps in the sample, this bill was considered as the variable cost of the water pumping costs. If there are some installations or repositioning costs which the bill accounts for, they are separated from the costs. The elements of this bill was also determined by asking information about operation and maintenance items, labor costs and energy costs. As most of the pumps used electropumps, the subscription code of each electricity bill was gathered during the survey and the full time series information of energy costs of each pump was extracted from the website of the North Kerman Electrical Power Distribution Company (NKEPD Co. $)^{1}$. It must be added that although the same rate was imposed by the NKEPD Co. on all pumps, there were differences in energy consumption so that the energy cost based on

\footnotetext{
${ }^{1}$ North Kerman Electrical Power Distribution Company (NKEPD Co.) website: http://nked.co.ir/
} 

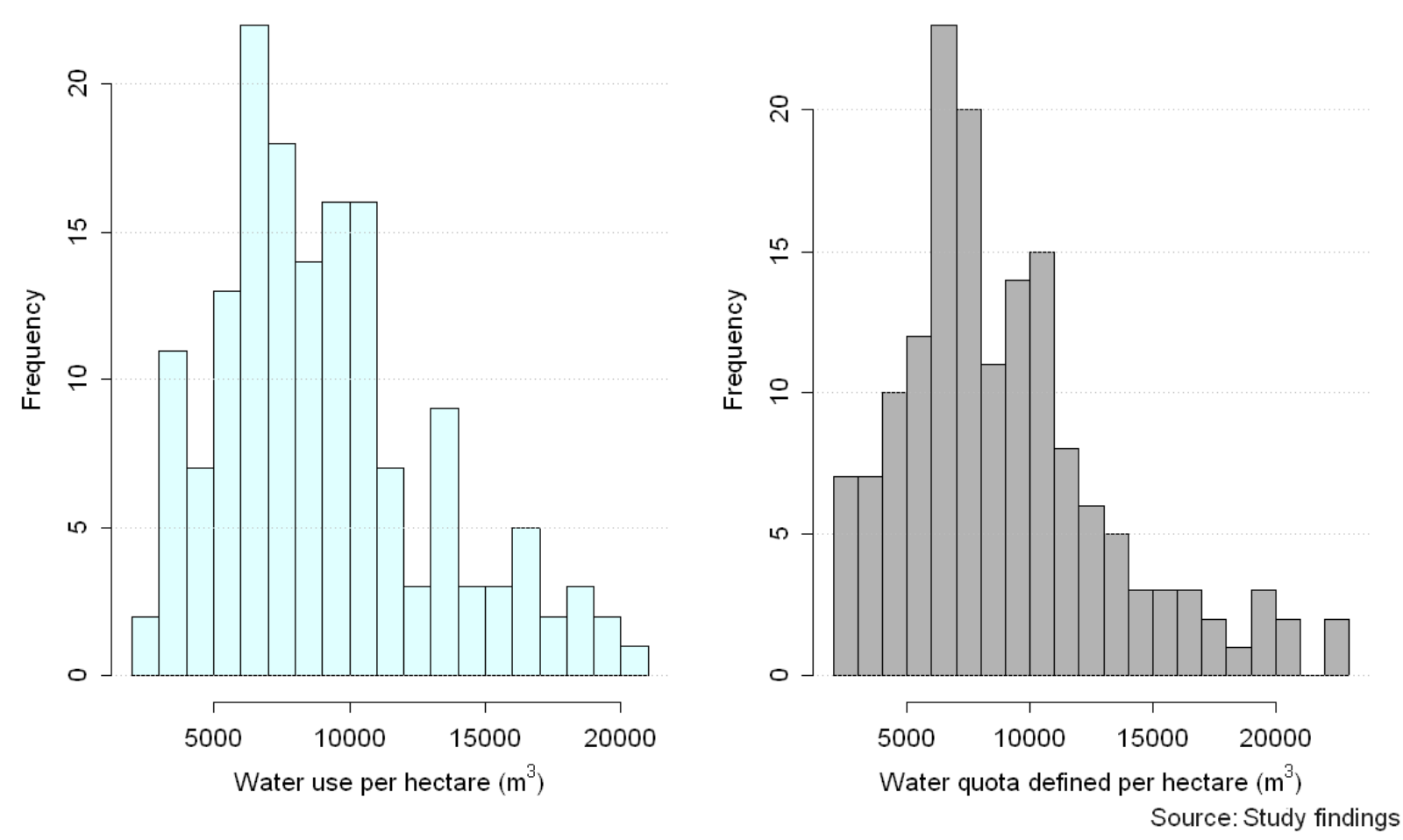

Figure 2.7.: Irrigation water use and water quota per hectare for the sample

the electricity use pattern of pumps over a 24-hour period and on the different quotas for electricity consumption permissions which were given to the electro-pumps, exhibits substantial differences, too. For the diesel pumps, the energy costs were collected during the survey.

If a farmer participated in the spot water market and bought water from his neighbours, its cost was also added to the water pumping costs. On the other hand, if some part of his quota was transferred to another farm, its cost was subtracted from the total costs. Finally, the cost per cubic meter of consumed water was defined as the water price in the model. For large farms with only one owner, the cost of pumping water was defined by adding up all the elements of pumping costs for one year. Information from these farms' internal booking systems was used for this calculation.

Energy prices change during last years At the time of the field survey (2008-2009) the energy prices for normal hours normal prices for the agricultural sector was 13.3 


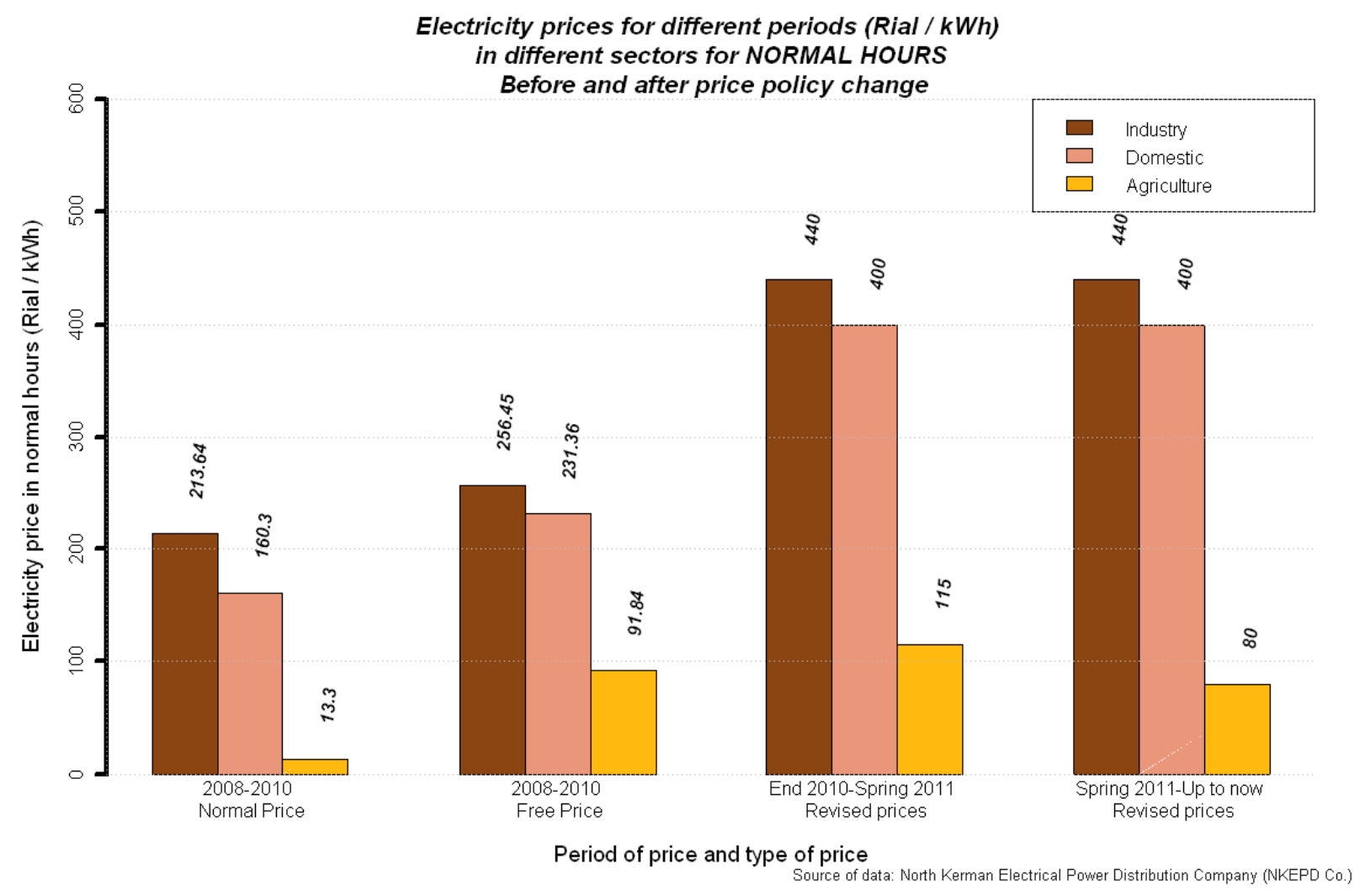

Figure 2.8.: Electricity tariffs for normal hours in different sectors

rials/kWh (in contrast the normal hours free price was 91.84 rials $/ \mathrm{kWh}$, the peak hours ${ }^{1}$ normal price was 33.3 rials $/ \mathrm{kWh}$, and the peak hours free price was 229.6 rials $/ \mathrm{kWh}$ ). The normal hours normal price for agricultural use was 12 times less than for domestic use (160.3 rials $/ \mathrm{kWh})$ and 16 times less than industry use (213.64 rials/kWh) at that time (NKEPD Co., 2011).

In December 2010 a price reform policy was implemented. Electricity prices for irrigation pumping were increased more than 10-fold to 140 rials/kWh for normal prices (Behzad (2010), Deputy of Ministry of Energy (MOE), announcement on 21.12.2010). After one month, the pumping price was reduced to 120 rials/kWh in the price reform program (Nikbakht (2011), Ministry of Agriculture Deputy, announcement on 26.01.2011). Finally in April 2011, the Minister for Agriculture announced the reduction of the irrigation pumping price to 80 rials/kWh for normal price (Khalilian, 2011). Further, if farmers pumped water only in non-peak hours, they would pay only 40 rials/kWh; 10 times less than the newly reformed urban and industrials water price. Figures, 2.8, 2.9 and 2.10

\footnotetext{
${ }^{1}$ In summer the peak hours are 19.00-23.00, and in winter are between 18.00-22.00
} 


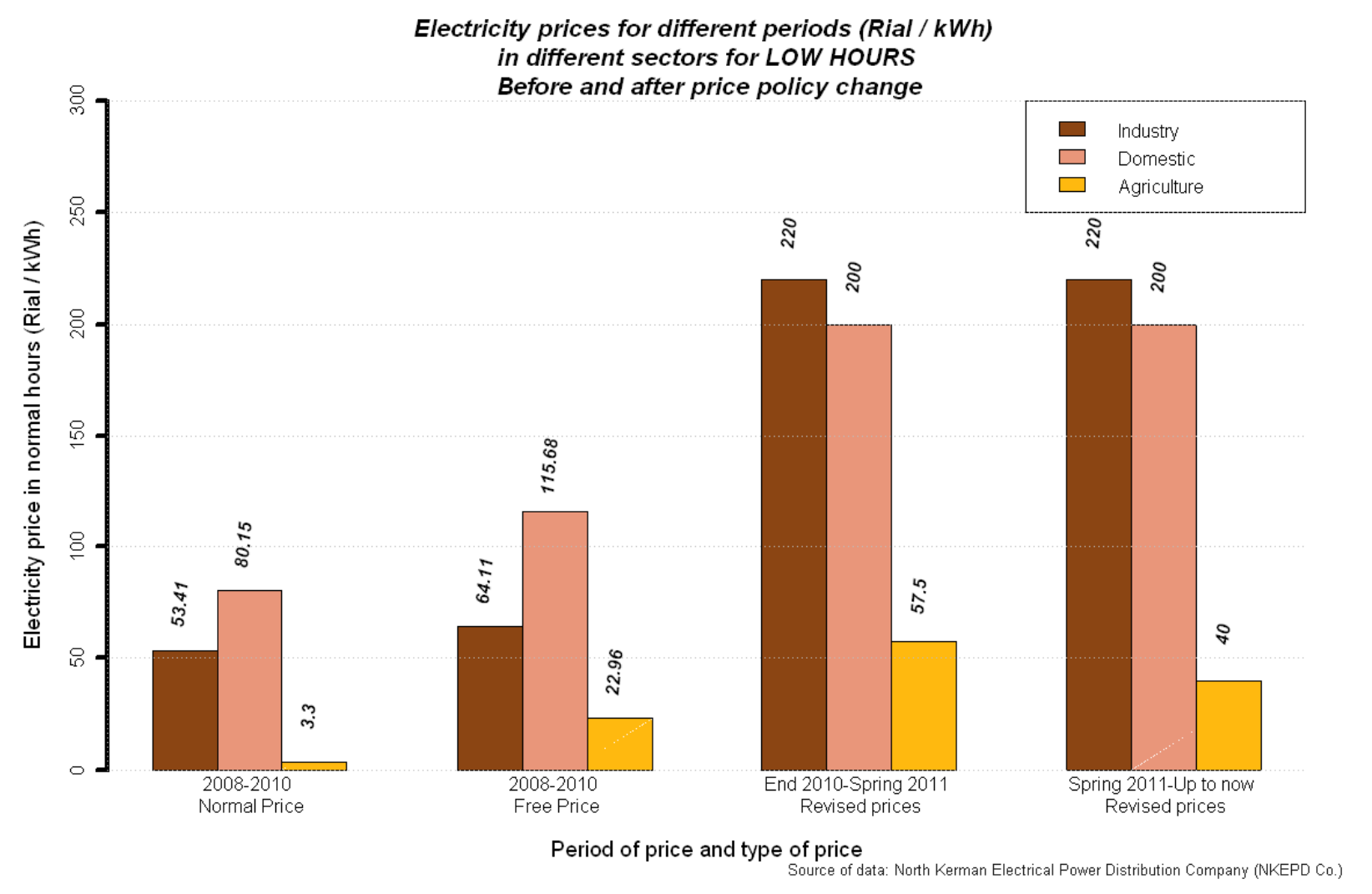

Figure 2.9.: Electricity tariffs for off-peak hours in different sectors

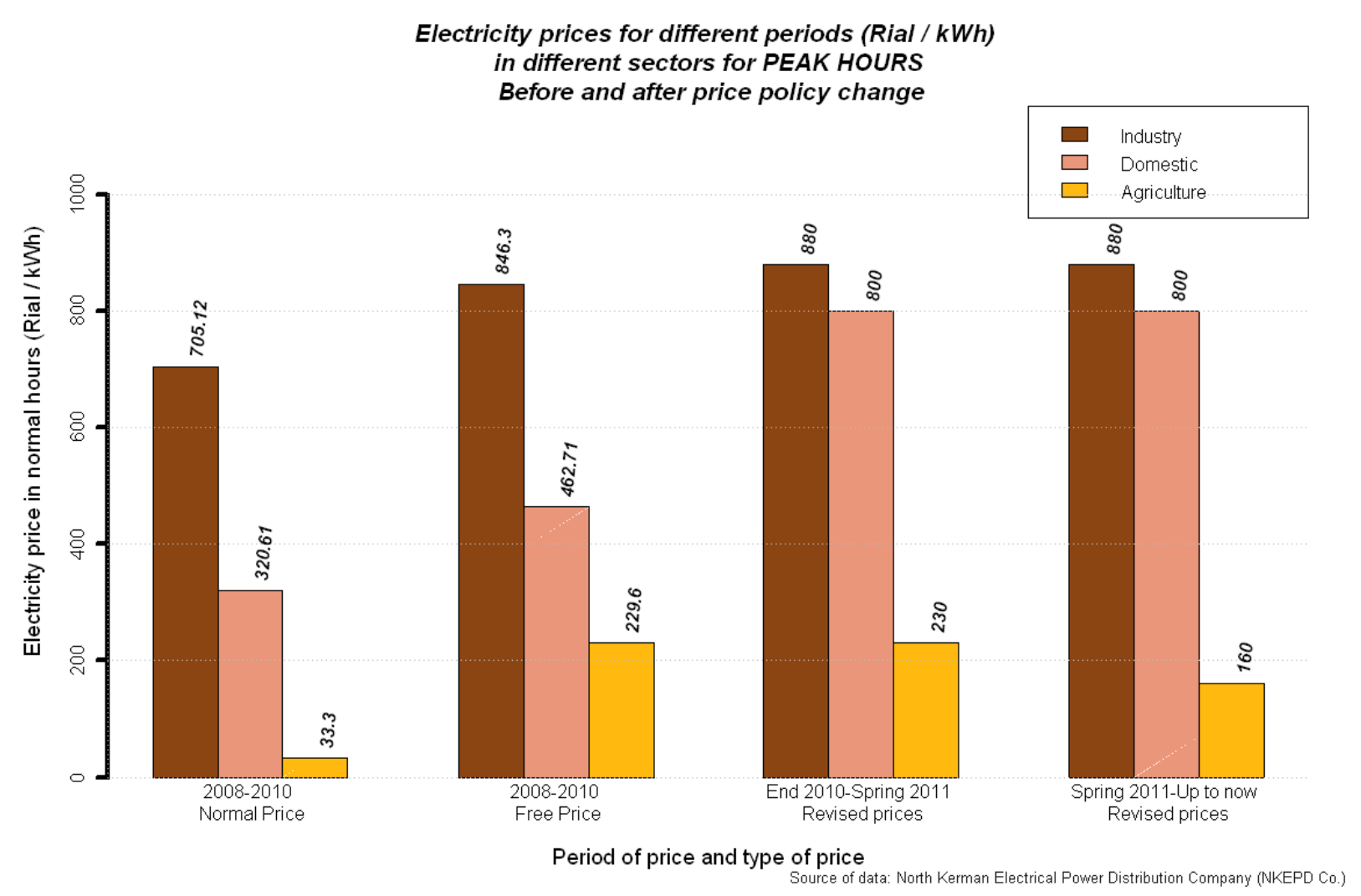

Figure 2.10.: Electricity tariffs for peak hours in different sectors 
show the electricity tariffs for normal, off-peak ${ }^{1}$ and peak hours respectively, for different uses before and after the price reform policy (2010) implementation.

It must be mentioned that since almost all of the farmers in the sample pumped water for 24 hours per day, they were paying for electricity at three different rates simultaneously. Many farmers had exceeded their annual normal price quota, and thus in most cases were paying free price tariff rates for this extra use. Some farmers even received additional electricity quotas based on industrials prices and tariffs. Therefore a fraction of their overall pumping costs were paid at the heavily subsidised price of energy for agricultural use, whilst occasionally they paid at other level tariffs.

Production Level Pistachios have bearing and non-bearing periods. This means the production level might be high in the first year while in the next year it is low. There are different types of pistachios available in the study area, and many farmers process, dry and separate good- and bad-quality pistachios. Some farmers do only the processing and drying but not the separation, and some large farmers sell the whole crop fresh without doing any processing. Many farmers produce different brands at the same time. Since these decisions by farmers made the cost spent for each brand almost impossible to calculate, the aggregate level of pistachio production is considered as the production level of each farm. The questionnaire asked each farm for its ratio of dry to fresh pistachio production. The level of production is adjusted for this group of farms. A dummy variable is considered in the model for the farms which sell entirely fresh kernels.

The study area was unusually cold during the spring of 2008. In spite of all costs which farms paid for operations during the 2007-2008 agricultural year, the crop production in the summer of 2008 was reduced dramatically. In order to develop the production level for the cost function, 2007's high yield production has been considered as a base, and, by asking the farmers about the possible relative level of the pistachio production in the bearing and non bearing years, the average of these high and low levels is considered as the production level of the farm. Expenditures during 2007-2008 are used for establishing the cost function and, as a result, the factor demand function. There were some young

\footnotetext{
${ }^{1}$ In summer the off-peak hours are $23.00-7: 00$, and in winter are between 22.00-6:00
} 


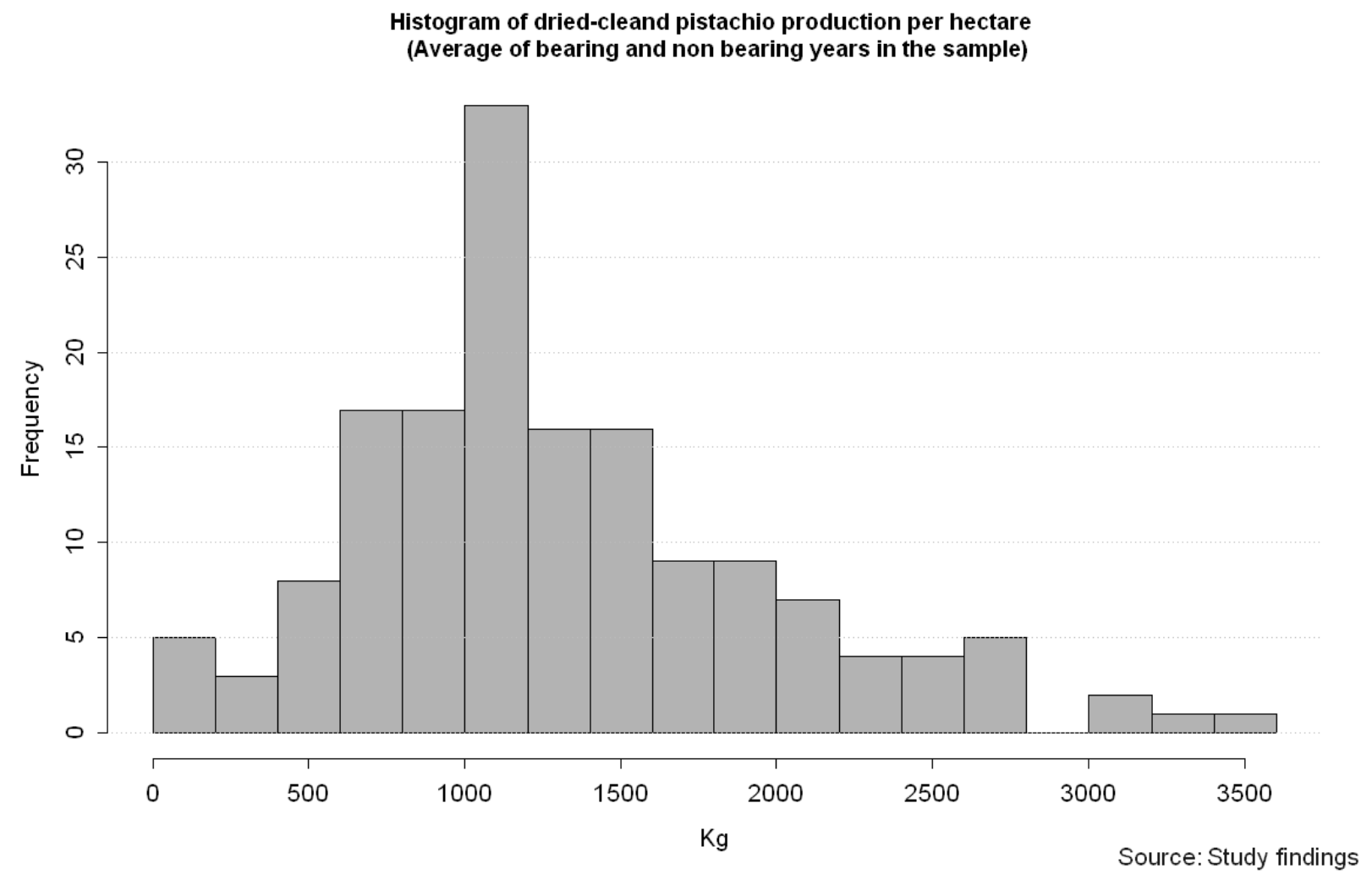

Figure 2.11.: The histogram of pistachio production per hectare as an average of bearing and non-bearing years

gardens in the sample which showed no crop production. Figure 2.11 shows the histogram of pistachio production per hectare as an average of bearing and non-bearing years, which is explained above. Figure 2.12 shows the average pistachio production per hectare for the bearing year 2007 and the non-bearing year 2008, which was caused by the unusually cold spring.

Manure and fertilizer costs and prices Farmers use many different types of chemical fertilizer (phosphate, nitrate, sulphate, etc.), manure (cow, sheep, chicken or fish) or natural fertilizers (agribiosol, agrihum, etc.). Some also distribute sand among the trees. These operations can be substituted. There are farmers using all of the above-mentioned elements, and there are farmers using only some of them. In order to have a price index representing sand, manure and fertilizer prices in a cost function without having any zeros on the right side of the equation, an aggregate price index has been established for sandmanure-fertilizer by considering cost share weight (Diewert, 1981; Pope and Chambers, 1989). The following aggregation formula has been used to establish the Divisia price index for manure, chemical fertilizers and natural fertilizers as well as sand use for each 

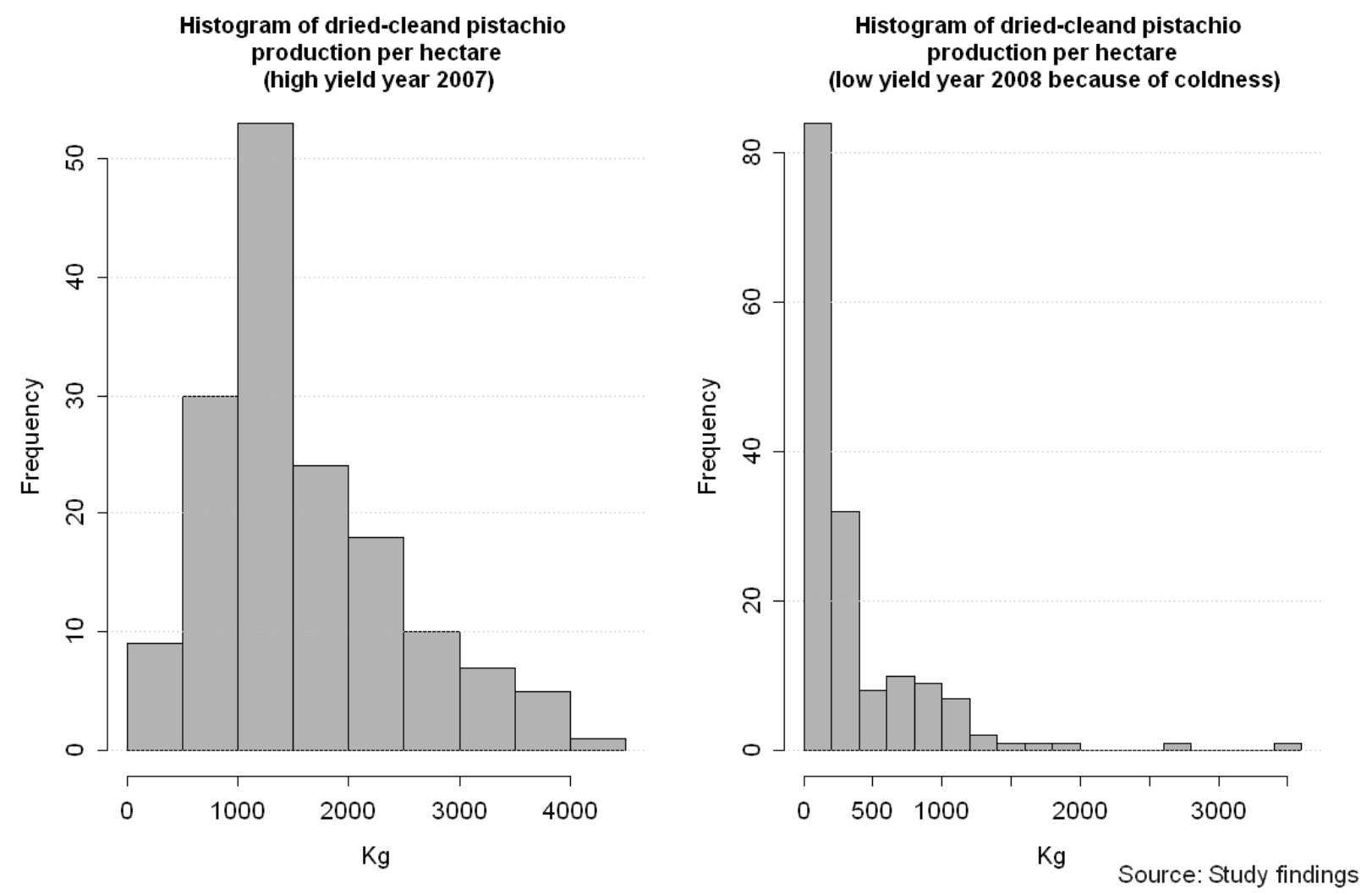

Figure 2.12.: the average pistachio production per hectare for the bearing year 2008 and the non-bearing year 2007

farmer (Lapp and Smith, 1992):

$$
\text { PriceIndex }=\sum_{i=1}^{n} w_{i}(W)_{i}
$$

where $w_{i}=\frac{W_{i} X_{i}}{\sum_{i=1}^{n} W_{i} X_{i}}$ is weight which adds up to one. $X_{i}$ is quantities, and $W_{i}$ is the price of that quantity (fertilizer or manure in this case) paid by the farmer.

Pesticide price Farmers use different pesticides in their gardens such as amitraz, endosulfan and herbicides at different volumes. Therefore, a single aggregate price index has been established for pesticides and herbicides together. The Divisia price index according to equation 2.14 has been used.

Machinery cost and price There are different types of machinery used in the pistachio gardens which can be categorized as machinery for pesticide distribution, hole digging, soil ploughing, soil rotating, etc. Costs for these different machines vary. Therefore, an aggregated price index has been established for machinery with the help of the equation 
2.14. It must be added that there are farmers who own tractors and pesticide sprayers, and there are farmers who borrow these machines by the hour. As it was almost impossible to find the whole annual operation and maintenance cost of machines (based on Iran's Tax Law, the agricultural sector is tax-exempt (Majlis of Iran, 1988, paragraph.81); therefore, no booking system is required for farmers), the number of hours which the machines had been working on the farm was asked during survey and the local cost of hourly machine work for each operation was recorded. Therefore, the cost of machinery reflects the opportunity cost of the machines for those who own them.

Labor cost and labor price The cost of hired labor also varies, especially depending on what type of labor it is (such as pruning, manure or fertilizer distribution, harvest, processing, irrigation, etc.). Large farms employ an annual labor force with specific insurance in accordance with the Iran Labor Law. The aggregate price index is established for the labor force as a daily price. The annual labor cost has been changed to a daily labor cost. Extra costs for daily or annual labor, such as food, are also considered. The contribution of family labor was gathered during the survey. As family labor had access to the local labor market by supplying work to other farms in this region, the local price of the labor was considered as opportunity cost of family labor.

Variable cost Variable cost consists of fertilizer, manure, sand distribution, machine work, labor, water pumping and irrigation, pruning and almost all possible costs concerning agricultural operations for the period of one year (2007-2008) in the study area.

Stock of capital There are two facts that encouraged us to develop an index for the stock of capital as a quasi-fixed factor in this study. The first issue is the differences among gardens in terms of age and the structure of the garden, which both affect productivity and input application at the farm level. Therefore, it was necessary to develop an index for capital to control for a group of factors which are not instantaneous. In the setting of this study, there are some challenges for defining the level of stock capital. In contrast to many investments, fruits and nut trees do not only follow a depreciating trend. Because trees continue to grow for a number of years after producing their first crop, and because 
the quality and quantity of the crop tends to improve as the tree reaches maturity, fruit and nut trees generally appreciate in value for a significant portion of their useful lives. Therefore, in contrast to many other depreciating assets, the application of equivalent economic life or useful life is not straightforward (Department of the Treasury, 1990, p.1). As Iran's Direct Tax Act has exempted the agricultural sector from direct tax (Majlis of Iran, 1988, paragraph.81), neither official financial standards nor a handbook have been developed for biological assets like fruit or nut trees.

By considering 40 years of useful life for pistachio orchards (Department of the Treasury, 1990; Karakaya, 2009) and a 12-year period of preproduction (Ferguson et al., 2005), a retention period of 52 years is defined for pistachio trees. The capital cost is defined as the discounted value of garden establishment costs that were incurred at the beginning. The costs are first appreciated and then depreciated to define the current stock of capital for pistachio orchards. The rate of 2.5 percent is considered for depreciation (Karakaya, 2009, p.301). For simplification, the same rate is considered for the gestation period. As many gardens were established many years ago, many respondents could not calculate an establishment cost for their gardens. Those who newly established a garden were asked for the quantity and the cost of different garden establishment activities, which were calculated based on 2008 prices. The cost of garden establishment per hectare was developed based on the each activity. Values were adapted by considering each garden's characteristics, which had been gathered by questionnaires. The value was then discounted by a rate of $7 \%, 14 \%$ and $20 \%$ with respect to the age of each part of the garden (information on the garden structure was gathered for each part of the farm if the garden was not unique but scattered).

The second consideration in developing the capital index was the phenomenon of well repositioning in the study area. In cases where the water charge of a well falls below the permitted level because of hydro-geological and geological changes to the aquifer as a result of intensive water use, farmers and pump owners are encouraged to relocate the well to restore permissible charge levels. This action imposes high costs to the farmers. Some pumps have been moved many times in the past 40 years, and some pumps have not been moved at all. By gathering the data on the cost of well digging and well 


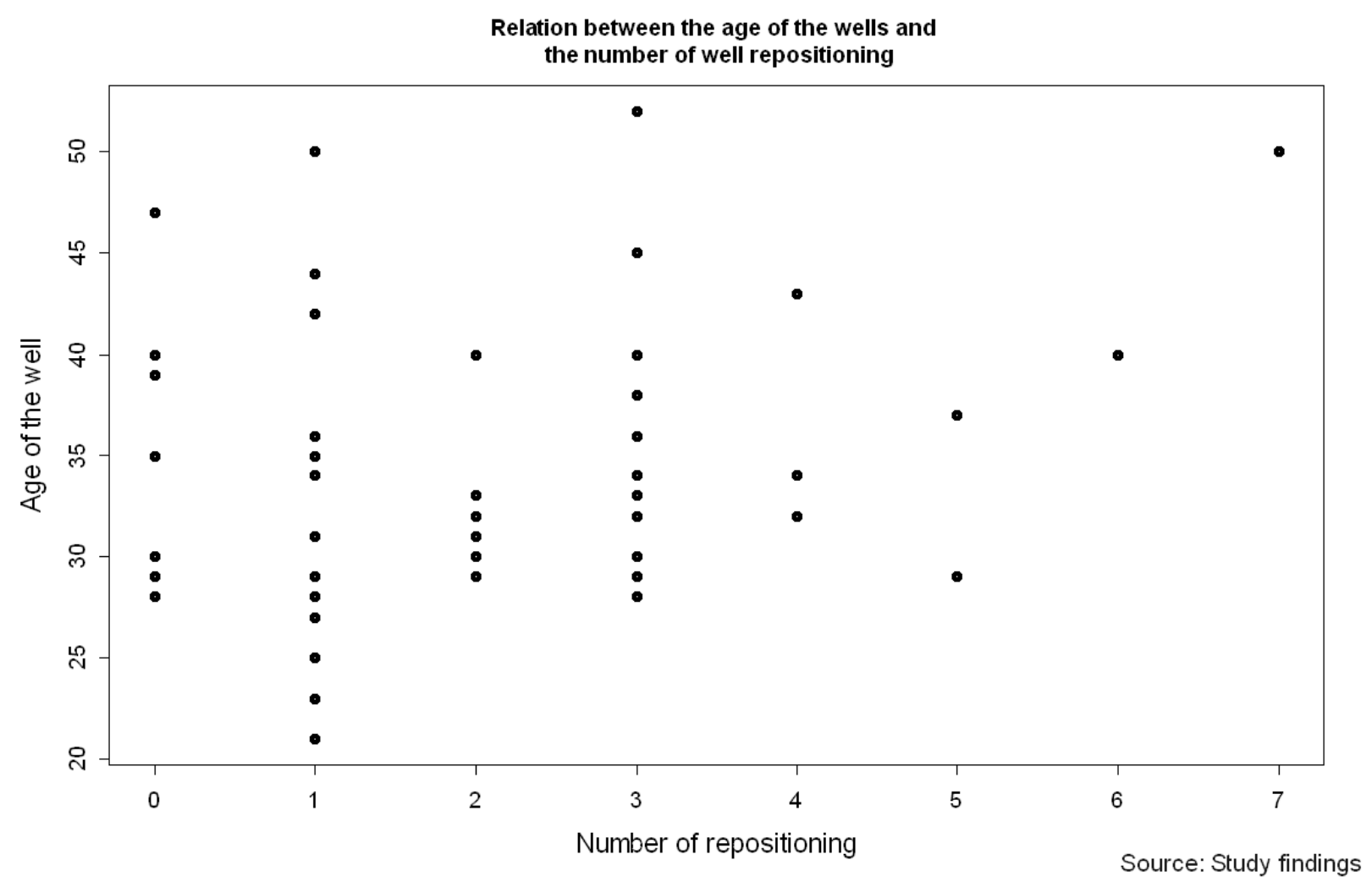

Figure 2.13.: The relation between the age of the wells and the number of well repositioning up to 2008 in the sample

jacketing from those who were familiar with this issue and by finding the depth of the wells during different periods in the past, another component of the capital index was developed. Figure 2.13 shows the relation between the age of the wells and the number of well repositioning up to 2008 .

This component was also discounted for the investments in the pump and summed up with the capital index of the garden. In the sample, a fraction of the owners of three wells had adopted modern irrigation (four farms). Their investment also added to their capital index. As mentioned above, all costs were calculated at 2008 price levels. The declining balance depreciation model is considered for depreciating the capital stock for each year (Diewert and Lawrence, 2001). Alternative discount rates of 7\%, $14 \%$ and 20\% have been used to construct three different capital stock series. There are some reasons for considering the above three discount rates. In Iran $7 \%$ is advised for cost benefit analysis of water resources development projects for irrigation without considering inflation rate in cash flows (Bureau of Technical Execution System, 2011, p.74). Moreover, the inflation rate in Iran is $13.2 \%$ according to Central Bank of the Iran. This rate has reached to $20 \%$ 

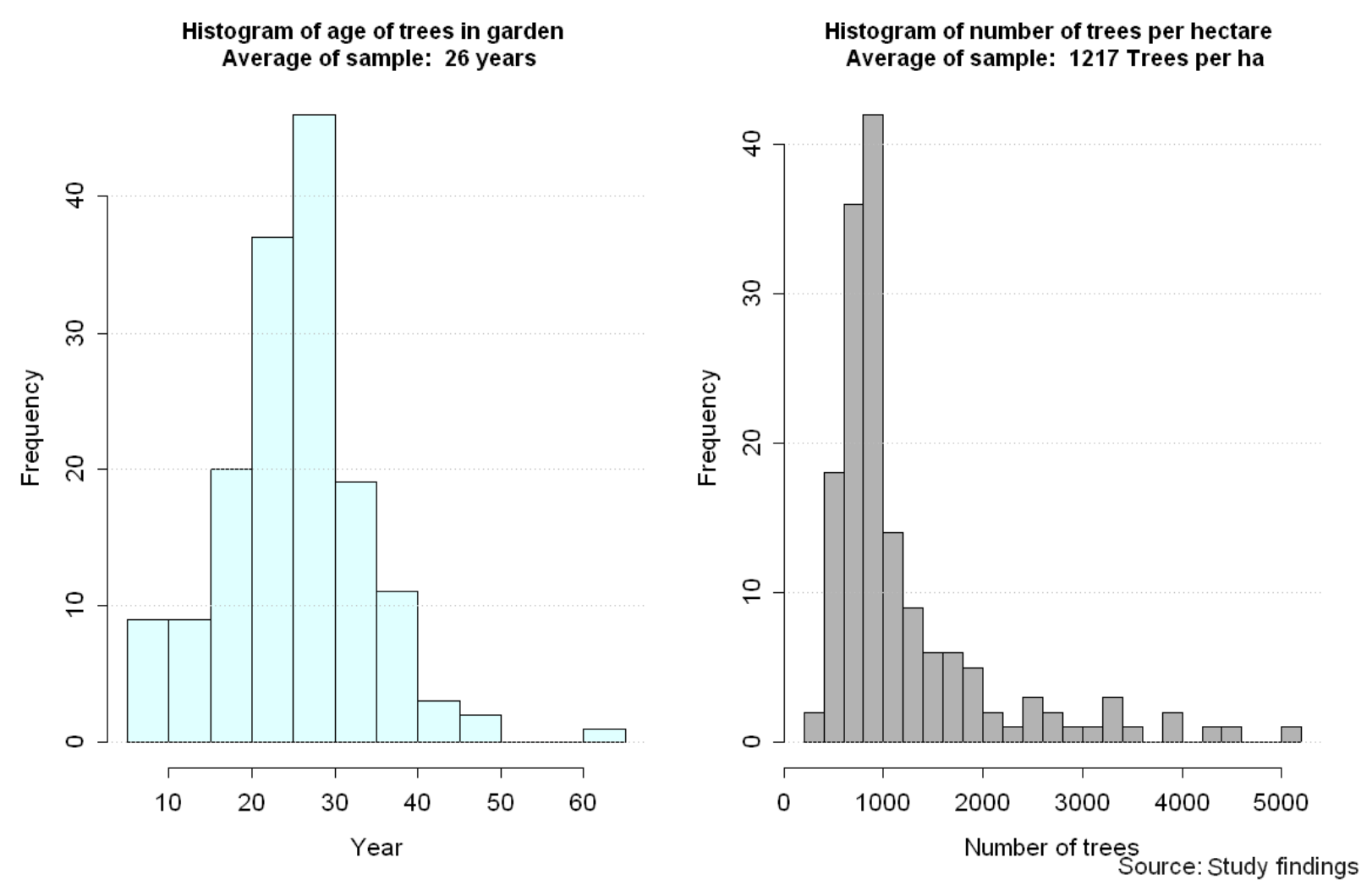

Figure 2.14.: Histogram of the average age of the trees on sampled farms and tree density per hectare

during last years. Additionally, different rates can be found for annual interest rate from official banks and financial institutions which varies between 12\%-18.5\% (Banki, 2011).

Farm tree density Sampled farms possessed a diverse variety of tree densities (measured in trees per hectare). Therefore, the number of trees is considered as a possible quasifixed factor in the model. To ascertain the number of trees per farm the following items were asked in the survey; number of pieces of land (if the farm is fragmented), number of rows of trees in each piece, distance between rows in each piece and finally the inter-tree distance in each row. The resulting index of number of trees per farm was then considered in the model.

Other variables The number of male trees per farm, the trees' age, the depth of water and of the well are four indices which have been considered as factors representing garden structure in the cost function. But as they were not significant, they were not considered in the model as quasi-fixed factors. Figure 2.14 shows the histogram of the average age 
of trees on sample farms and tree density per hectare.

\subsection{Empirical model and estimation}

\section{Empirical model}

Following Guyomard and Vermersch (1989) and Halvorsen and Smith (1991), the empirical translog cost function has been developed as follows:

$$
\begin{aligned}
\ln C R= & a_{0}+a_{1}(\ln Y)+\frac{1}{2} a_{2}\left(\ln Y^{2}\right)+\sum_{i=1}^{5} b_{i} \ln W_{i}+\frac{1}{2} \sum_{i=1}^{5} \sum_{j=1}^{5} c_{i j} \ln W_{i} \ln W_{j}+ \\
& \sum_{i=1}^{5} d_{i} \ln Y \ln W_{i}+\sum_{k=1}^{4} e_{k} \ln Z_{k}+\frac{1}{2} \sum_{k=1}^{4} \sum_{g=1}^{4} f_{k g} \ln Z_{k} \ln Z_{g}+\sum_{i=1}^{5} \sum_{k=1}^{4} \theta_{i k} \ln W_{i} \ln Z_{k} \\
& +\sum_{k=1}^{4} \gamma_{k} \ln Y \ln Z_{k}+\lambda_{1} D_{1}+\epsilon_{C R}
\end{aligned}
$$

where $C R$ is the variable cost; $Y$ is the output (pistachio); $W_{i}$ is the variable input prices ( $i=1$ is the manure, fertilizer and sand price index, $i=2$ is the water pumping price, $i=3$ is the pesticide price index, $i=4$ is the machine operation price index, $i=5$ is the labor price index); $Z_{k}$ is the water quota per ha $(k=1)$, the tree density per farm $(k=2)$, well capital index $(k=3)$ and $E C(k=4)$. $D_{1}$ is a dummy reflecting farms with heavy sand-manure use during 2007-2008.

Symmetry is imposed on the parameters $c_{i j}$ and $f_{k g}$. Shephard's lemma gives the cost share equations, on which we add the disturbance $\epsilon_{i}$ to reflect errors in optimization:

$$
\frac{\partial \ln C R}{\partial \ln W_{i}}==M_{i}=W_{i} X_{i} / C R=b_{i}+\sum_{j=1}^{5} c_{i j} \ln W_{j}+\sum_{k=1}^{4} \theta_{i k} \ln Z_{k}+d_{i} \ln Y+\epsilon_{i}
$$

Adding-up requires that the cost shares add to one, $\sum_{i=1}^{5} M_{i}=1$. This addiditivity constraint implies the following parameter restrictions:

$$
\sum_{i=1}^{5} b_{i}=1, \sum_{i=1}^{5} d_{i}=0, \sum_{j=1}^{5} c_{i j}=0 \forall j, \sum_{i=1}^{5} \theta_{i k}=0 \forall k
$$

Estimation of this model allows to estimate the shadow price of the water quota based 
on the long-run Hicksian level of quasi-fixed inputs:

$$
\frac{\partial C R}{\partial Z_{k}}+p_{Z_{k}}=0 \quad k=1,2,3,4
$$

where

$$
\frac{\partial C R}{\partial Z_{k}}=\left[e_{k}+\sum_{g=1}^{4} f_{k g} Z_{g}+\sum_{i=1}^{4} \theta_{i k} \ln W_{i}+\gamma_{k} \ln Y\right]\left(\frac{C R}{Z_{k}}\right)
$$

In the case of EC, $\frac{\partial C R}{\partial E C}$ is expected to be positive as the marginal effect of cumulative extraction of groundwater on water quality should be negative. The short run Hicksian price elasticity of the water pumping can be estimated by:

$$
\begin{array}{cc}
\epsilon_{i j}^{-S R}=\left(c_{i j}+M_{i} M_{j}\right) / M_{i} & \\
\forall i, \forall j, \quad i \neq j \\
\epsilon_{i i}^{-S R}=\left(c_{i i}+M_{i}^{2}-M_{i}\right) / M_{i}
\end{array}
$$

The translog cost function and the cost share equations are estimated simultaneously by seemingly unrelated regression (SUR). As we have imposed the adding-up restriction, the problem of singularity is solved by dropping one of the factor demand equations (labor costs in this case) (Berndt, 1996, p.472). For smooth estimation, homogeneity is imposed by normalizing prices with the labor price and estimating the whole models with the normalised prices by $\mathrm{SUR}^{1}$.

\section{Spatial econometrics}

As groundwater is a hydrogeological variable, the possibility of spatial dependence in the model should be considered. A spatial weight matrix $\left(W_{S}\right)$ has been constructed by the inverse distance with a cut-off point of $18.5 \mathrm{~km}$. This distance has been selected in order to avoid having isolated points in the weight matrix, and separating the second and third

\footnotetext{
${ }^{1}$ The inclusion of the capital stock within the cost function suggests that the use of the dynamic factor approach would be appropriate, as formulated by Morrison and Siegel (1997), Morrison (1988) and Pindyck and Rotemberg (1983). We attempted to implement this framework in the translog cost function, however as there were very few wells which had been repositioned annually and because few annual investment costs could be defined inside the sample, the model suffered from multicollinearity. A further problem involved interpretation of the adjustment cost function in the case of well repositioning. Therefore this approach was not followed in the study.
} 


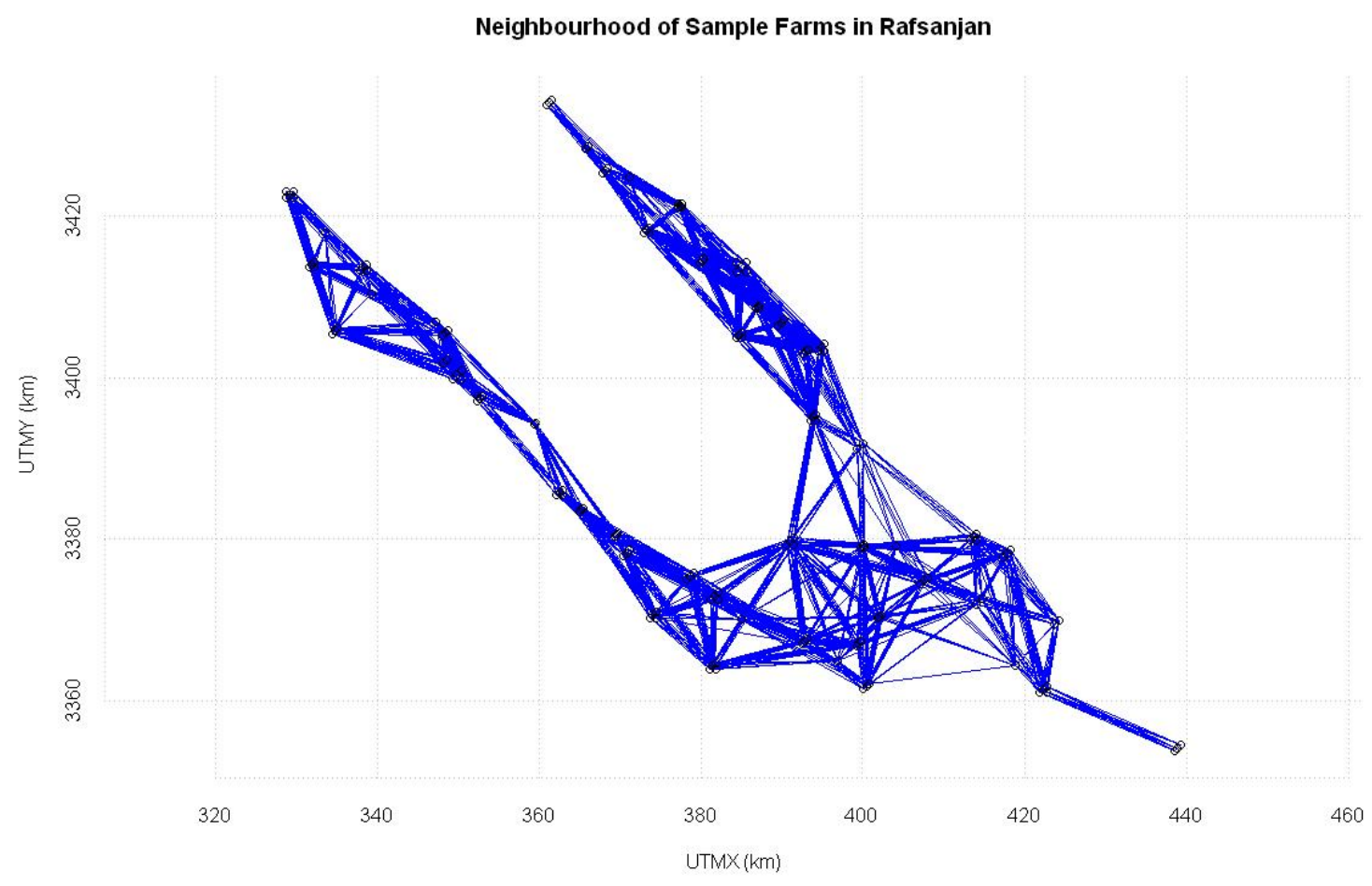

Figure 2.15.: Spatial neighborhood

parts of the aquifer from each other (Anar-Koshkoiyeh and Bahraman-Javadiyeh). There is a mountain between these two parts which separates any direct hydrogeological or social connections between these two areas. The spdep package in $\mathrm{R}$ statistical software is used for the estimation of the weight matrix (Bivand, 2006). Figure 2.15 shows the spatial neighborhood.

A spatial autocorrelation framework is required for correcting the model. Applying Kelejian and Robinson (1992)'s spatial autocorrelation test for the residuals of each equation, we found a significant spatial correlation in water pumping and translog cost equations. To obtain a consistent estimation of the spatial error parameter, we used Kelejian and Prucha (1999)'s Generalised Method (GM) approach on the residuals achieved through the SUR estimation of the two mentioned models (more details are given below). With respect to the taxonomy of spatial simultaneous equation systems (Rey and Boarnet, 2004), there is no reason to think about the theoretical availability of feedback simultaneity, spatial autoregressive lag simultaneity or spatial cross regressive lag simultaneity in the translog cost function and its Shephard's lemma equations. Therefore, Kelejian and Prucha (2004)'s approach for estimating the spatial simultaneous equation systems is not 
required.

\section{Kelejian-Prucha-GM spatial approach}

The starting point with Cliff-Ord Type model (Kelejian and Prucha, 1999):

$$
\begin{array}{cc}
y=\lambda W y+X \beta+u & |\lambda|<1 \\
u=\rho W u+\epsilon & |\rho|<1
\end{array}
$$

where $\mathrm{y}$ is the vector of dependent variables, $\mathrm{X}$ is the matrix of exogenous regressors, $\mathrm{W}$ is a spatial weight matrix, $\lambda$ and $\rho$ are scalar parameters, typically referred to as the spatial lag and the spatial autoregressive parameter, respectively, and $\epsilon$ is i.i.d. $\left(0, \sigma_{\epsilon}^{2}\right)$. Considering the spatial lag parameter ( $\lambda$ in the above formula) in the translog cost function (see equation 2.15) and the cost share equations (see equation 2.16) complicate the standard microeconomics theoretical framework. The authour did not find any published literature which add the spatial lag parameter in the cost function and the cost share equations. The major publication (Cohen and Paul, 2007) in this field has focused on spatial autoregressive parameter. Therefore, $\lambda=0$ is considered in this case.

With only spatial autocorrelation present, a two-step estimator can be applied. In the first step, we use the OLS residuals to obtain $\tilde{u}=y-X \tilde{\beta}, \tilde{\bar{u}}=W \tilde{u}$ and $\tilde{\bar{u}}=W^{2} \tilde{u}$. In the second step, GM used to estimate $\rho$.

Based on Kelejian and Prucha (1999, p.515)'s GM approach:

$$
G_{n}\left[\rho, \rho^{2}, \sigma^{2}\right]^{\prime}-g_{n}=\nu\left(\rho, \sigma^{2}\right)
$$

where

$$
G_{n}=\left[\begin{array}{ccc}
\frac{2}{n} \tilde{u}^{\prime} \tilde{\bar{u}} & \frac{-1}{n} \tilde{\bar{u}}^{\prime} \tilde{\bar{u}}^{\underline{u}} & 1 \\
\frac{2}{n} \tilde{\bar{u}} \tilde{\bar{u}} & \frac{-1}{n} \tilde{\bar{u}}_{\overline{\bar{u}}} & \frac{1}{n} \operatorname{tr}\left(W^{\prime} W\right) \\
\frac{1}{n}\left(\tilde{u}^{\prime}, \tilde{\bar{u}}+\tilde{\bar{u}}^{\prime} \tilde{\bar{u}}\right) & \frac{-1}{n} \tilde{\bar{u}}^{\prime} \tilde{\bar{u}}^{\tilde{u}} & 0
\end{array}\right], g_{n}=\left[\begin{array}{c}
\frac{1}{n} \tilde{u}^{\prime} \tilde{u} \\
\frac{1}{n} \tilde{\bar{u}}^{\prime} \tilde{\bar{u}} \\
\frac{1}{n} \tilde{u}^{\prime} \tilde{\bar{u}}
\end{array}\right]
$$


where the vector $\nu\left(\rho, \sigma^{2}\right)$ can be defined as a vector of residuals. We now define the generalized moments estimator for $\theta^{0}=\left(\rho, \rho^{2}, \sigma^{2}\right)$ ' as the OLS estimator:

$$
{\widetilde{\theta_{n}}}^{0}=\left(\tilde{\rho}_{O L S, n}, \tilde{\tilde{\rho}}_{O L S, n}^{2}, \tilde{\sigma}_{O L S, n}^{2}\right)^{\prime}
$$

in correspondence with 2.21. Since $G_{n}$ is square, then:

$$
{\widetilde{\theta_{n}}}^{0}=G_{n}^{-1} g_{n}
$$

After estimating $\rho$, the new dependent and explanatory matrices are defined by letting $y^{*}(\tilde{\rho})=y-\tilde{\rho} W y$ and $X^{*}(\tilde{\rho})=X-\tilde{\rho} W X$. Finally, with the help of this Cochrane-Orcutt type transformed model, we estimate the model again:

$$
y^{*}(\tilde{\rho})=X^{*}(\tilde{\rho})+\epsilon
$$

\section{Application to translog cost function and factor demand equation}

Kelejian and Prucha (1999)'s approach allows us to use the estimated spatial autoregressive parameter $(\rho)$ for a spatial Cochrane-Orcutt transformation on each of the original equations in the equation system that has been corrected for spatial autocorrolation (recognising their different spatial lag lengths). Subsequently, this transformed system of equations has been estimated using SUR (Cohen and Paul, 2007). The estimated spatial autoregressive parameter is 0.35 for the pumping equation and 0.36 for translog cost function. All of this analysis has been done in $\mathrm{R}$ statistical software using the systemfit package (Henningsen and Hamann, 2007) for the estimation of the simultaneous system.

\subsection{Results}

Figure 2.16 shows the boxplot of relative cost share of five groups of variable costs. Labor accounts for the largest share, as pistachio production is a labor-intensive operation. As the graph shows, water costs (mainly pumping costs) are not large compared to labor, fertiliser, manure and sand costs. Water pumping costs constitute a small part of total 


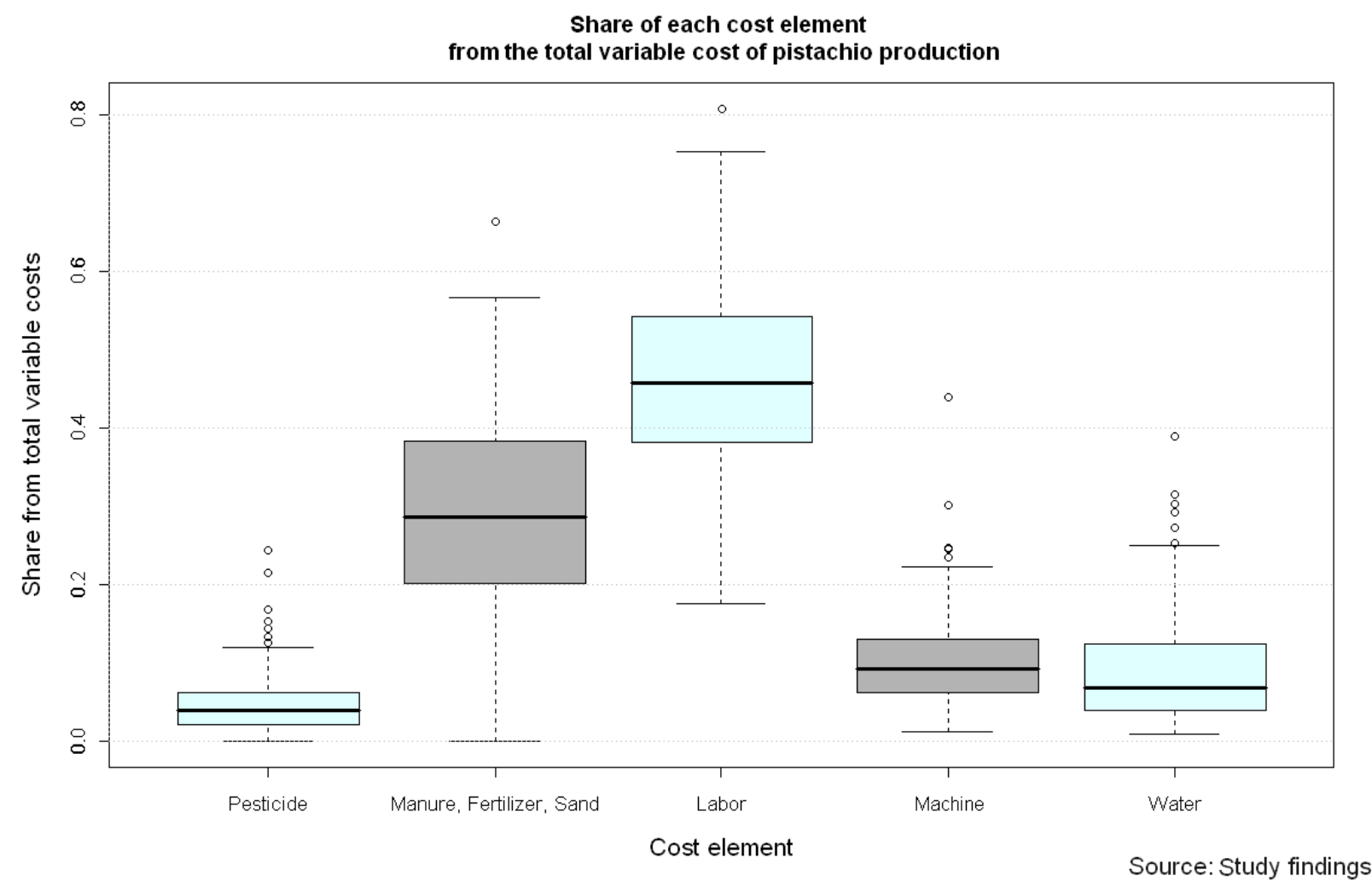

Figure 2.16.: Boxplot of the share of variable costs

variable costs because energy for pumping was partially subsidised during the study period (see section 2.3.4). As a result, figure 2.17 shows that energy costs for the two agricultural periods of 2006-2007 and 2007-2008 account for only a relatively small share of pumping costs.

Model selection criteria were used to select factors affecting the system of equations. The significance and effects of quasi-fixed factors were controlled and checked using a likelihood ratio test, the adjusted $R^{2}$ of the five equations, and the effect that they had on the curvature condition of the translog cost function, as explained by Diewert and Wales (1987). These checks were repeated for the SUR models as well as the spatially corrected SUR models. As explained in methodology (see 2.4), all variables which reflect the quantitative in situ value of the resource were insignificant to the model and did not improve it: Depth of water, depth of wells and depth of the pumps inside the wells were insignificant. This is explained in the discussion part. Figure (2.18) shows the difference between the depth of water levels and the depth of the wells.

Variables such as age of trees, number of male trees per farm and number of fragmented 
Share of each energy costs and other costs

from total variable pumping costs per cubic meter during 2006-2008

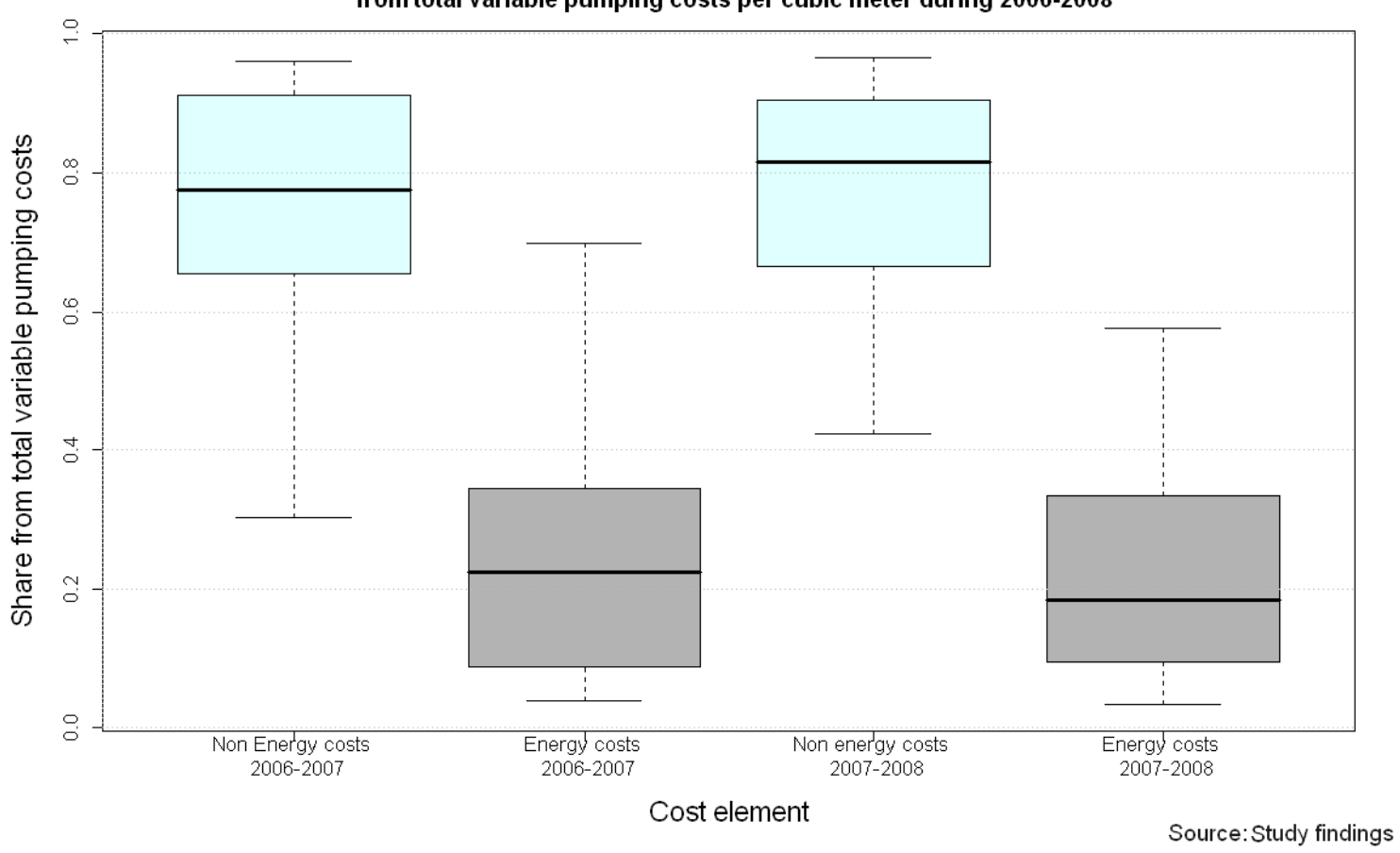

Figure 2.17.: Boxplot of the energy share of the variable pumping costs

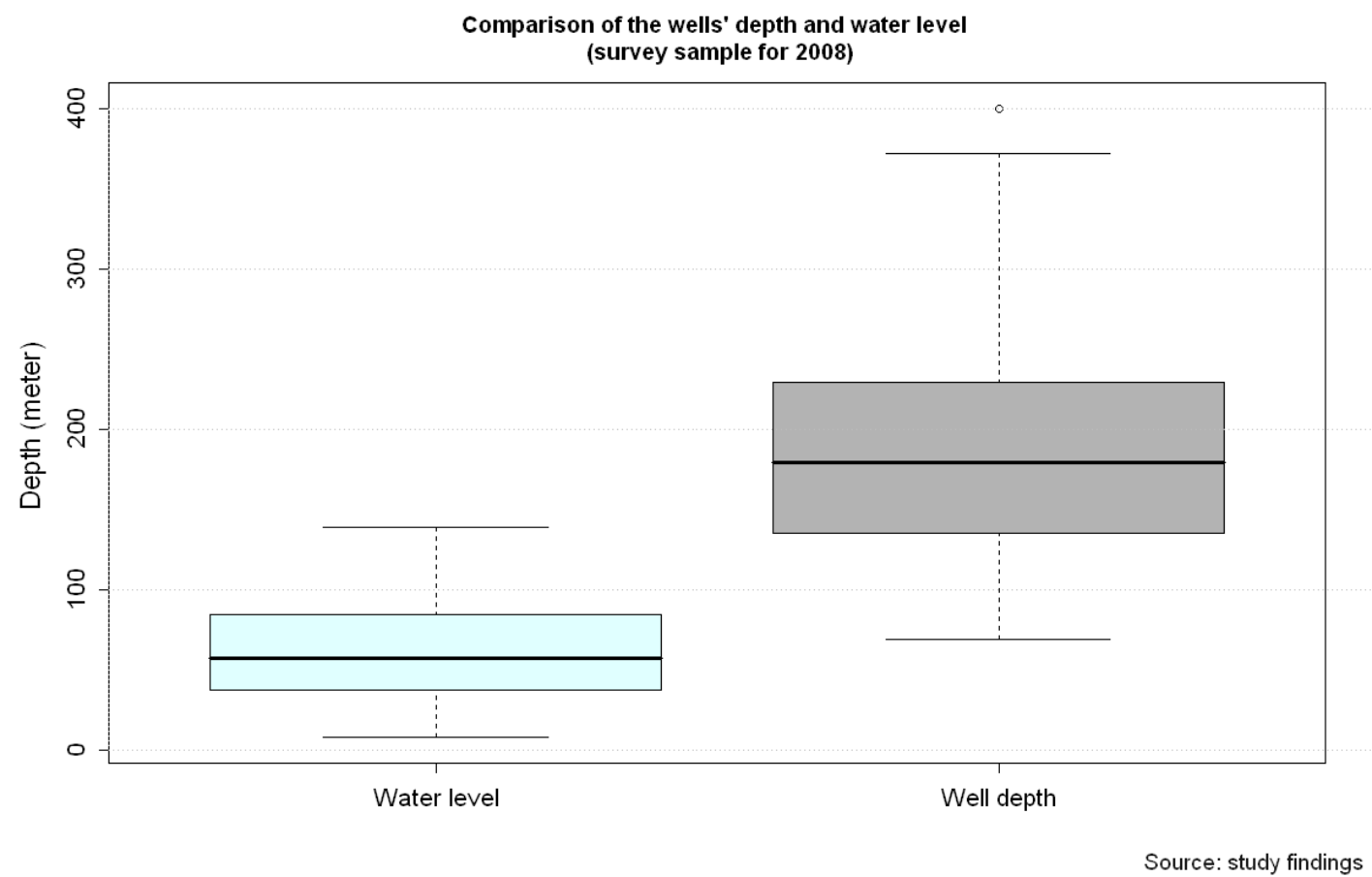

Figure 2.18.: The difference between the depth of water levels and the depth of the wells 
land parcels did not significantly improve the model. Among the water quality variables, most (e.g., pH) did not improve the model. The only significant variable for water quality was EC. The index for the capital stock embedded in the pistachio orchards did not improve the model. This may be explained by the fact that the capital stock of older orchards is altered mainly by depreciation and discounting rather than by investment. Separating investments, e.g. low level replanting, from variable costs was difficult and was also hard to value. Therefore, the total capital index is insignificant in the model. Only the capital index of wells is significant. This variable is considered in the model as a quasi-fixed factor. Finally $14 \%$ is selected as discount rate as this rate is near to inflation rate and banks interest rates.

Many additional dummy variables were checked in the model, although only one was found to be significant: The Manure-Sand dummy $\left(D_{1}\right)$, which distinguishes farmers who used manure and sand on their farms during winter 2007-2008. Other dummy variables such as: Privately owned-Grouped owned pump, availability of water market, participation in water market, the Dry-Fresh dummy which reflects whether the crop was processed before sale, dummy for younger-older pistachio orchards, and regional dummies did not improve the model.

Table 2.6 shows the results of the translog cost function. Two different models are presented in the table 2.6:

1. The SUR-estimated translog cost function with four quasi-fixed factors (this will be called SUR)

2. The spatial correction of the above model (this will be called SAR)

In this table, $w_{i}, \mathrm{i}=1,2,3,4$ refers to normalised prices of fertiliser-manure-sand (FMS) price index, water, pesticides and machines respectively which are normalized by labor prices. $y$ is the production and $z_{i}, \mathrm{i}=1,2,3,4$ refers to quasi-fixed factors of water quota, tree density, wells capital index and EC respectively.

As explained above, homogeneity is imposed on the model by normalising the prices. The curvature of the model is tested using Diewert and Wales (1987, p.47)'s approach. The eigen values of the hessian matrix of the coefficients was semi definite negative on 
Table 2.6.: Parameter estimates of translog cost function in SUR and SAR

\begin{tabular}{|c|c|c|c|c|c|c|c|c|c|}
\hline & \multicolumn{2}{|c|}{ SUR } & \multicolumn{2}{|c|}{ SAR } & & \multicolumn{2}{|c|}{ SUR } & \multicolumn{2}{|c|}{ SAR } \\
\hline Variables & Coef & T-values & Coef & T-values & Variables & Coef & T-values & Coef & T-values \\
\hline (Intercept) & -3.332 & -0.322 & 0.27 & 0.04 & $w_{2} w_{4}$ & -0.021 & -4.718 & -0.02 & -4.758 \\
\hline$y$ & -0.007 & -0.007 & -0.36 & -2.267 & $w_{2} z_{1}$ & 0.039 & 5.453 & 0.039 & 4.41 \\
\hline$w_{1}$ & 0.27 & 1.26 & 0.351 & 1.668 & $w_{2} z_{2}$ & -0.012 & -2.244 & -0.016 & -2.518 \\
\hline$w_{2}$ & 0.508 & 5.472 & 0.299 & 3.661 & $w_{2} z_{3}$ & -0.007 & -1.516 & -0.006 & -0.868 \\
\hline$w_{3}$ & 0.042 & 0.623 & 0.04 & 0.607 & $w_{2} z_{4}$ & -0.015 & -1.884 & -0.006 & -0.578 \\
\hline$w_{4}$ & -0.093 & -0.946 & -0.079 & -0.807 & $w_{3}^{2}$ & 0.013 & 3.029 & 0.013 & 3.026 \\
\hline$z_{1}$ & -0.965 & -0.644 & 0.036 & 0.027 & $w_{3} w_{4}$ & 0.004 & 0.772 & 0.003 & 0.72 \\
\hline$z_{2}$ & 1.743 & 1.661 & 1.171 & 1.089 & $w_{3} z_{1}$ & -0.005 & -0.963 & -0.005 & -0.927 \\
\hline$z_{3}$ & 0.876 & 0.786 & 0.528 & 0.503 & $w_{3} z_{2}$ & 0.008 & 1.879 & 0.008 & 1.875 \\
\hline$z_{4}$ & -0.42 & -0.27 & -0.73 & -0.416 & $w_{3} z_{3}$ & 0 & 0.054 & 0 & 0.045 \\
\hline$y^{2}$ & 0.065 & 2.846 & 0.047 & 2.327 & $w_{3} z_{4}$ & 0.001 & 0.092 & 0.001 & 0.155 \\
\hline$w_{1} y$ & 0.004 & 0.495 & 0.004 & 0.437 & $w_{4}^{2}$ & 0.037 & 3.948 & 0.035 & 3.755 \\
\hline$w_{2} y$ & -0.011 & -3.419 & -0.01 & -2.986 & $w_{4} z_{1}$ & -0.009 & -1.159 & -0.009 & -1.128 \\
\hline$w_{3} y$ & 0.001 & 0.468 & 0.001 & 0.488 & $w_{4} z_{2}$ & 0 & -0.048 & 0 & -0.017 \\
\hline$w_{4} y$ & -0.001 & -0.181 & -0.001 & -0.17 & $w_{4} z_{3}$ & 0.006 & 1.11 & 0.006 & 1.083 \\
\hline$z_{1} y$ & -0.094 & -1.226 & -0.145 & -1.494 & $w_{4} z_{4}$ & 0.019 & 2.185 & 0.018 & 2.168 \\
\hline$z_{2} y$ & 0.049 & 0.995 & 0.066 & 1.086 & $z_{1}^{2}$ & 0.072 & 0.435 & 0.106 & 1.09 \\
\hline$z_{3} y$ & 0.036 & 0.659 & 0.09 & 1.523 & $z_{1} z_{2}$ & 0.024 & 0.25 & -0.013 & -0.487 \\
\hline$z_{4} y$ & -0.035 & -0.379 & -0.034 & -0.474 & $z_{1} z_{3}$ & 0.012 & 0.187 & 0.025 & 0.543 \\
\hline$w_{1}^{2}$ & -0.002 & -0.203 & -0.004 & -0.355 & $z_{1} z_{4}$ & 0.118 & 0.84 & 0 & 0.003 \\
\hline$w_{1} w_{2}$ & -0.014 & -4.847 & -0.014 & -4.893 & $z_{2}^{2}$ & -0.066 & -0.682 & -0.037 & -0.611 \\
\hline$w_{1} w_{3}$ & 0.007 & 2.319 & 0.007 & 2.325 & $z_{2} z_{3}$ & -0.091 & -1.806 & -0.091 & -1.719 \\
\hline$w_{1} w_{4}$ & 0.013 & 2.858 & 0.015 & 3.289 & $z_{2} z_{4}$ & -0.016 & -0.153 & 0.052 & 0.509 \\
\hline$w_{1} z_{1}$ & -0.011 & -0.62 & -0.009 & -0.561 & $z_{3}^{2}$ & 0.047 & 0.808 & 0.004 & 0.075 \\
\hline$w_{1} z_{2}$ & 0.013 & 0.916 & 0.015 & 1.105 & $z_{3} z_{4}$ & -0.155 & -1.61 & -0.096 & -1.135 \\
\hline$w_{1} z_{3}$ & -0.015 & -1.332 & -0.019 & -1.67 & $z_{4}^{2}$ & 0.288 & 1.864 & 0.251 & 1.3 \\
\hline$w_{1} z_{4}$ & 0.019 & 0.964 & 0.013 & 0.665 & $D_{1}$ & 0.258 & 3.022 & 0.257 & 3.089 \\
\hline$w_{2}^{2}$ & 0.075 & 17.307 & 0.081 & 12.755 & & & & & \\
\hline$w_{2} w_{3}$ & -0.004 & -1.315 & -0.003 & -1.227 & & & & & \\
\hline $\begin{array}{l}\mathrm{R}- \\
\text { Squared }\end{array}$ & \multicolumn{2}{|c|}{0.85} & \multicolumn{2}{|c|}{0.86} & LogLike & \multicolumn{2}{|c|}{878.91} & \multicolumn{2}{|c|}{883.62} \\
\hline $\begin{array}{l}\text { Adjusted } \\
\text { R- } \\
\text { Squared }\end{array}$ & \multicolumn{2}{|c|}{0.77} & \multicolumn{2}{|c|}{0.78} & $\begin{array}{l}\text { df (for } \\
\text { likelihood } \\
\text { ratio } \\
\text { test) }\end{array}$ & \multicolumn{2}{|c|}{71} & \multicolumn{2}{|c|}{71} \\
\hline Observations & \multicolumn{2}{|c|}{157} & \multicolumn{2}{|c|}{157} & \multirow{2}{*}{\multicolumn{5}{|c|}{ Source: Study findings }} \\
\hline \begin{tabular}{l|l}
$\mathrm{df}$ &
\end{tabular} & \multicolumn{2}{|c|}{101} & \multicolumn{2}{|c|}{101} & & & & & \\
\hline
\end{tabular}



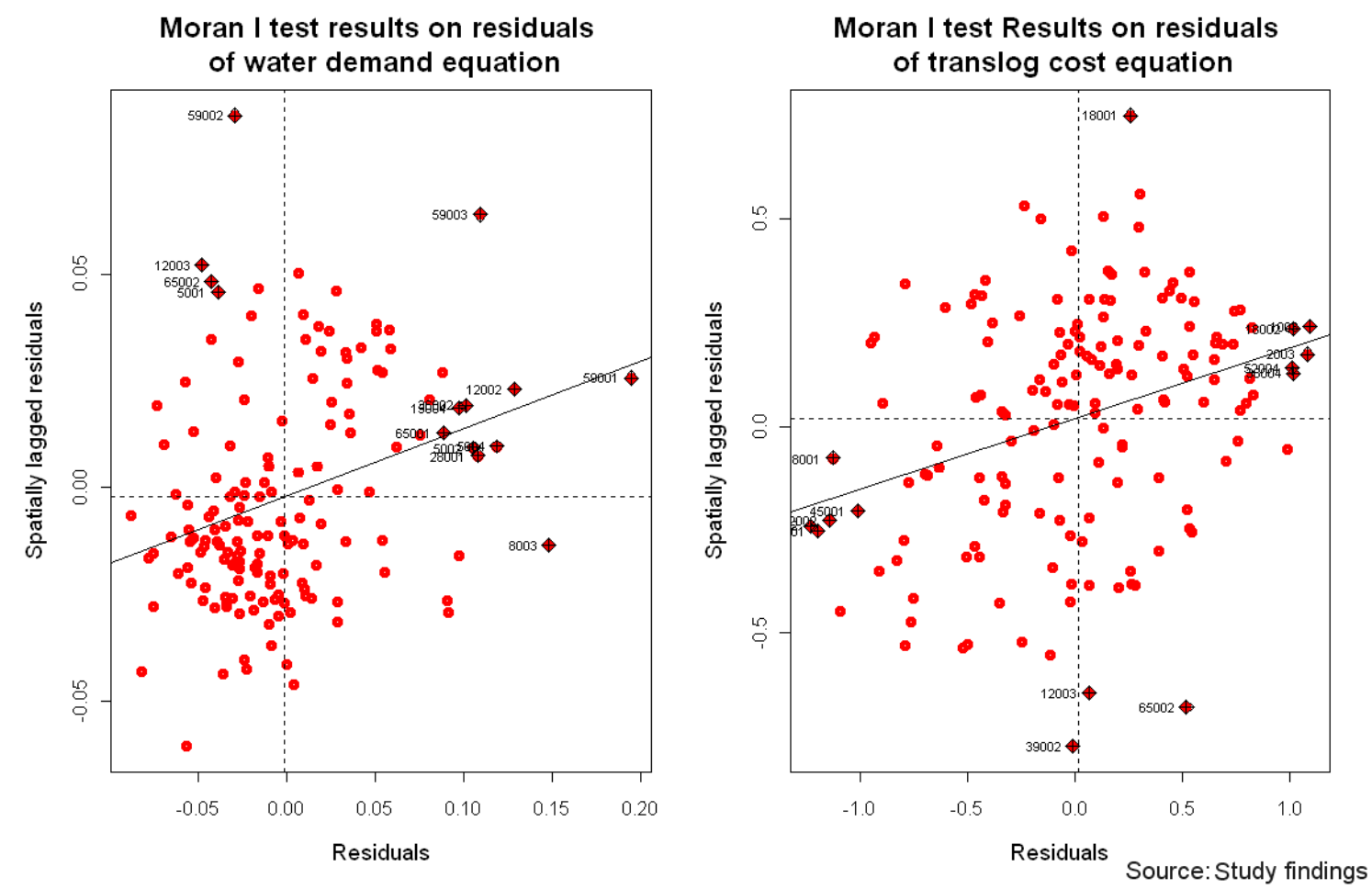

Figure 2.19.: Moran's I test results on the residuals of the water equation and translog cost function

$n-1$ coefficients, which is the condition of concavity in the translog cost function. As mentioned before (see 2.4), the Kelejian and Robinson (1992) test shows that the water demand equation and translog cost functions are spatially autocorrelated. Figure 2.19 shows the Moran's I test results on the residuals of the water equation and the translog cost equation. Different conditions are tested for the system of equations, but spatial effects are not recognised by other equations. Therefore, we used only the GM approach, followed by the Cochrane-Orcutt type transformation of the water equation and translog cost functions, as explained in the empirical model (see 2.4). The spatial correction model can not be rejected vs. SUR translog cost function by likelihood ratio test. The differences between the loglikelihoods of the two models were large enough to accept the spatially corrected simultaneous equations system as a statistically considerable model. If the loglikelihood was not significant, there were no reason to think the results of two models are different. The shadow prices and the elastisities are also different. Therefore, for any econometric empirical work on groundwater shadow pricing, neglecting the spatial aspects of water demand can cause biases in the results.

Table $2.7,2.8,2.9$ and 2.10 shows the results of the fetilizer-manure-sand, water, 
Table 2.7.: SUR and SAR estimation of Shephard's lemma equation for sand-manurefertlizer

\begin{tabular}{|c|c|c|c|c|}
\hline \multirow[b]{2}{*}{ Variables } & \multicolumn{2}{|c|}{ SUR } & \multicolumn{2}{|c|}{ SAR } \\
\hline & Coef & T-value & Coef & T-value \\
\hline (Intercept) & 0.27 & 1.26 & 0.351 & 1.668 \\
\hline$w_{1}$ & -0.002 & -0.203 & -0.004 & -0.355 \\
\hline$w_{2}$ & -0.014 & -4.847 & -0.014 & -4.893 \\
\hline$w_{3}$ & 0.007 & 2.319 & 0.007 & 2.325 \\
\hline$w_{4}$ & 0.013 & 2.858 & 0.015 & 3.289 \\
\hline$z_{1}$ & -0.011 & -0.62 & -0.009 & -0.561 \\
\hline$z_{2}$ & 0.013 & 0.916 & 0.015 & 1.105 \\
\hline$z_{3}$ & -0.015 & -1.332 & -0.019 & -1.67 \\
\hline$z_{4}$ & 0.019 & 0.964 & 0.013 & 0.665 \\
\hline$y$ & 0.004 & 0.495 & 0.004 & 0.437 \\
\hline \multicolumn{2}{|c|}{ Degrees of freedom } & 147 & & 147 \\
\hline \multicolumn{2}{|c|}{ Multiple R-squared } & 0.035 & & 0.037 \\
\hline \multicolumn{2}{|c|}{ Adjusted R-squared } & -0.02 & & -0.02 \\
\hline
\end{tabular}

Source: Own calculation

Table 2.8.: SUR and SAR estimation of Shephard's lemma equation for water

\begin{tabular}{|c|c|c|c|c|}
\hline \multirow[b]{2}{*}{ Variables } & \multicolumn{2}{|c|}{ SUR } & \multicolumn{2}{|c|}{ SAR } \\
\hline & Coef & T-value & Coef & T-value \\
\hline (Intercept) & 0.508 & 5.472 & 0.299 & 3.661 \\
\hline$w_{1}$ & -0.014 & -4.847 & -0.014 & -4.893 \\
\hline$w_{2}$ & 0.075 & 17.307 & 0.081 & 12.755 \\
\hline$w_{3}$ & -0.004 & -1.315 & -0.003 & -1.227 \\
\hline$w_{4}$ & -0.021 & -4.718 & -0.02 & -4.758 \\
\hline$z_{1}$ & 0.039 & 5.453 & 0.039 & 4.41 \\
\hline$z_{2}$ & -0.012 & -2.244 & -0.016 & -2.518 \\
\hline$z_{3}$ & -0.007 & -1.516 & -0.006 & -0.868 \\
\hline$z_{4}$ & -0.015 & -1.884 & -0.006 & -0.578 \\
\hline$y$ & -0.011 & -3.419 & -0.01 & -2.986 \\
\hline \multicolumn{2}{|c|}{ Degrees of freedom } & 147 & & 147 \\
\hline \multicolumn{2}{|c|}{ Multiple R-squared } & 0.52 & & 0.44 \\
\hline \multicolumn{2}{|c|}{ Adjusted R-squared } & 0.49 & & 0.41 \\
\hline
\end{tabular}

Source: Own calculation 
Table 2.9.: SUR and SAR estimation of Shephard's lemma equation for pesticide demand

\begin{tabular}{|c|c|c|c|c|}
\hline \multirow[b]{2}{*}{ Variables } & \multicolumn{2}{|c|}{ SUR } & \multicolumn{2}{|c|}{ SAR } \\
\hline & Coef & T-value & Coef & T-value \\
\hline (Intercept) & 0.042 & 0.623 & 0.04 & 0.607 \\
\hline$w_{1}$ & 0.007 & 2.319 & 0.007 & 2.325 \\
\hline$w_{2}$ & -0.004 & -1.315 & -0.003 & -1.227 \\
\hline$w_{3}$ & 0.013 & 3.029 & 0.013 & 3.026 \\
\hline$w_{4}$ & 0.004 & 0.772 & 0.003 & 0.72 \\
\hline$z_{1}$ & -0.005 & -0.963 & -0.005 & -0.927 \\
\hline$z_{2}$ & 0.008 & 1.879 & 0.008 & 1.875 \\
\hline$z_{3}$ & 0 & 0.054 & 0 & 0.045 \\
\hline$z_{4}$ & 0.001 & 0.092 & 0.001 & 0.155 \\
\hline$y$ & 0.001 & 0.468 & 0.001 & 0.488 \\
\hline \multicolumn{2}{|c|}{ Degrees of freedom } & 147 & & 147 \\
\hline \multicolumn{2}{|c|}{ Multiple R-squared } & 0.186 & & 0.187 \\
\hline \multicolumn{2}{|c|}{ Adjusted R-squared } & 0.136 & & 0.137 \\
\hline
\end{tabular}

Source: Own calculation

Table 2.10.: SUR and SAR estimation of Shephard's lemma equation for machine demand

\begin{tabular}{|c|c|c|c|c|}
\hline \multirow[b]{2}{*}{ Variables } & \multicolumn{2}{|c|}{ SUR } & \multicolumn{2}{|c|}{ SAR } \\
\hline & Coef & T-value & Coef & T-value \\
\hline (Intercept) & -0.093 & -0.946 & -0.079 & -0.807 \\
\hline$w_{1}$ & 0.013 & 2.858 & 0.015 & 3.289 \\
\hline$w_{2}$ & -0.021 & -4.718 & -0.02 & -4.758 \\
\hline$w_{3}$ & 0.004 & 0.772 & 0.003 & 0.72 \\
\hline$w_{4}$ & 0.037 & 3.948 & 0.035 & 3.755 \\
\hline$z_{1}$ & -0.009 & -1.159 & -0.009 & -1.128 \\
\hline$z_{2}$ & 0 & -0.048 & 0 & -0.017 \\
\hline$z_{3}$ & 0.006 & 1.11 & 0.006 & 1.083 \\
\hline$z_{4}$ & 0.019 & 2.185 & 0.018 & 2.168 \\
\hline$y$ & -0.001 & -0.181 & -0.001 & -0.17 \\
\hline \multicolumn{2}{|c|}{ Degrees of freedom } & 147 & & 147 \\
\hline \multicolumn{2}{|c|}{ Multiple R-squared } & 0.167 & & 0.163 \\
\hline \multicolumn{2}{|c|}{ Adjusted R-squared } & 0.115 & & 0.112 \\
\hline
\end{tabular}

Source: Own calculation 
Table 2.11.: SUR and SAR estimation of demand elasticities on the mean of sample cost shares

\begin{tabular}{|c|c|c|c|c|c|c|}
\hline & & \multicolumn{5}{|c|}{ Price } \\
\hline & Quantity & FMS & Water & Pesticide & Machine & Labor \\
\hline \multirow{5}{*}{ SUR } & $\begin{array}{l}\text { Fertiliser, manure and sand } \\
\text { (FMS) }\end{array}$ & -0.718 & 0.043 & 0.074 & 0.149 & 0.451 \\
\hline & Water & 0.137 & -0.095 & 0.007 & -0.126 & 0.077 \\
\hline & Pesticide & 0.434 & 0.013 & -0.682 & 0.176 & 0.059 \\
\hline & Machine & 0.261 & -0.158 & 0.057 & -0.539 & 0.153 \\
\hline & Labor & 0.488 & 0.289 & 0.247 & 0.302 & -0.338 \\
\hline \multirow{6}{*}{ SAR } & & & & & & \\
\hline & $\begin{array}{l}\text { Fertiliser. manure and sand } \\
\text { (FMS) }\end{array}$ & -0.724 & 0.044 & 0.074 & 0.155 & 0.449 \\
\hline & Water & 0.141 & -0.025 & 0.013 & -0.115 & -0.013 \\
\hline & Pesticide & 0.435 & 0.024 & -0.683 & 0.171 & 0.054 \\
\hline & Machine & 0.279 & -0.149 & 0.055 & -0.56 & 0.148 \\
\hline & Labor & 0.509 & 0.31 & 0.268 & 0.323 & -0.317 \\
\hline
\end{tabular}

Source: Own calculation

pesticide and machine demand equations respectively. The weakest explanatory power can be seen by FMS equation. It seems that the prices and quasi-fixed factors do not explain the demand well in this equation. Moreover, this low explanatory power remains stable for this specific equation and it is robust against the specific model selection; alternative model specifications did not improve the explanatory power. The other equations exhibit higher explanatory power, in particular in the water demand equation. Most of the factors in the water equation are significant. Although the water quality variable is not significant in the water equation, this variable should be retained in the full mode because of its improvement of the the overall model. It seems that in this specific area, water quality is more important than water level as EC can affect the whole model. The SAR model does not improve the Shephard's lemma equations a lot.

Table 2.11 shows the short-run Hicksian price elasticity of variable inputs. All elasticities are calculated by substituting the estimated coefficients and the average values of the actual cost shares into the equation 2.19. The sign of the own prices for all variable inputs are negative. The results of the water pumping cost show that water demand in regard to water price (consisted mainly of pumping costs) is inelastic, as it is for all other inputs in general. This happens often with own price elasticities derived from a translog cost function. 
Table 2.12.: SUR and SAR estimation of shadow prices for the average of sample

\begin{tabular}{|l|c|c|c|c|}
\hline \multirow{2}{*}{} & \multicolumn{2}{|c|}{ SUR } & \multicolumn{2}{c|}{ SAR } \\
\cline { 2 - 5 } & mean & SD & mean & SD \\
\hline Shadow price of water quota ( rials $\left./ \mathrm{m}^{3}\right)$ & -1195 & 865 & -437 & 840 \\
Shadow price of trees ( rials / tree) & -5149 & 7511 & -5114 & 7520 \\
Shadow price for increase in well capital & -0.39 & 0.51 & -0.4 & 0.56 \\
index (rials ) & & & & \\
$\frac{\partial C R}{\partial E C}\left(\right.$ rials $\left./ \mathrm{m}^{3} /(\mu S / \mathrm{cm})\right)$ & -5297 & 28190 & -14477 & 45102 \\
\hline
\end{tabular}

Source: Own calculation

The cross price elasticites for water demand show by and large inelastic conditions. An unexpected result is the effect of a $1 \%$ machine price increase on water demand which is estimated at 0.12 percent. It shows that if the pistachio production can be more mechanised, there is some potential to affcect water demand. Most of the other cross price elasticities are mostly in line with the a priori expectations. Machinery and labor are found to be substitutes as illustrated by the positive signs of the cross-price elasticities in table 2.11. As pistachio production is labor intensive, the machine price effect on labor demand is higher than the opposite case. The SAR correction of the model decreases the elasticities of water price dramatically. It is a supporting result for applying spatial econometric for analysis of groundwater demand. It shows that the farmers water use follow a same pattern in the neighbourhoods and water price change of neighbouring farms and wells are similar. Therefore, considering individual farm and pump water costs without an overview on their interaction with neighbours can produce bias parameters in demand analysis. Both tables together present the inelastic condition of demand for groundwater with respect to water price (mainly pumping costs). A small scale energy increase price policy, regardless whether it could be successfully implemented, would not affect the pumping behaviour of the farmers at all. A surprising finding is the relatively high effect of the increase in other factors' prices on the demand for labor. For instance, 50 percent increase in labor demand as a results of 100 percent increase in fertilizer-manurepesticide prices is relatively high.

Table 2.12 shows shadow prices for quasi-fixed factors. In this table the $\left(\frac{\partial C R}{\partial E C}\right)$ reflects the stock quality change effects on restricted cost function. Table 2.13 shows the shadow prices of quasi-fixed factors for two groups of observations with positive and negative 
Table 2.13.: SUR and SAR estimation of shadow prices for the average of positive and negative groups

\begin{tabular}{|c|c|c|c|c|c|c|}
\hline & & & $\begin{array}{c}\text { Shadow } \\
\text { price of } \\
\text { water } \\
\text { quota ( } \\
\left.\text { rials / } m^{3}\right)\end{array}$ & $\begin{array}{c}\text { Shadow } \\
\text { price of } \\
\text { trees ( rials } \\
\text { / tree) }\end{array}$ & $\begin{array}{c}\text { Shadow } \\
\text { price for } \\
\text { increase in } \\
\text { well capital } \\
\text { index (rials } \\
\text { ) }\end{array}$ & $\begin{array}{c}\frac{\partial C R}{\partial E C}(\text { rials } / \\
\left.m^{3} /(\mu S / \mathrm{cm})\right)\end{array}$ \\
\hline \multirow{2}{*}{ SUR } & Positive & $\begin{array}{l}\text { Observations } \\
\text { Mean } \\
\text { sd }\end{array}$ & $\begin{array}{c}2 \\
663 \\
65\end{array}$ & $\begin{array}{c}36 \\
2404 \\
2768\end{array}$ & $\begin{array}{c}10 \\
0.37 \\
0.54\end{array}$ & $\begin{array}{c}97 \\
3332 \\
4625 \\
\end{array}$ \\
\hline & Negative & $\begin{array}{l}\text { Observations } \\
\text { Mean } \\
\text { sd }\end{array}$ & $\begin{array}{c}155 \\
-1219 \\
845\end{array}$ & $\begin{array}{c}121 \\
-7397 \\
6992\end{array}$ & $\begin{array}{c}147 \\
-0.44 \\
0.47\end{array}$ & $\begin{array}{c}60 \\
-19247 \\
41786\end{array}$ \\
\hline \multirow{2}{*}{ SAR } & Positive & $\begin{array}{l}\text { Observations } \\
\text { Mean } \\
\text { sd }\end{array}$ & $\begin{array}{c}33 \\
308 \\
318 \\
\end{array}$ & $\begin{array}{c}27 \\
3524 \\
4778 \\
\end{array}$ & $\begin{array}{c}9 \\
0.66 \\
0.70\end{array}$ & $\begin{array}{c}38 \\
781 \\
984 \\
\end{array}$ \\
\hline & Negative & $\begin{array}{l}\text { Observations } \\
\text { Mean } \\
\text { sd }\end{array}$ & $\begin{array}{r}124 \\
-635 \\
825\end{array}$ & $\begin{array}{c}130 \\
-6912 \\
6697\end{array}$ & $\begin{array}{c}148 \\
-0.47 \\
0.49\end{array}$ & $\begin{array}{c}119 \\
-7294 \\
50892\end{array}$ \\
\hline
\end{tabular}

values for shadow price.

Contrary to expectations, the model did not reveal, on average, a positive shadow price for the extra water quota. Figure 2.20 shows the relation between shadow price for extra water in farm to the water quota per hectare in SUR and SAR estimation. Figure 2.20 shows that only the few farmers who have lower per hectare water quotas had WTP, which is explained in the discussion. In SAR model, we can see that this extra WTP is more among the farmers with lower defined water quota per hectare.

Figure 2.21 shows the relation between the shadow price for extra tree in farm and tree density per hectare. The results show that on average there are no positive shadow prices for new trees. Dividing the sample into two parts shows that farms with lower tree densities may have only limited WTP for an increase the density of trees.

Figure 2.22 plots the relation between the available capital stock embedded in the well and the estimated shadow price for an additional unit investment in well repositioning. Repositioning and reinstalling investment costs have only negative shadow values as their roles are limited to maintaining access to water quotas. The results for the water quality variable were also unexpected. On average, there is a small negative shadow price for each 


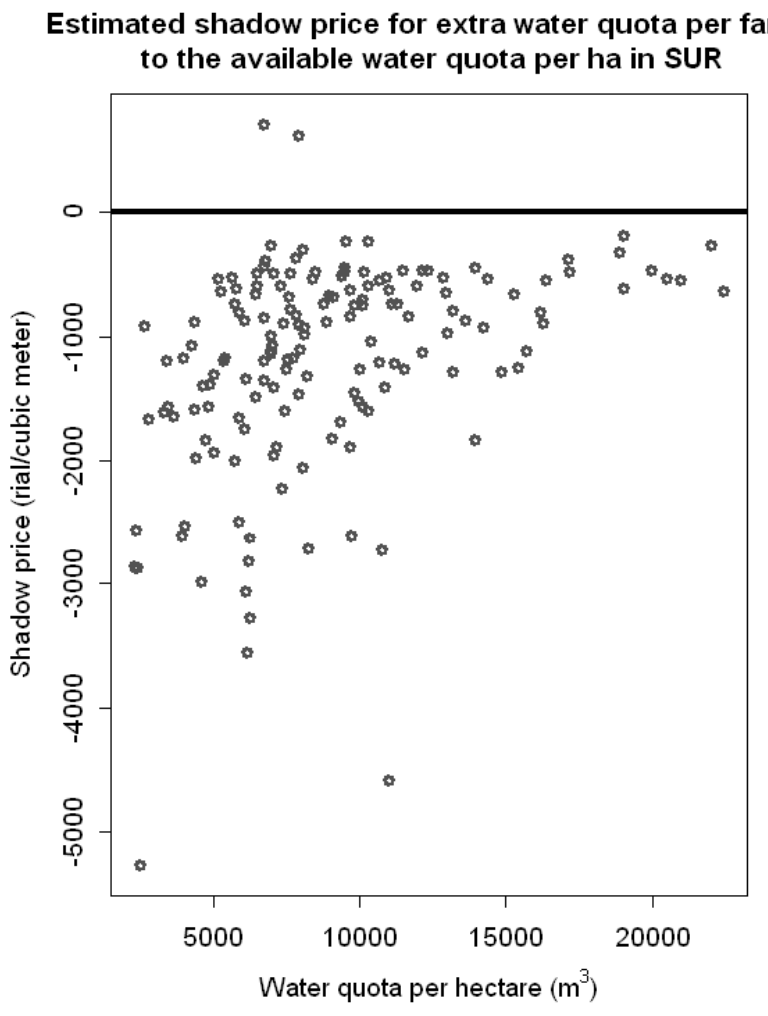

Estimated shadow price for extra water quota per farm

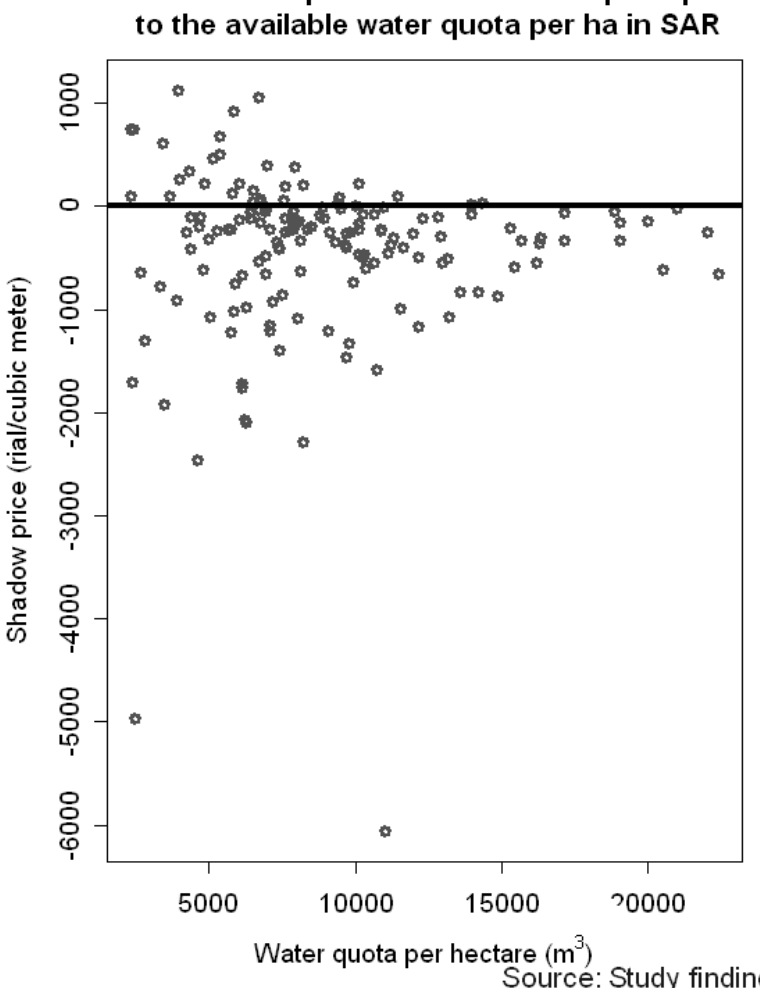

Figure 2.20.: The relation between shadow price for extra water in farm to the water quota per hectare in SUR and SAR
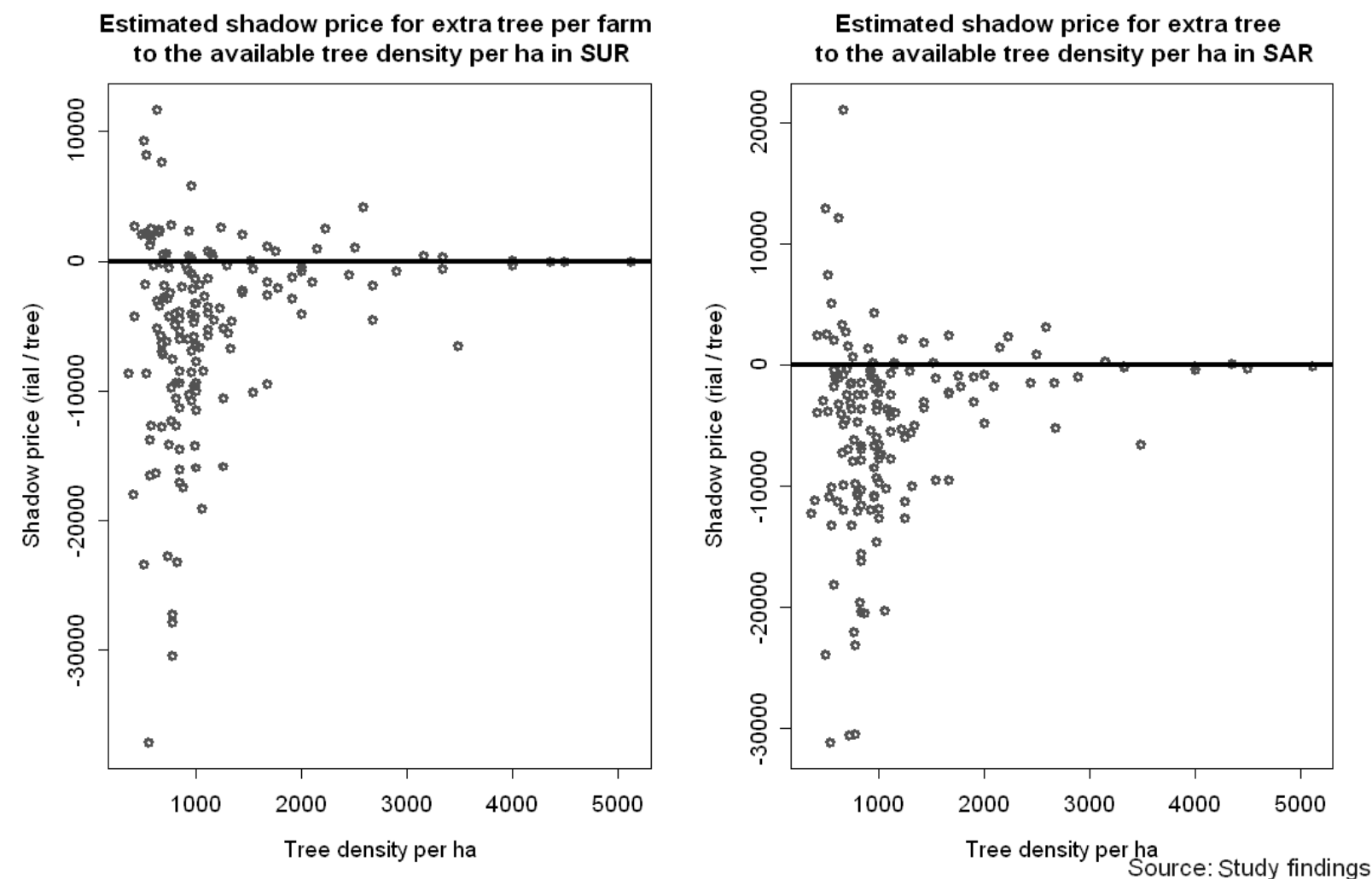

Figure 2.21.: The relation between the shadow price for extra tree in farm and tree density per hectare 

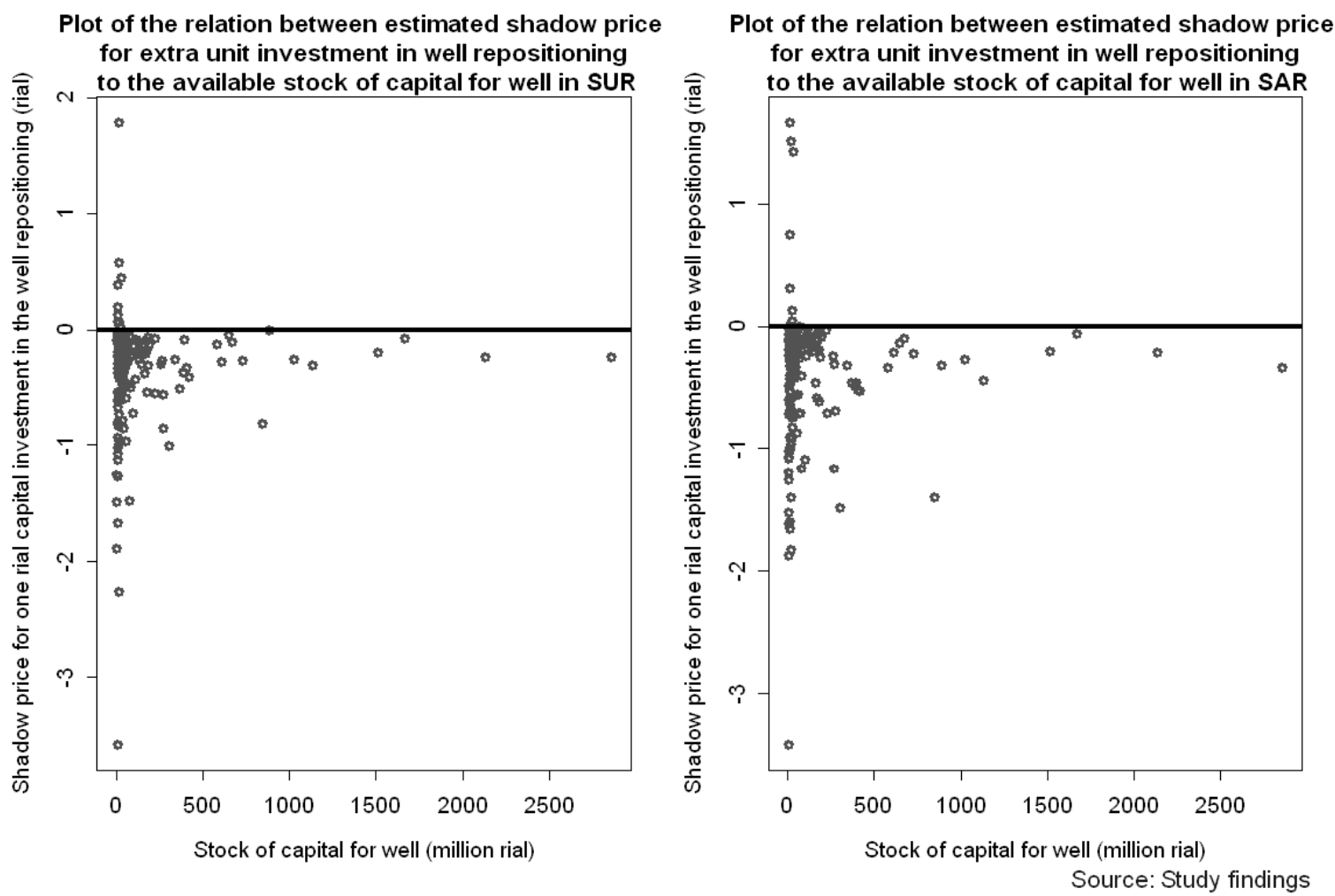

Figure 2.22:: The plot of the relation between the available stock of capital for well and estimated shadow price for extra unit investment in well repositioning in SUR and SAR

unit decrease in EC. Within the sample, 2 clear groups of farms can be observed; the first have lower EC and negative prices, whilst the second have higher EC and positive shadow prices. Figure 2.23 shows the relation between EC level, and stock quality change effects on restricted cost function (shadow price for water quality). As explained before, pistachio is a relatively resistant crop to salinity (up to a level of $8000 \mu \mathrm{S} / \mathrm{cm}$ (Iran Pistachio Association, 2011)). Therefore, separating the sample in figure 2.23 into observations above and below this threshold, we find a positive level of the stock quality change effect in SUR model for high salinity values. However, this positive value almost completely vanishes in the spatial autocorrelation model. Figure 2.24 shows the relation between EC >6000 level, and shadow price for water quality (EC). In order to show the changing behaviour of the observations on the border of $8000 \mu \mathrm{S} / \mathrm{cm}$, the figure 2.24 shows the shadow price of observations with more than $6000 \mu \mathrm{S} / \mathrm{cm}$. The explanation of the results is given in the discussion. 

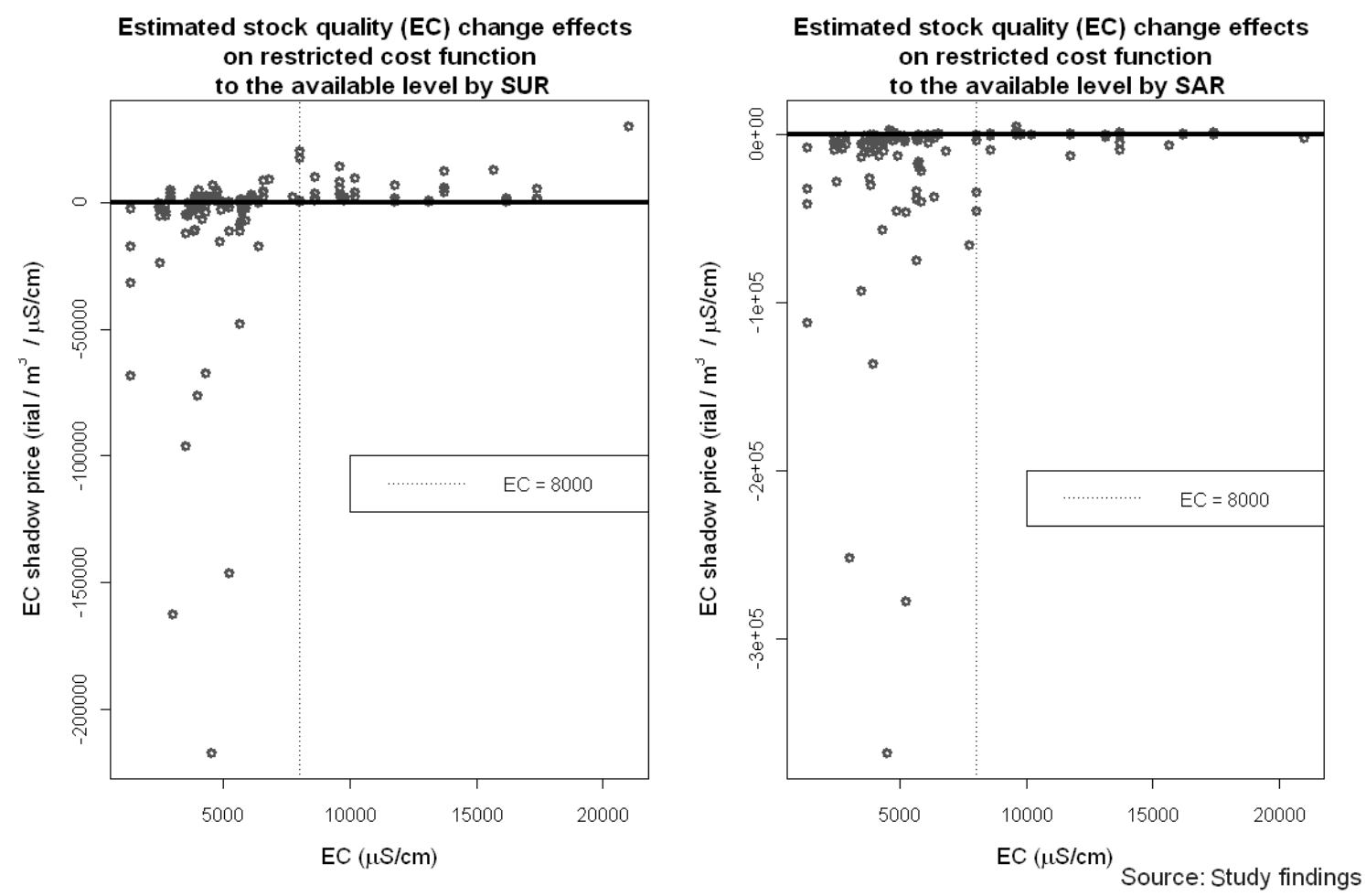

Figure 2.23.: Relation between EC level, and shadow price for EC
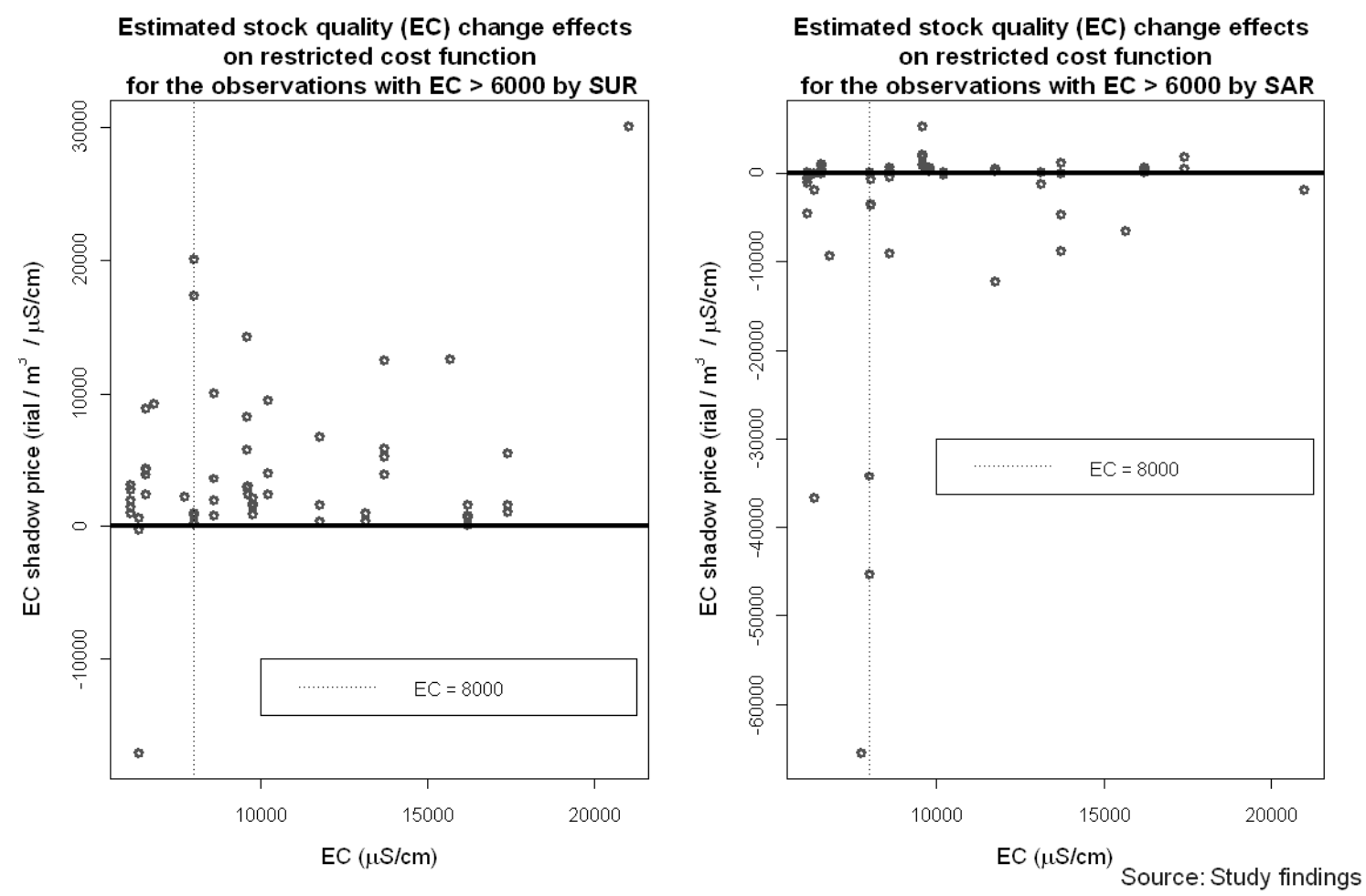

Figure 2.24.: Relation between EC level, and shadow price for EC larger than 6000 


\subsection{Discussion}

The results offer several interesting contrasts with the hypotheses which are commonly found in the literature. Changes in water table (or depth of the wells), as a proxy of the in situ quantity of groundwater, did not play a significant role in the model. Further, a variety of model selection tests has shown that neither water table or well depth affects the translog cost function as quasi-fixed factors. Therefore the GSE can not be challenged in Rafsanjan aquifer and empirical results show that water level changes are almost irrelevant to farmers. This may be due to the difference between well depth and groundwater level (figure 2.18). The small annual changes in the water table do not affect users in the short term. Another possible explanation is that farmers do not have to pay the increasing energy costs implicit in groundwater depletion, as a result of receiving energy subsidies. A myopic approach of farmers towards the in situ value of renewable natural resources (groundwater in this case) is another explanation.

The most unexpected results were the negative shadow prices for water quotas as control variables for the other observations. In order to check the robustness of the results, many models have been tested and compared. Neither of the normal SUR models or spatial autoregressive correction of SUR showed any large positive changes. The fact that 28 farmers from the sample of 157 paid high prices in the spot water market in 2008 makes it impossible to say that WTP is zero for extra unit of water. Clearly two groups, who have different WTP for extra units of water, can be defined. We may point out, however, the imperfectness of restricted cost function in the case of defining the shadow price of groundwater in tree crop production in a mono culture, with infelxible water quotas. As the average age of the trees in the sample is 26 , it can be said that pistachio production is adapted to the available water based on institutional permission, stable plantation choices (no multi crop setting), resistance of pistachio to the drought, and an adequate supply of water for most farms sampled (figure 2.7). As a result, many farms actually do not need more water. The main concern for most farmers in the sample was to maintain their access to their available quota. This explains why wells are repositioned in spite of heavy costs. The author has observed and confirmed a phenomenon in a local book that can 
support this idea. In one of the pumping units in the east part of the aquifer (Davaran village), repositioning of the well resulted in a higher pumping rate than the defined quota, which was beyond the average requirement of the gardens. Some farmers planted new gardens despite the danger that the pumping rate could reduce in the future. Indeed after 2-3 years this extra rate was reduced and those farmers were forced to abandon the new gardens. Abtahi (2006) argues that in many areas of Rafsanjan, if repositioning results in increased pumping rates, and as surplus water can damage the gardens, the owners do not turn the pump off. Farmers usually decide to expand their farms by planting new orchards, in order to exclude neighbouring pumps from using the available extractable resources (tragedy of commons).

The negative shadow price which is derived from the cost function supports the argument that for existing gardens which are adapted to their water quotas, there is no demand for extra water resources. It is worth noting that the quantity of traded water, compared with the available water quota, is very low among those 28 farmers. The demand for extra units of water is instantaneous and short term only for few farmers in the sample. If we had found more farmers who were participated in informal water market, probably the results would have been different. It shows that the short run extra need for more volume of water is not considerable.

An interesting result is the shadow price of water quality in the model. Logically we would expect to see a positive values for stock quality change effects on restricted cost function as reductions in water quality and increases in water salinity, should lead to demand for better water quality (see equation 2.13). However, results show that this is not necessarily true, as illustrated by a village in the southeastern part of aquifer. In Kabutar Khan village, farmers were applying salt to their gardens, as the water quality was very good and they believed that some salinity could improve the quality of production. As previously mentioned, EC up to $8000 \mu \mathrm{S} / \mathrm{cm}$ (Iran Pistachio Association, 2011) does not significantly affect pistachio production. $\partial C R / \partial E C$ are positive for producers with very high EC values and negative for lower level of EC in SUR model (figure 2.23). Although such salt distribution is not advised by extension officers, some of the farmers are following their beliefs. Furthermore, the specific approach of considering the water 
quality index (EC) in the cost function can be criticised. Few available studies on economic effects of water quality change on agricultural crops used experimental field research. The little existing research done has been a cooporation between biologists and agricultural economists who simulated different scenarios. Nonetheless, in this study EC, as an index of in situ stock quality, and quasi-fixed factors have been entered into the model. Results show that the shadow price value, as defined as a unit change of EC (for more than 8000 $\mu S / \mathrm{cm}$ ) is negligible and doesn't justify any intervention, as also concluded by theoretical studies (Roseta-Palma, 2002). If this shadow price finds to be considerable, we could recognise a high level of shadow price for in situ quality of the reservoir which may justify intervention and taxing users per unit of groundwater abstraction.

The negative shadow price for a new orchard reflects the fact that many new gardens were very dense and may have needed clearance. This concurs with the local knowledge of farmers regarding the creation of new plantations.

The existence of spatial dependence shows that any collective action which does not cover the whole aquifer and the neighbourhoods probably has little effect on water consumption or water saving practices. In spite of spatial effects among neighbourhoods and pumps, if one part of the aquifer implement water saving methods or periodically turn off the pumps, probably its benefit will not be considerable. It is better that such an operations can be implemented all over the aquifer.

GSE is available on both quantity and quality aspects of the aquifer. This research did not find the same results as Koundouri and Xepapadeas (2004) study based on Halvorsen and Smith (1991) approach. The restricted cost approach which is implemented in this study is not the right way to define shadow prices for different aspects of groundwater. In spite of this shortcoming, this approach is able to consider the influential factors in demand structure in an empirical setting, which is not manageable by numerical dynamic optimisation.

As previously mentioned, the main irrigation technology is the furrow system and adoption of new technologies is uncommon. Only 4 farms out of all 157 observed in this study had adopted any form of modern irrigation. Even the implementation of new irrigation technology does not guarantee that the farmers would not simply use any water saved to 
plant new orchards. If long term sustainable pistachio production is the issue of concern, a policy which encourages temporarily turning off the pumps and lower levels of water pumping may be the solution.

\subsection{Conclusion}

In this research we have analysed the demand structure for groundwater in Rafsanjan aquifer in southeastern Iran. Rafsanjan is one of the main pistachio production centres in Iran. The high value of the pistachio crop has encouraged the intensive use of groundwater for irrigation during last years and the public is worried about the future of the resource and the sustainability of pistachio production. Factors affecting the demand function for irrigation water from depleting groundwater resources have been analysed by restricted cost function. Not only economic factors but also hydrogeological and water quality factors have been considered in this study. Spatial econometrics has been used to improve the model. This approach extends the standard methodological toolbox found in the literature. We find an important role of spatial dependence in the demand analysis of water from depleting aquifers. The study area especific conditions were considered in developing the empirical factor demand model. In this case, repositioning of a well is considered as water provision capital stock and added to the translog cost function. The results show that the demand is inelastic to the changes in water prices, which consist mainly of pumping costs. The GSE is strongly present in the model so that there are only small gains to be expected from optimal control of the aquifer. For groundwater quota allotments, the shadow price for the groundwater in situ value was negligible. As the farms had adapted to their historical water quota from the groundwater reservoir, a positive shadow price could not be found for the increase in the availability of water resources on average of the sample. Based on the results of this research, the heavily subsidised energy costs, the slow uptake of modern irrigation methods and an inelastic water demand price structure makes it impractical to advise an energy price increase as the sole solution for reducing the intensive water use in this area. However, the fact that the government could not follow its primary goal of price reform policy program for 
energy prices of irrigation pumping, either a tax-based approach towards shadow prices or changing the energy prices to controlling the pumping pattern of water users, are not optimal or politically achievable methods for improving the conditions in this aquifer if they are implemented alone.

Encouraging a participatory approach of self governance for aquifer management, expansion of water markets by redefining institutional barriers of water rights in common pool resources, providing incentives for advanced irrigation technologies which use groundwater efficiently, and whilst simultaneously encouraging less pumping might be such alternative means. Future research into such strategies can be done without focusing on shadow pricing or dynamic optimisation of water use patterns as separate issues. Moreover, finding the right method for defining shadow price for the setting like Rafsanjan remains a research question. Future studies can be focused on improving the factor demand model which accounts for the adjustment cost function for investment of the owners in orchards and pumps in a dynamic cost function setting, as well as developing switching factor demand analysis for different groups with different WTP for water in such an aquifer. Defining institutional settings which encourage the participatory governance of the aquifer and expansion of the water market are further possible areas of research. 


\section{Participation of Tree-crop Farmers in Spot Water Markets in Semiarid}

\section{Areas}

\subsection{Introduction}

Meeting the water demand of a growing population at the existing level of per capita water use requires increasing water abstraction. Yet the cost of water supply rises with every new dam built and concerns over adverse environmental and social effects of large water projects are mounting. These considerations limit prospects to increase water diversion and extraction. The remaining solution is to use available water resources more efficiently (Tsur, 2005, p.32). Agriculture is the world's primary user of water and agricultural irrigation not only competes for water resources, but in some cases may also contribute to major water quality degradation (Dinar and Letey, 1991, p.211). Achieving efficient water use requires taking account of the full cost of water, which beyond the engineering cost of water extraction (diversion) and conveyance includes also the opportunity cost associated with the alternative uses of water at present and in the future. One way to achieve this goal may be water pricing in water markets (Tsur, 2005, p.32). Under certain conditions (no externalities, full information, perfect competition, and non-increasing returns to scale) markets will achieve first-best allocations (Johansson, 2000, p.9).

A water market is a set of arrangements that permit water rights (for abstraction and use) to be traded (Theesfeld, 2010, p.135). In a stylised water market, in any year, each irrigator is given a water endowment (or entitlement) and is free to buy or sell shares of 
entitlements from other farmers at an agreed price. Water entitlements may be based on historical or legal rights, or they may be set by an elected or assigned committee (or water agency) (Tsur and Dinar, 1997, p.246). As water is expensive to transport, the development of water markets is generally localised. Due to the localised nature of many water markets the number of users and suppliers is limited. Such situations may lead to non-competitive markets, and preclude first-best allocations (Johansson, 2000, p.10).

There are multiple advantages of property rights arrangements for common pool resources (such as groundwater) including flexibility, cost-savings, information generation, migration to high-value uses and better alignment of incentives for conservation or investment in the resource. More complete property rights lead to a merging of private and social net benefits of resource use, eliminating externalities and losses from the common resource pool. Furthermore, when users own a part of the resource, they benefit from reduction of externalities and thus, have greater incentives to comply, to police one another, and potentially, invest in the stock (Libecap, 2009, p.134)

Water markets are often found to improve irrigation water efficiency (Manjunatha et al., 2009; Deepak et al., 2005) since they provide direct incentives to the individual farmer to improve irrigation technology (Dinar and Letey, 1991, p.222). They typically entail opportunities to increase profitability; at least, in voluntary water markets and with full information, no farmer obtains lower profits in the presence of a water market than without the water market. Gisser (1983, p.1001) argues that under circumstances that generally prevail in semi-arid zones, assigning property rights to groundwater and permitting the market to determine the allocation of water use can lead to second best solution. The first best solution in this view is a free market condition, although this cannot happen in a water market, as participants are limited. Water markets as second best water allocations may surpass volumetric pricing and other pricing methods in efficiency even when distorted (Johansson et al., 2002, p.186).

Water markets exist in different forms throughout the world. They may be formal or informal, organised or spontaneous. Their participants may trade water rights (e.g. the right to purchase a quantity of water at a particular price during specific periods of time), or they may trade water at the spot price or for future delivery (Tsur and Dinar, 
1997, p.246). In some countries, markets for water or water rights have been formed and determine water prices (usually measured on a volumetric or water flow basis). They range from sanctioned markets for water rights, such as in Chile, to spontaneous spot markets such as in Brazil (Tsur, 2005, p.39). Trading water in annual spot markets can reduce farmers' economic vulnerability caused by water supply variability across irrigation seasons (Calatrava and Garrido, 2005). Informal trade of water consists of farmers selling surplus ground or surface water for a period of time (crop season) to a neighbouring farm or town (Johansson, 2000, p.6). The creation of informal water markets to distribute groundwater within command areas is further evidence of the need to build in as much flexibility in regulation as possible (Burke, 2003, p.73).

There are also some studies critical of the application of water markets. For instance Tisdell (2001) examined the consequences of introducing trade to allocate water for environmental use in Australia. The results showed that (1) trade in water entitlements is likely to increase the differential between extractive demand and historical flow regimes since extractive water-use concentrates on the most profitable crops, and (2) water markets are likely to limit the effectiveness of water policies aimed at restoring natural flow regimes.

Governments and water authorities interested in establishing water markets as a tool to reallocate water away from inefficient uses and towards more valuable applications should learn more about the factors influencing irrigators' decisions to participate in water trading (Wheeler et al., 2009, p.642). As there are few transactions among water users (Young, 1986; Donohew, 2009, p.102), analysing available water markets and their participants would be particularly useful for policy makers who may need to alter existing institutions, so that the costs of water trade do not outweigh the potential gains from trade. The results of participatory studies are also of interest to farmers and municipal water providers which are actively engaged in developing water-leasing alternatives (Pritchett et al., 2008, p.436).

In Iran, the Law of Fair Distribution of Water (Majlis of Iran, 1983) shapes the institutions for water use. Under this law, people receive legal permission to use groundwater, which is a public good. However, these permissions are a form of property ownership and have very high shadow values, according to water charge levels of wells and water quality. 
There is a restriction in this law which can operate versus any water market expansion. Paragraph 28 of this law has forbidden any usages of the water which is different from the given permission. Moreover, the transmission of the permission should be done under the supervision of Ministry of Energy (MOE) with the transmission of the land to the new user by keeping the same permitted usages. In 2007 a new department - the Office of Regulation and Market Development of Water and Electricity - was established within the MOE whose intended main task was to regulate water markets ${ }^{1}$. To the author's knowledge, this task has not yet been accomplished.

In this paper we study the factors affecting the decision of farmers to participate in water markets and buy groundwater for irrigation of pistachio gardens during the 20072008 agricultural year in the Rafsanjan aquifer region in southeastern Iran. The logit model is used for the analysis and factors which affect the farmers participation are statistically defined and analysed.

\subsection{Literature review}

There are few studies on the issue of participation in water markets. As there are not many water markets documented, gathering information about market transactions and the characteristics of participants is difficult in the context of the developing countries. There are few research studies similar to water market participation studies, but they do not follow the same goal as this study here. For instance Ranjan et al. (2004) analysed the participation in a water market by mathematical programming, or Hadjigeorgalis (2008) analysed farmer preferences for selecting among different water market choices. The author could not find many other studies analysing the factors that affect the farmer decisions to participate in a water market. However, some existing studies are reviewed below.

Sharma and Sharma (2006) studied the factors influencing farmers' decisions to buy groundwater resources for irrigation in Rajestan, India. 280 farmers were selected from eight villages within four districts. The study sample consisted only of farmers who bought

\footnotetext{
${ }^{1}$ Office website: http://rcewm.moe.org.ir/HomePage.aspx?TabID=5803\&Site=rcewm.moe.org\&Lang=fa-
} IR (accessed 4th Octobor 2011, in persian) 
and sold water, whilst those not involved in water trading and those who both bought and sold water were eliminated from analysis, in order to obtain a mutually exclusive sample. The logit model was used for analysis. Significant factors were: size of land holding, negatively; land fragmentation, positively; higher capacity of water lifting device, negatively; and education, positively. Non-significant factors which affected the model positively were: family workers per ha, proportion of high-valued crops and proportion of joint-installed wells. They concluded that this water market, which was based on an undefined property right system, failed to bring social equity as water sellers were charging exorbitant prices to poor, small-scale and marginal farmers. They advised state intervention to regulate the water markets.

Pritchett et al. (2008) studied the factors affecting the willingness to lease, rather than permanently transfer, irrigation water to municipal areas of the South Platte basin in Colorado, USA. Questionnaires were mailed to farmers and 329 (19\%) were returned. Leasing attitudes were measured in this survey using Likert scale ordinal responses. The results were analysed with an ordered logit model. Statistically significant variables which had a negative impact on willingness to lease were: debt ratio, which may indicate a more urgent need to sell water rights; percentage of water supply from groundwater, high levels of which preclude one from leasing water; and proximity to urban centres, which implies increased pressure for urban development and thus increased likelihood of selling of water rights. Statistically significant variables which had a positive effect on willingness to lease were: quantity of acres under irrigation, which may indicate a large quantity of water available for lease; concern for rural communities; and willingness to work with municipalities and other organisations, which is necessary to establish a lease agreement.

Wheeler et al. (2009) investigated whether the adoption of water trading was associated with the same factors that influenced the adoption of agricultural innovations in general. The data came from water trading during 1998-1999. The sample consisted of 100 buyers, 100 sellers and 100 non-traders. The data were obtained by telephone interview. These three different groups in the sample were compared with each other. Two different analyses were done; (1) The logit model was used to study the factors influencing the decision to trade generally, (2) A Multinominal logit was used to compare the factors affecting 
decisions to buy, sell, or not trade. Results showed that irrigators were more likely to participate in allocation trading if they: were older; lived in the region; had a farm plan; had a higher total water entitlement; irrigated more hectares of land; were newer to farming; had a higher percentage of total irrigated crop land; were female; were education beyond the level of Year 10; had a higher farm operational surplus; believed their farm had low productivity; had a lower percentage of irrigated areas for cattle than for cropland; and did not agree that irrigators should provide water for the environment. They concluded that water trading did conform to many expectations held about the adoption of agricultural innovations. Results suggested that water trading can be better categorised as a "normal" agricultural innovation with benefits mostly for private agents, rather than as a "sustainable" innovation with benefits mostly for the public. They suggested that the adoption of water trading is similar to the adoption of general agricultural innovations. They found only limited evidence to support the market efficiency hypothesis that water moved from lower value uses to higher value uses.

\subsection{Methodology}

As the dependent variable in this study, participation in the water market, is a binary variable (0 or 1$)$, a binary response model is required. The linear probability model (LPM) which uses the ordinary least square (OLS) approach has some shortcomings for the analysis of binary variables. Generalised linear models (GLM), with an appropriate link function, can be used to overcome the shortcomings of the LPM. The functional form for a model from the GLM family has to be choosen for the further analysis.

In the binary response model, interest lies primarily in modeling the response probability conditional on a set of covariates:

$$
\operatorname{Pr}(Y=1 \mid X)=\operatorname{Pr}\left(Y=1 \mid x_{1}, x_{2}, \ldots, x_{m}\right)
$$

where $Y$ is the dependent binary variable which has two possibilities: Farmers who bought water from spot water market $(Y=1)$ and farmers who did not buy water $(Y=0)$. The vector of explanatory variable $X$ denotes the full set of independent variables. These 
variables cover both technical aspects of farm and pump, and household characteristics.

The GLM family are appropriate models for analysing the impact of changes in $X$ on the probability of participation in water market. It can be presented as follows:

$$
\operatorname{Pr}(Y=1 \mid X)=F(X, \beta)=F\left(\beta_{0}+\beta_{1} x_{1}+\beta_{2} x_{2}+\ldots,+\beta_{m} x_{m}\right)=F(\beta X)
$$

$$
\operatorname{Pr}(Y=0 \mid X)=1-F(X, \beta)=1-F\left(\beta_{0}+\beta_{1} x_{1}+\beta_{2} x_{2}+\ldots,+\beta_{m} x_{m}\right)=1-F(\beta X)
$$

where $\beta$ is the set of parameters that reflects the impacts of changes in $X$ on the probability of participation. The function $F($.$) takes on values strictly between zero and one (0<$ $F()<$.1 ), and could be any cumulative distributions function.

Equation 3.2 shows the probability of the farmer participating in a spot water market and equation 3.3 shows the probability that the farmer does not try to buy water from a spot water market. An appropriate functional form for $\mathrm{F}$ ensures that the probabilities are between zero and one. The logit model is used in this analysis, rather than the probit model which is often used in applied economics studies. It must be added that the logit and probit models tend to produce similar results. Different results between two models can be observed with the availability of large data or by using multivariate GLM models,. In the logit model, $F($.$) is the logistic function and can be written as follows:$

$$
F(\beta X)=\frac{\exp (\beta X)}{1+\exp (\beta X)}
$$

which is between zero and one for all real numbers. Because of the nonlinear nature of the logit model, maximum likelihood estimation (MLE) is the suitable tool for the estimation of this model (Wooldridge, 2004, ch.17.1).

The goodness fit of the model In GLM models, the deviance is used to assess the adequacy of a model by comparing it to a more general model which can estimate the maximum number of parameters. This general model is called saturated model. Let 
$L(\beta ; Y)$ denote the maximum value of the likelihood function for the model of interest and let $L\left(\beta_{\max } ; Y\right)$ denote the maximum value of the likelihood function for the saturated model. The deviance, also called the log likelihood (ratio) statistic, is $D=2\left[L\left(\beta_{\max } ; Y\right)-L(\beta ; Y)\right]$.

In addition, the difference of the deviances between two models (indicated below with subscripts 0 and 1, where model 0 is supposed to be nested in model 1) can be used to test hypotheses (Dobson, 2001, p.86) using the difference of the deviance statistics:

$\Delta D=D_{0}-D_{1}=2\left[L\left(\beta_{\max } ; Y\right)-L\left(\beta_{0} ; Y\right)\right]-2\left[L\left(\beta_{\max } ; Y\right)-L\left(\beta_{1} ; Y\right)\right]=2\left[L\left(\beta_{1} ; Y\right)-L\left(\beta_{0} ; Y\right)\right]$

If both models describe the data well then $D_{0} \sim \chi^{2}(N-q)$ and $D_{1} \sim \chi^{2}(N-p)$ so that $\triangle D \sim \chi^{2}(p-q)$ (Dobson, 2001, p.87).

\subsection{Study area and data}

The study area is reviewed briefly below using the same survey data in chapter 2 . The details can be reviewed in section 2.3. Field work was conducted for 3.5 months during November 2008- February 2009 in the Rafsanjan county in the southeastern part of Iran. The main reason for selecting Rafsanjan was its unique agricultural production pattern and its size. Table 3.1 shows some general characteristics of the Rafsanjan aquifer. The general hydrograph of Rafsanjan shows an annual drop of $72 \mathrm{~cm}$ on average.

Data was gathered using two-stage random sampling. Considering the different water quality found within the study area, and the high cost of water quality studies, a readily available 4-year data set from the Rafsanjan Irrigation Water Authority (RIWA) was used for the first-stage sample selection. The RIWA randomly sampled 60 agricultural wells within the aquifer, and checks chemical and water parameters such as EC, pH, etc. seasonally in order to observe any quality changes that may occur.

The survey comprised two different questionnaires; one concerning wells and the other concerning households. The questionnaire concerning wells was designed after consul- 
Table 3.1.: General information about the Rafsanjan aquifer region

\begin{tabular}{|c|c|c|}
\hline $\begin{array}{l}\text { General } \\
\text { information }\end{array}$ & $\begin{array}{l}\text { County's total area } \\
\text { Population }\end{array}$ & $\begin{array}{r}10266 \mathrm{~km}^{2} \\
295,000 \\
\end{array}$ \\
\hline $\begin{array}{l}\text { Agricultural } \\
\text { information }\end{array}$ & $\begin{array}{l}\text { Crop pattern } \\
\text { Estimated planting area }\end{array}$ & $\begin{array}{l}\text { Only pistachio orchards } \\
\text { Estimated } 80000-120000 \text { ha }\end{array}$ \\
\hline $\begin{array}{l}\text { Hydrogeological } \\
\text { information }\end{array}$ & $\begin{array}{l}\text { Area of Rafsanjan plain } \\
\text { Annual extraction volume } \\
\text { Volume of water used by } \\
\text { agriculture } \\
\text { Storativity coefficient } \\
\text { Annual drop of water level } \\
\text { Aquifer condition } \\
\text { Average height from sea level } \\
\text { Average depth of water table } \\
(2010)\end{array}$ & $\begin{array}{r}6234 \mathrm{~km}^{2} \\
693 \text { million } \mathrm{m}^{3} \\
666 \text { million } \mathrm{m}^{3} \\
5 \% \\
72 \mathrm{~cm} \\
\text { Red Zone } \\
1609 \mathrm{~m} \\
55.5 \mathrm{~m}\end{array}$ \\
\hline
\end{tabular}

Sources : Statistical Center of Iran (2008), WRS (2011),

Kerman Agrijahad Organization (2012)

tations with irrigators, pumpers and well-representatives. This questionnaire contains questions regarding the well ownership, technical aspects, historical trends, well management, labor force, energy consumption, maintenance, water charge and property value. The household questionnaire contains questions about garden management, garden structure, the value of harvested crops, household socioeconomic structure, inputs, garden operational costs, processing costs, water provision costs and water trade. Also included within the questionnaires were questions asking for agricultural expenditures over a oneyear period, and crop yield levels and product sale prices for a two year period. As the sample of wells was random it includes both large and small-scale farmers.

The ownership pattern is very diverse. There were cases where 2-3 wells belonged to one landlord or where one well was owned by 200 people. Representatives of the 52 pumping units $^{1}$ were interviewed, along with more than 157 farmers whose land is dispersed around the aquifer. Figure 3.1 shows the position of target wells in the study area.

Description of data As a result of heterogeneous water-land ownership of the area, the spot water market is not recognised by all 52 pumping units. We found that water markets were operating among those pumping units with many owners, rather than those

${ }^{1}$ Each pumping unit refers to the number of wells which irrigate a specific farm area. There could be one well or many. Usually, a pumping unit has one management pattern for all wells inside that pumping unit and it's water is mixed for irrigation. 


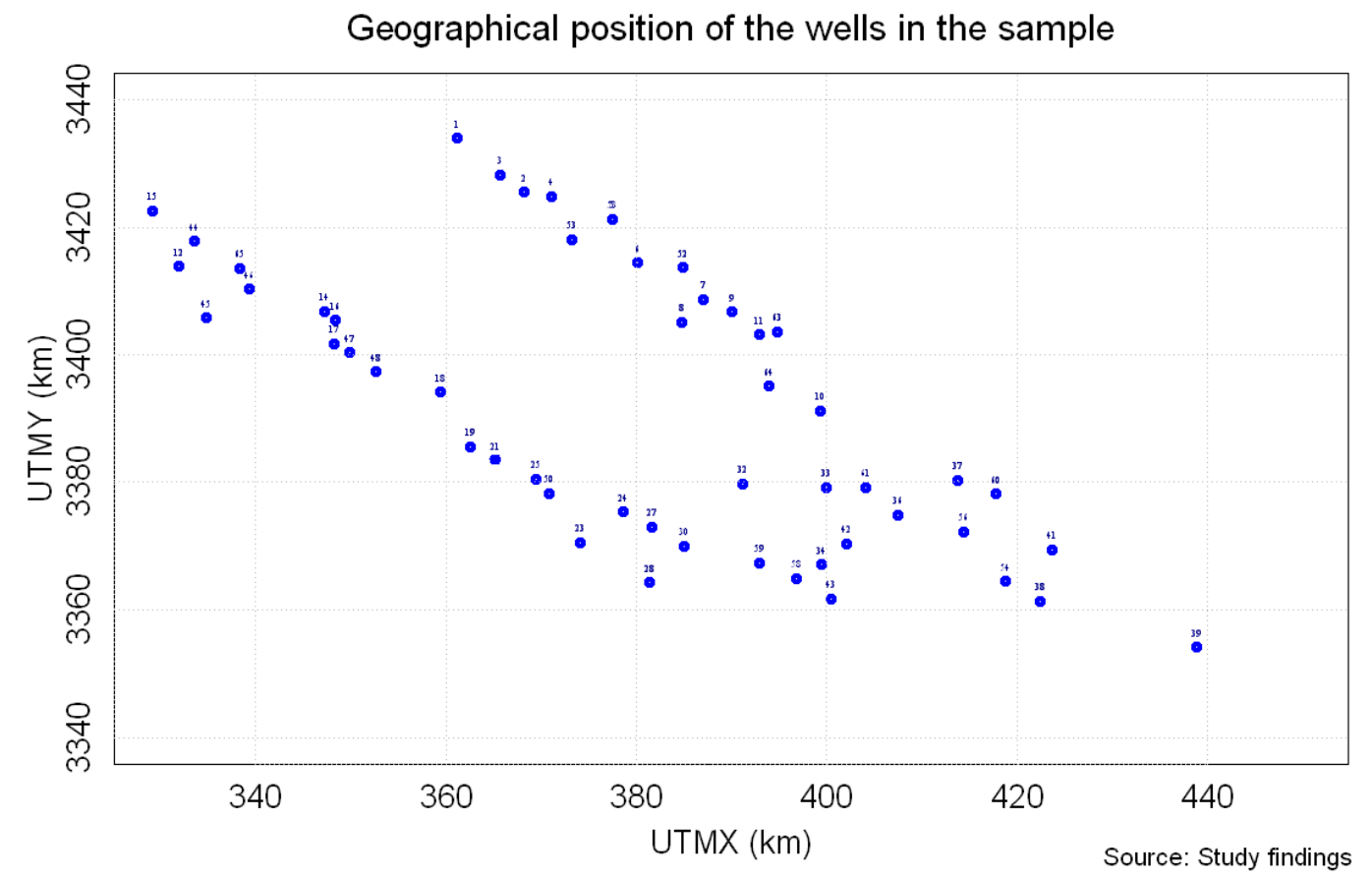

Figure 3.1.: Geographical position of wells and farms

Table 3.2.: Pumping unit and farm participation in water market

\begin{tabular}{|l|c|c|}
\hline & $\begin{array}{c}\text { Number of pumping } \\
\text { units }\end{array}$ & Number of farms \\
\hline Total number in sample & 52 & 157 \\
Availability of spot water market & 41 & 145 \\
Active participation in spot & - & 28 \\
market & & \\
(during 2008) & & \\
\hline
\end{tabular}

Source: Study findings

with few owners. Table 3.2 shows the number of farms and wells which are considered in the analysis. Importantly, only 4 farms are using modern drip irrigation whilst the others still apply traditional furrow irrigation systems.

The detailed cost data regarding the pumps and the farms were extracted from the questionnaires and entered into a database (MS ACCESS 2003). Pumps and farms were dealt with separately. Table 3.3 shows a summary of variables used in the establishment of the model. These variables were selected from many possible variables within the questionnaires based on model selection criteria. Figure 3.2 shows the histograms of $\mathrm{EC}^{1}$ and $\mathrm{pH}$ as water quality variables. We have distinguished between water quota, defined

\footnotetext{
${ }^{1}$ There are different ways of measuring EC of water. The most popular one is $\mu S / \mathrm{cm}$. By dividing this value by 1000 , we obtain $d S / m$. For econometric analysis, the second unit has been used as a 1 unit change in $\mu S / \mathrm{cm}$ is too small to be discussed.
} 
Table 3.3.: Descriptive summary of variables

\begin{tabular}{lrrrr}
\hline & Means & sd & Max & Min \\
\hline $\begin{array}{l}\text { Participation in water market (dummy as } \\
\text { dependant variable) }\end{array}$ & 0.19 & 0.40 & 1.00 & 0.00 \\
Using Other Wells (dummy) & 0.16 & 0.37 & 1.00 & 0.00 \\
Having other jobs (dummy) & 0.38 & 0.49 & 1.00 & 0.00 \\
No of fragmented lands & 3.43 & 2.57 & 15.00 & 1.00 \\
Average age of trees in garden & 25.13 & 8.83 & 65.00 & 4.67 \\
Insuarnce cost (1000 rials) & 2125.52 & 9010.74 & 100000.00 & 0.00 \\
Pistachio production (kg per ha) & 1311.33 & 694.59 & 3453.33 & 0.00 \\
Water quota per ha (cubic meter) & 9902.04 & 4483.32 & 22776.00 & 2463.75 \\
Water level (meter) & 63.05 & 30.50 & 123.47 & 8.11 \\
Share of labor costs from all variable costs & 45.90 & 11.76 & 79.63 & 17.37 \\
EC (mhoS/cm) & 6364.04 & 3753.68 & 17400.00 & 1314.00 \\
pH & 7.58 & 0.39 & 8.60 & 6.70 \\
\hline
\end{tabular}

as the farm's theoretical maximum share of well water based on pumping for 365 days per year, and actual water use. Furthermore, we have distinguished between the volume of the water transferred to the farm from other wells or transferred to the other farms, and traded water.

In water market analysis, three different possible groups should be distinguished: water buyers, water sellers and those who both buy and sell. In well-established water markets, we can even consider non-trading water users as separate category. In this study we focus only on buyers and their characteristics, whom we compared with non-buyers in order to obtain a mutually exclusive sample. Hour is the unit of water trading among neighbours. When the buyer and seller reach a compromise, they have to arrange the delivery with the well representative or a technical observer. Afterwards, the number of traded hours of well water is delivered to the buyer from the pump. It must be considered that the traded water is a commodity which can not be transported simply and most of the time trade is only possible for neigbouring farmers. The pattern of wells' water distribution can encourage or discourage spot water market expansion. 

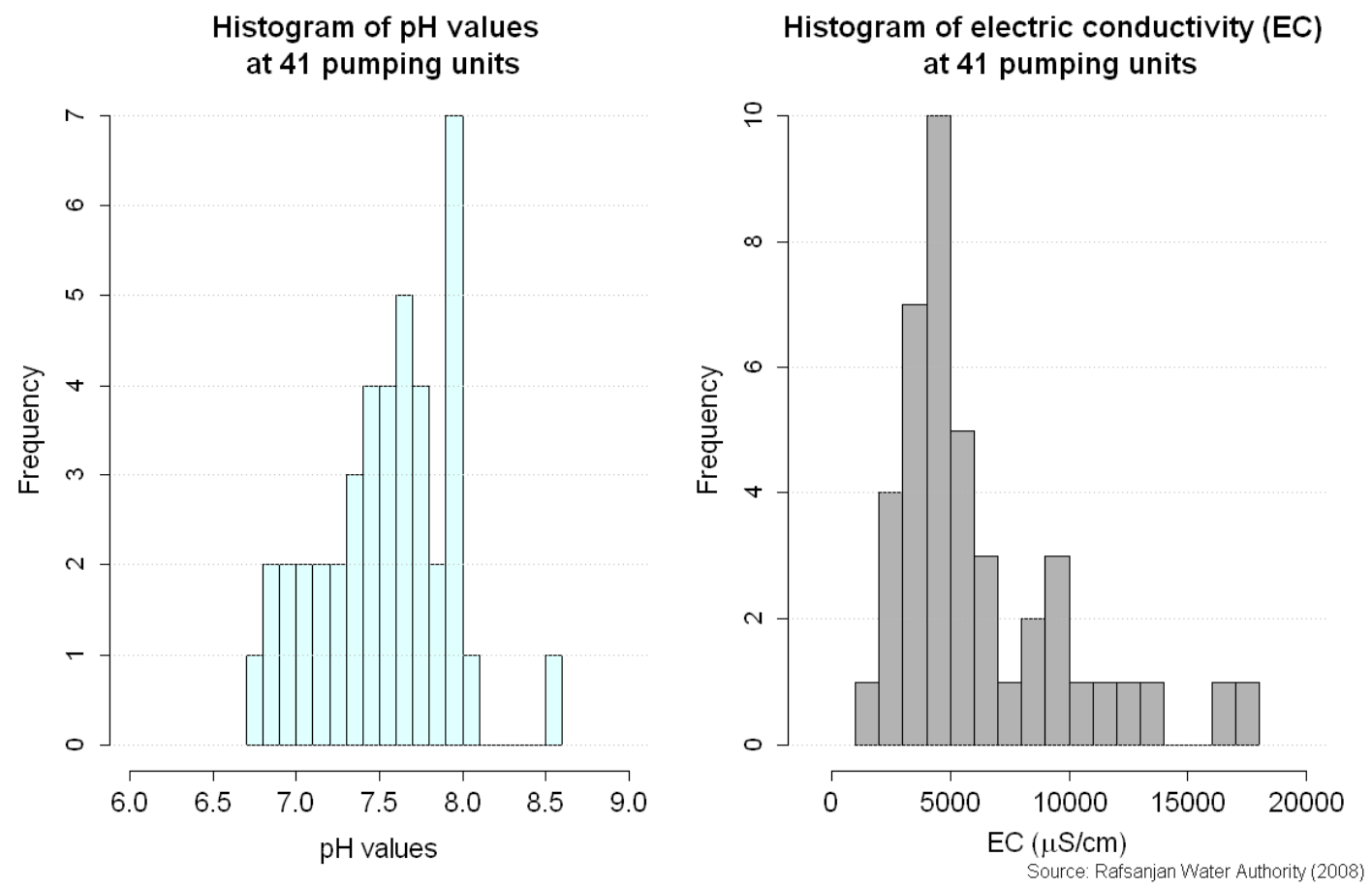

Figure 3.2.: Irrigation water quality at water pumping units

\subsection{Results}

\subsubsection{Description of results}

Water trade covers a small share of water use per hectare among farmers in the sample. Figure 3.3 shows 2 histograms displaying the volume of traded water as a percentage of total water use, and a plot chart showing the relationship between farm size and the share of bought water as a percentage of total water use. Table 3.4 and table 3.5 categorise the participants in the water market according to land ownership and water quota. Altogether table 3.4, table 3.5 and figure 3.3 show that smallholders are more active participants within water markets.

\subsubsection{Analysis of results}

There are several factors which affect the decision by farmers to buy groundwater. The relative importances of these factors are quantified using a logit regression with water buying as the binary variable.

Table 3.6 shows the results of the logit regression. As the coefficients in the logit model do not reflect the marginal effects of the explanatory variables on the probability of 

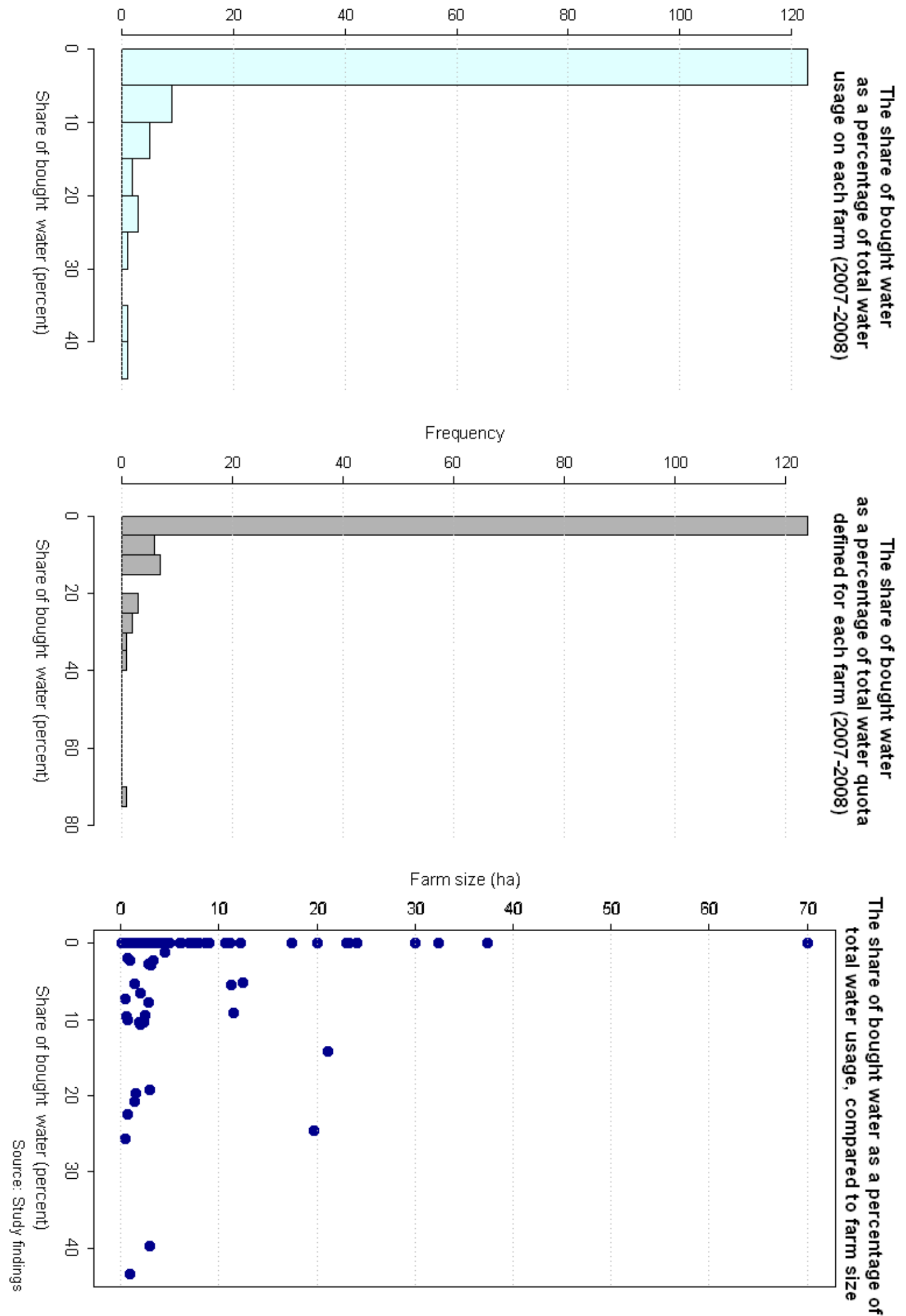

Figure 3.3.: Relative shares of bought water as a percentage of water used, water quota and related to farm size 
Table 3.4.: Land ownership status of study participants in spot water market

\begin{tabular}{|c|c|c|c|}
\hline \multirow[t]{2}{*}{$\begin{array}{l}\text { Area of land } \\
\text { owned (ha) }\end{array}$} & \multicolumn{2}{|c|}{$\begin{array}{c}\text { Number of participants and } \\
\text { non-participants in spot water } \\
\text { market }\end{array}$} & \multirow[t]{2}{*}{$\begin{array}{c}\text { Sum of } \\
\text { observations }\end{array}$} \\
\hline & Participants & $\begin{array}{c}\text { Non- } \\
\text { participants }\end{array}$ & \\
\hline $0-5$ & 23 & 97 & 120 \\
\hline $5-10$ & 0 & 8 & 8 \\
\hline $10-15$ & 3 & 3 & 6 \\
\hline $15-20$ & 1 & 2 & 3 \\
\hline $20-25$ & 1 & 3 & 4 \\
\hline $25-30$ & 0 & 1 & 1 \\
\hline $30-35$ & 0 & 1 & 1 \\
\hline $35-40$ & 0 & 1 & 1 \\
\hline$>40$ & 0 & 1 & 1 \\
\hline Sum & 28 & 117 & 145 \\
\hline
\end{tabular}

Source: Study findings

Table 3.5.: Water quota per hectare and participation in water market

\begin{tabular}{|c|c|c|c|}
\hline $\begin{array}{c}\text { Water quota } \\
\text { (cubic meters) }\end{array}$ & $\begin{array}{c}\text { Number of participants and } \\
\text { non-participants in spot water } \\
\text { market }\end{array}$ & \multirow{2}{*}{$\begin{array}{c}\text { Sum of } \\
\text { observations }\end{array}$} \\
\cline { 2 - 3 } & Participants & $\begin{array}{c}\text { Non } \\
\text { participants }\end{array}$ \\
\hline $0-5000$ & 4 & 10 & 14 \\
$5000-10000$ & 11 & 58 & 69 \\
$10000-15000$ & 8 & 34 & 42 \\
$15000-20000$ & 5 & 9 & 14 \\
$>20000$ & 0 & 6 & 6 \\
\hline Sum & 28 & 117 & 145 \\
\hline
\end{tabular}

Source: Study findings 
Table 3.6.: Logistic regression coefficients of factors affecting the decision to buy groundwater

\begin{tabular}{lrrrr}
\hline & Estimate & Std. Error & z value & $\operatorname{Pr}(>|\mathrm{z}|)$ \\
\hline (Intercept) & 18.12 & 7.55 & 2.40 & 0.02 \\
Using Other Wells (dummy) & 2.08 & 0.76 & 2.73 & 0.01 \\
Having other jobs (dummy) & 1.18 & 0.56 & 2.09 & 0.04 \\
No of fragmented lands & 0.29 & 0.11 & 2.74 & 0.01 \\
Average age of trees in garden & -0.08 & 0.03 & -2.27 & 0.02 \\
Insurance cost (1000 rials) & 0.00 & 0.00 & 1.39 & 0.17 \\
Pistachio production (kg per ha) & 0.001 & 0.00 & 2.61 & 0.01 \\
Water quota per ha (cubic meter) & -0.0002 & 0.00 & -2.05 & 0.04 \\
Water level & 0.04 & 0.01 & 3.32 & 0.00 \\
Share of labor costs from all variable costs & -0.06 & 0.03 & -2.20 & 0.03 \\
PH & -2.40 & 0.95 & -2.52 & 0.01 \\
EC (dS/m) & -0.26 & 0.11 & -2.31 & 0.02 \\
\hline Null deviance & 142.301 & $\mathrm{df}$ & 144 & $\cdot$ \\
Residual deviance & 98.122 & $\mathrm{df}$ & 133 &. \\
AIC & 122.12 & - & - & - \\
Model Test : & - & - & - & - \\
Difference of deviance & 44.179 & - & - & - \\
Difference of df & 11 & - & - & - \\
Model P-value & 0.00000 & - & - & - \\
Wald statistic & 40.3 & - & - & - \\
\hline
\end{tabular}

participation, the following formula is used to calculate the marginal effects (Wooldridge, 2004, p.536):

$$
\triangle \widehat{\operatorname{Pr}}(Y=1 \mid X) \approx\left[d F(X, \widehat{\beta}) \beta_{i}\right] \triangle x_{i}
$$

Often the sample averages of the $x_{i}$ are used to evaluate the term $d F(\bar{X}, \widehat{\beta})$. Table 3.7 shows the calculated probability at the sample average for the explanatory variables affecting participation, and also the calculated probability by considering zero and one to be the values for two dummy explanatory variables.

One of the most striking results of the model comes from the two dummy explanatory variables. A farmer who transfers water from other wells to the target farm or transfers water from a target well to other farms (if such a possibility exists), is 31 percent more likely to buy water, which simply reflects farm water shortages. For every further piece of fragmented land, the farmer is 2.6 percent more likely to buy water. For one year increase 
Table 3.7.: Calculated probabilities of factors affecting the outcome according to the logit model (percent)

\begin{tabular}{lrrr}
\hline & Average & Dummy $=0$ & Dummy $=1$ \\
\hline Using Other Wells (dummy) & 30.95 & 0.00 & 0.00 \\
Having other jobs (dummy) & 11.78 & 0.00 & 0.00 \\
No of fragmented lands & 2.56 & 1.31 & 7.23 \\
Average age of trees in garden & -0.67 & -0.34 & -1.90 \\
Insurance cost (1000 rials) & 0.0003 & 0.0002 & 0.0010 \\
Pistachio production (kg per ha) & 0.01 & 0.00 & 0.03 \\
Water quota per ha (cubic meter) & -0.0013 & -0.0007 & -0.0037 \\
Water level & 0.31 & 0.16 & 0.88 \\
Share of labor costs from all variable costs & -0.49 & -0.25 & -1.40 \\
PH & -20.93 & -10.70 & -59.15 \\
EC (dS/m) & -2.25 & -1.15 & -6.35 \\
\hline
\end{tabular}

in the average age of a garden, the probability of participation decreases by 0.67 percent. For each extra cubic meter of water quota granted per hectare, there is a decrease in the probability of participation by 0.0013 percent; the significance of increasing water quotas becomes clear when one considers that volumes may be hundreds or thousands of cubic meters. A one meter increase in the depth of the water table increases the probability of participation by 0.31 percent. A yield increase of one kg dry pistachio per hectare encourages participation by 0.01 percent. A one percent increase in the share of labor costs, as a proportion of total annual variable costs, reduces the likelihood of water market participation by 0.5 percent. Labor costs were the most significant of all costs.

An explanation about our quality variables is required. As mentioned before (section 3.4), a single unit increase in EC of one $\mu S / \mathrm{cm}$ has a limited impact on water quality. EC was significant in the logit model, however it's probability effect was very low. Therefore we have converted the variable to $d S / m$, or $1000 \mu S / \mathrm{cm}$. A one unit increase in $d S / m$ decreases the probability of buying water by 2.25 percent, which we consider to be a low effect as $1000 \mu \mathrm{S} / \mathrm{cm}$ is such a large change that it occurs rarely. A similar consideration applies for $\mathrm{pH}$, since $\mathrm{pH}$ is a logarithmic scale variable and therefore the difference between $\mathrm{pH} 7$ and 8 is equivalent to changing river water quality to that of sea water, which is unlikely. Therefore the 21 percent reduction in the probability of buying water associated 
with a one unit change in $\mathrm{pH}$ can be considered of minor importance, as actual changes in water quality are small.

Table 3.6 shows that quantitative water scarcity, technical aspects of farming and pumping and water quality are the major influential factors in the logit model. From the long list of farmer characteristics, the only significant variable in the model is the dummy variable which shows occupations of respondents in addition to farming. On average, having other occupations increases the participation likelihood by 12 percent.

The only variable which can not be simply explained is the insurance costs for the previous year, which has a positive effect in the model. Although this variable is insignificant, it could not be eliminated by considering different model selection criteria. In contrast, insurance costs for the current year had no effect in the model.

Spatial autocorrelation As farms have proximities to both groundwater (a hydro-geological variable) and neighbouring farms (a social variable), spatial autocorrelation could exist between these two variables. A farmer's decision to participate in the water market could be influenced by the decisions of neighbouring farmers, or the error term in the logit model could be spatially correlated. Therefore, the Moran I test was used to test the spatial autocorrelation among the residuals. Inverse distance was used to establish a spatial weight matrix. As sample residuals are not appropriate criteria in GLM models, Pearson residuals and deviance residuals are checked with the Moran I test. No spatial autocorrelation was found in the model.

\subsection{Discussion}

In spite of a lack of regulation, we could identify a spot water market in the study area. The results show that this market is small and accounts for a limited share of water used for irrigation. Smallholders are the main participants in the market and water distribution patterns can affect the size of this market. Technical factors and profit-driven factors are more significant factors within this water market than farmer characteristics, household members, or social characteristics. The latter group of variables are not significant factors 
in the Logit model. These results contrast with the findings of Wheeler et al. (2009) who regarded water markets as normal extensions of agricultural technology. The development of monoculture and the reality of market-oriented agriculture in Rafsanjan may explain the importance of profit and technical factors found. Interpretation of table 3.6 shows that water quantity factors affect the model more than water quality factors, which shows water scarcity is more important within the study area than quality. The groundwater depletion effect on participation decision is an interesting finding of this study. The participation decision is not defined only by the farmers level of water quotas, but it also defined by reservoirs overall depletion level. It means in a market setting, the reservoir in situ value becomes an important issue for the users. This suggests that groundwater depletion in areas with good water quality may result in an expansion of spot water markets. Furthermore technical innovations affecting productivity can encourage spot water market expansion. Regional labor market factors such as labor costs can affect the decision to participate in the water market. Increases in labor costs negatively affect water market participation rates. However, other variable costs do not affect the model. This difference could be largely due to the high labor intensity of pistachio production. It is therefore likely that labor efficiency improvements or technological adaptations which reduce labor costs might encourage water market participation. Although the increase in the age of the trees reduces the participation decision, the size of the effect is very low. It shows that increases in the age of the trees in the study area will not affect the participation dramatically. The reason could be the depth of the roots as ability of the trees increases to uptake water from deeper layers of soil. As many farmers are aging, probably the land and water ownership will be more fragmented, which may be another argument for possible market expansion in the future. The significant effect of having other jobs on market participation shows that if income sources of the residents and farmers increase as a result of any regional industrials change or project implementation, the spot water market will expand more. 


\subsection{Conclusion}

In this paper we studied factors affecting farmers' decisions to participate in a fragmented spot water market in Rafsanjan aquifer, southeastern Iran. Logit model is used. The results show that a spot water market exists, mostly for use by smallholders. Moreover, the volume of water traded within this market is relatively small. Water quantity factors affect the decision to participate more than water quality factors. The results show that the spot water market probably will be expanded in the future considering factors that significantly affect this model. Regulating the groundwater market may encourage water trade expansion among farmers, by relaxing current limitations on water use and land laws, as the area has already the potential for a more expanded water market.

It must be added that the farmers in study area have never answered positively that they sell water. They mentioned the fact that they transfer water to other farms. This behaviour could be due to the law restriction on water permits that forbids any usage of water different from the permit. Therefore, the response to buying water is much simpler to be achieved in survey as the answer to the selling question. By the availability of possible answers to selling question, the factors that affect the decision to sell can be studied. This is also another area of further research.

Future studies could analyse factors affecting the willingness to pay (WTP) in this fragmented market, in order to assist groundwater valuation research. Of regional interest might be an institutional study of groundwater regulation and laws to encourage the expansion of water markets. Another area of research is formal water market expansion without destroying available norms in informal spot water markets. 


\section{Willingness to Pay for Irrigation}

\section{Water from Groundwater in Spot}

\section{Water Market by Self Selectivity}

\subsection{Introduction}

\subsubsection{Water valuation and water pricing}

The economic valuation of water is a topic which gains importance both in societal and scientific terms. E.g., the Dublin Conference on Water and Environment (ICWE, 1992) has explictly highlighted the necessity to focus more strongly on the economic value of water. Dublin Conference was a turning point that wide variety of disciplines have recognised economic aspects of water management. The fourth Principle states that "the past failure to recognize the economic value of water has led to wasteful and environmentally damaging uses of the resource. Managing water as an economic good is an important way of achieving efficient and equitable use, and of encouraging conservation and protection of water resources"1.

There are two schools of thought with different interpretations of this 4 th principle. The first group is the neoclassical economic view which advocates for the pricing of water by its economic value. In this view the market ensures that water is allocated to its best uses. The price of water needs to reflect the full supply cost including environmental externalities (Rogers et al., 2002). The second group promotes the integrated decision

\footnotetext{
${ }^{1}$ http://www.wmo.int/pages/prog/hwrp/documents/english/icwedece.html
} 
making on the allocation of the scarce resources, which does not necessarily involve financial transactions. The second school mainly believes that integrated water resources management (IWRM) is the solution to water scarcity and is more adapted to all Dublin principles (Savenije and van der Zaag, 2002, p.98).

Nevertheless, economic incentives and mechanisms, such as water pricing and the introduction of water markets, are in many contexts efficient and effective measures in water demand management (Fraiture and Perry, 2007, p.94). However, with the wide-spread absence of well-functioning water markets, the "correct" price of irrigation water is difficult to ascertain (Birol et al., 2006; Hanemann, 2006; Young, 2005). The decisions by all parties, i.e., regulators in implementing policies, and users in harvesting, extracting and emitting water, take place in the absence of information about the value of alternative resource uses (opportunity costs) that market trade otherwise would generate. This condition frequently results in wasteful misallocation (Libecap, 2009, p.132). In such a situation, any plan to adjust irrigation water allocation or pricing regimes must carefully consider how the adjustments may impact agricultural production. As a central step, the economic value of irrigation water for farmers needs to be quantified (Tardieu and Prefol, 2002). Therefore, applied economic valuation methods play a key role in water resources management.

Understanding the economics of water can help inform decision makers of the full social costs of water use in agriculture and the full social value or benefits that agriculture's use of water can provide (Hanemann, 2006). The value to the user may be quantified by his/her willingness to pay, but there are additional benefits, such as benefits from return flows, multiplier effects from indirect uses and in a broader sense the benefits to meeting societal objectives (Savenije and van der Zaag, 2002, p.101).

Reviews of the approaches to estimate the economic value of water can be found in Birol et al. (2006), Young (2005) and Turner et al. (2004) and with specific regards to irrigation water Johansson (2005). The theoretical and empirical basics of irrigation water pricing is analysed in Tsur (2005), Tsur et al. (2004), Johansson et al. (2002), Johansson (2000) and Tsur and Dinar (1997). Young (2005, p.46) classifies the methods for determining the economic value of water into two main groupings: deductive and 
inductive. Deductive methods involve the derivation of shadow prices where water is an input into production systems. Inductive methods comprise valuations based on observed behaviour in real markets or production settings, usually when the public good aspects of water are being considered. In the absence of market prices, the value of water needs to be derived from modelling, starting from production functions and setting up the farmer's optimization problem (Fraiture and Perry, 2007, p.95). The use of stated preference methods to investigate the economic value of water has more typically been concerned with its public good aspects, such as the value of recreational waterways. These methods are less commonly used for pricing irrigation water in agriculture (Rigby et al., 2010, p.99).

Although the first school of thought promotes economic water pricing as the most important demand management tool, there is limited scientific evidence to support that claim (Savenije and van der Zaag, 2002, p.100). Water saving technology choices are hardly driven by water prices. They are mainly determined by structural factors, agronomic conditions and financial constraints (Fraiture and Perry, 2007, p.96). Farmers are often unable or at least unwilling to pay the full provision costs of irrigation water (Hanemann, 2006; Young, 2005; Johansson, 2005; Wilson, 1997; Sampath, 1992). Additionally, political considerations may deter policy makers from implementing the necessary price increases which are typically involved when the full provision costs are to be borne by the farmers. E.g., in mid 1990s, farmer lobby groups in Gujarat, India, influenced the state's politics by resisting any increase in the flat-rate power tariff or decreasing the daily hours of farm power supply for pumping groundwater for irrigation (Shah et al., 2008, p.4). Similarly, during 2010-2011, the Iranian government was not able to successfully enforce a price reform policy which would have increased the pumping energy price for irrigation in order to impose the full cost recovery of groundwater pumping to the users. The government was more successful at eliminating subsidies from energy in other sectors during the same period. 


\subsubsection{Water market and water property rights}

When water market data are available, economists rely on observed prices and market transactions to infer the value of a particular good for analyses of policy impacts. Commonly, the demand curve - as the basis of quantitative economic analyses - is determined through econometric curve fitting techniques using field data. This 'direct' approach is difficult in the analysis of water demand in agriculture. The price of water is only rarely determined in the market (Fraiture and Perry, 2007, p.95). The water market availability depends on the structure of water property rights for and water entitlements to the use of groundwater and surface water. As the focus of this paper is groundwater, the private property rights concerning groundwater will be discussed below.

Three categories of policy instruments are typically distinguished for groundwater management and governance: regulatory or command and control, economic policy, and voluntary / advisory / participatory (Theesfeld, 2010; Shah et al., 2008). Direct administrative regulation involves laws or executive orders requiring the issue of licences/permits, prescribing the volume of groundwater the permit holder is entitled to extract, or specifying norms for the distance to be maintained between existing and new wells. Economic instruments include charges and taxes levied on irrigation wells or the volume of water withdrawn. Tradable water rights for groundwater as an economic instrument have been tried in the western United States and in Chile. By making these rights tradable, some countries have tried to create markets for water rights. Participatory aquifer management by groundwater communities is based on the western United States experience with groundwater districts (Shah et al., 2008, p.3).

Allowing for trade in water entitlements along the watercourse is a market mechanism that could, in principle, increase productivity although it may exert a negative influence on the traditional and accepted systems (Hellegers et al., 2007, p.203). The private property right regime includes the right to divide a property rights into access rights, withdrawal rights, management rights, exclusion rights, and alienation rights (Schlager and Ostrom, 1992, p.250-251) which is difficult to be defined for water generally and groundwater specifically. The mobility of water and the opportunity for sequential use and re-use make water relatively distinctive as a commodity (compare to land for instance). Keeping 
track of water flows is costly and sometimes difficult. Consequently, it is often hard or impractical to enforce excludability or to establish property rights to return flows. In this respect, water is very different as an asset than land, which is relatively easy to divide and fence. The common solution is to resort to some form of collective right of access; in effect, this internalizes the externality associated with the mobility of return flows (Hanemann, 2006, p.72).

Based on Provencher and Burt (1994, p.876), private property rights could be implemented by granting firms an initial endowment of tradeable permits to the in situ groundwater stock, which they control over time. Each year, a firm's consumption of groundwater is constrained by its endowment of permits, which it can adjust by buying or selling permits. Moreover, the number of permits held by the firm is decreased annually to reflect the firm's entitlement to natural recharge of the aquifer. The firm's claim on the groundwater stock does not necessarily equal the stock of groundwater beneath its land. The allocation of the water resource over time is in this setting achieved by the market for groundwater stock permits, and does not require direct demand management by a regulator. The role of the regulator is confined to choosing the initial allocation of groundwater stock permits, developing the rule for the annual allocation of natural recharge, and enforcing that all users obey to the rules. However, the market mechanism might fall short of achieving full recovery of the potential gains the viewpoint of society at large. Provencher and Burt (1994) argue that the equilibrium price of permits fails to equal the marginal net social value of the in situ groundwater stock. They conclude that although the private property rights regime recovers a relatively large proportion of the potential gain from groundwater management, in absolute terms this gain is relatively small. In addition, poorly defined property rights for the access to the water reservoirs can even lead to increased inefficiency in the resource management by establishment of water markets (Brennan, 2008). Even if the rights in a water market are well defined, price dispersion and price discrimination can be recognized inside the water markets (Yoskowitz, 2002).

One particular problem with market based coordination mechanisms is related to the fact that in some countries market systems are largely ineffective due to corruption 
(Theesfeld, 2010, p.135). The impacts of corruption are often more extreme in developing countries, although the phenomenon is not limited to low or lower middle-income countries (Plummer, 2008, p.3). Corruption can be found in a range of interactions at all levels and in all aspects of the water sector, but it also affects the allocation between different uses and users. One type of corruption is when public servants abuse their power to extract small bribes, such as a water meter reader who offers to reduce a customer's bill in return for payment (Plummer, 2008, p.6). Once the market system is distorted, economic policy measures are unlikely to be effective (Theesfeld, 2010, p.135) ${ }^{1}$.

In typical water markets, the transaction frequency among water users is low (Young, 1986; Donohew, 2009, p.102). Hence, analysing available water markets and the WTP and price for water are particularly useful practices to define factors affecting water demand and for improving non-market valuation methods. The shortages of the available data for the price analysis of formal and informal water markets is an issue of concern. Mukherji (2008, p.1086) has advised national survey programs in India to gather data on irrigation service hiring and groundwater markets information, such as the prices paid for buying water or renting pumping equipment.

In this paper, we have focused on the factors which affect the WTP for irrigation from depleting groundwater resources of the Rafsanjan aquifer in Southeastern part of Iran during the agricultural year of 2007-2008. In Iran, the Law of the Fair Distribution of Water (Majlis of Iran, 1983) regulates water using by the common property rights. Under this law, citizen receive legal permission to use groundwater, which is a public good. However, these permits are a form of property ownership and have very high shadow values, according to water charge levels of wells and water quality, although there is a restriction of this law which can operate against any water market expansion. Paragraph 28 of this law forbids any use of water which is not stated in the given permits. Moreover, the water use permits should be administered under the supervision of the Ministry of

\footnotetext{
${ }^{1}$ Moreover, there are two different views on the equity and fairness issues of informal water markets. One group of scholars, such as Sharma and Sharma (2006, p.53), claims that the price of the informal water market is not fair and water sellers heavily charge the smallholders and farmers who are on the margin. However, there are other views which hold that informal groundwater markets have been crucial in alleviating rural poverty (Fujita and Hossain, 1995).
} 
Energy (MOE) and, in the case of buying and selling land, new landholders are required to follow the original permit stipulations. In spite of this law, water trade among water users has been recognised mostly among smallholders of this aquifer.

The price that is paid for an extra unit of irrigation water reflects the WTP of farmer. Analysing this WTP give us the chance to find the right value of water. But caution has to be given as not all of the farmers are participated in the spot water market. The fact that 2 distinct groups of participants and nonparticipants are available, motivate a WTP study by considering the self selection of the participants. The existing water valuation literature is largely ignorant on self-selectivity issues. Self selectivity is an issue which we have recognized in this spot water market and as a contribution, the factors affecting the WTP has been analysed by the Heckman sample selection model with emphasis on the effects of the farmers' decisions to participate in the spot water market. The price which is paid by the farmers is considered as the WTP in this research. In the following section (4.2), the existing literature in this field is selectively reviewed. Subsequently, in section 4.3 the Heckman sample selection model for analysing WTP is developed and adapted to our context. Finally, the results are presented and discussed.

\subsection{Literature Review}

Tsur (2005) and Tsur et al. (2004) present the common approach for defining water value and the water prices for irrigation water pricing mainly for surface water in irrigation networks. The framework which is given in this model is pricing based on marginal costs and value marginal products (VMP). As Boggess et al. (1993) mentioned, the frequently used alternative to estimate the economic value of water in agriculture is the VMP, even though that does not mean that the farmers would actually pay such a price. Jaghdani et al. (2012) have shown that the WTP obtained by direct and indirect valuation methods exhibits substantial differences. As the focus of the present study is the identification and quantification of the WTP through revealed values in spot water market transactions, the literature review mainly focuses on those studies which consider market transactions, direct WTP estimations and the role of self selectivity in value estimations. Interested 
readers are refered to Booker et al. (2012) and Young (2005) for a literature rieview on alternative valuation methods.

Descriptive analysis of the water market in the case of the availability of the market and registered transactions (Libecap, 2010; Donohew, 2009) can provide first insights into the price formation process. Yoskowitz (2002) has found price dispersion and price discrimination within the spot water market for raw water along the lower sections of the Rio Grande in Texas, USA. There existed significant differences between industrials firms, municipalities, and agriculture in terms of prices per acre foot, and these prices did not converge over time in the spot water market. The data, collected over a seven year time period from 1993 to 2000, resulted in 1,330 transactions with more than 813 active water rights. He concluded that different behaviours take place within the market. Firms explicitly discriminate, consumers engage in search and learning for lower purchase prices, and consumers may also pay higher prices over time, possibly due to increased search costs. The extent of the information that the sellers of water have regarding the pricing practices of other sellers is undetermined.

In advanced water markets, when registered data is available, the market analysis can be done with the help of econometric approaches. An example is Brookshire et al. (2004). They analysed the price history of three water markets in Arizona's Central Arizona Project, Colorado's Colorado Big Thompson Project, and New Mexico's Middle Rio Grande Conservancy District in USA. They used water transfers over 11 years and estimated a simultaneous system of market equations, one for price and the other for quantity demanded. Results showed that markets were becoming more efficient in these regions despite the considerable institutional and historical impediments to the evolution of water markets. Alevy et al. (2010) used "framed field experiment" data from an auction to analyse the WTP for irrigation water in spot water market on Limari valley of Chile. According to the Chilean water code, approved in 1981 and modified in 2005, water rights are private, seperate from land holding and tradable. Trade can occur by permanent transfer of rights, long-term leases and spot water market transactions for water used in the current growing season. The researchers surveyed 41 auction participants, who pay for water in genuine spot water market setting. The Tobit model was 
used to estimate the bid function. The results show that the WTP of participants is 68 percent higher than the price paid by the research team to the water authority to acquire water for experiment. These sorts of analysis are limited and almost impossible in the case developing countries without any water market institutions available. Using market transactions which indirectly reflect the value of water is another approach. If the data is available, hedonic analysis is a promisisng approach.

Faux and Perry (1999) applied a hedonic price analysis to agricultural land sales in Treasure Valley, Oregon, in order to estimate the value of water irrigation, using the sales of agricultural property during the years of 1991-1995. There was a total number of 225 properties in the sample. The implicit prices of water, of land, and of other components of the property resources were revealed. The model accounted for heteroskedasticity. Observed differences in the sales prices between the districts was attributed to differences in the quality of soils which was found in the districts.

Mathematical programming and deductive reasoning is often used for scenario establishments and water market policy developments. Michelsen and Young (1993) have developed an integrated hydrologic-economic model system for Northeast Colorado to estimate the economic and hydrologic factors required to calculate option values, as option contracts have the potential to provide secure urban drought water supplies at a lower cost than water right purchases. Brennan (2008) used mathematical modelling to analyse the missing markets for storage and the potential economic costs of expanding the spatial scope of water trade. She concluded that because of poorly defined water rights, the irrigators have no incentives to trade-off the benefits of current uses (or sales) with the value of water storage. Furthermore, she argues that the introduction of clearly defined property rights for storage would allow for the development of a storage market which would then allow for the gains from trade to be achieved in both spatial and temporal dimensions.

Self selectivity has rarely been used in irrigation water valuation studies. Moore et al. (2000) estimated the supply functions for multioutput irrigators in the Pacific Northwest of the USA by using a tobit model in order to analyse the economic welfare of the producers. Farm level survey data $(1986,1990)$ was used for the study. For a particular crop, some 
producers choose to grow the crop while others choose not to grow. Output data of this type generated a censored dependant variable on supply. This experiment predicted increases in the water pumping costs and decreases in the producers' surplus. Mullen et al. (2009) used a Heckman model with a profit function to analyse the demand structure for water and water decision issues for corn, cotton, peanuts and soybeans in Georgia, USA using panel data sets of 1988, 1994, 1998 and 2003 (USDA-Farm and Ranch Survey). Pumping costs were used as a proxy for water prices. The Heckman model, namely crop selection, does not appear to be significantly affected by water-related decisions.

Basarir et al. (2009) analysed producers' willingness to pay for higher quality irrigation water and the factors which influenced it. 130 farmers were surveyed in Turhal and Suluova in Turkey. In these two areas, intensive beef production has caused huge manure management problems. Moreover, the intensive use of fertilizer in agriculture has polluted the groundwater and surface water. The nitrate increase of water has reduced the electric conductivity (EC) of water which has negatively affected the production of beans, strawberries, carrots, onions, etc. As $55 \%$ of the respondents were interested in participating and paying for the quality increase in water, a Heckman selection model and Tobit model were used for the analysis of the hypothetical WTPs of the contingent valuation study (option price approach). They concluded that the Tobit model is a better choice than a Heckman selection model for this study.

Koundouri and Pashardes (2003) considered the simultaneity between hedonic valuation and sample selection in the context of a model of producer behaviour. They demonstrated the self selectivity argument in a model where land close to the seaside was demanded for use as an input either for agriculture production or for touristic development. They considered fresh groundwater quality as an attribute of the land. The factors which affected the price of land were controlled for by considering the selection decision of using land for agriculture if it was far from sea (with good fresh groundwater quality) and for other uses when the land was near to the sea. They used production survey data (1999) from the Island of Kiti in Cyprus (193 observations). The results showed that the econometric estimation, when correcting for sample selection bias, wasn't statistically significant. They argued that the decision to switch to more lucrative uses of land such 
as tourism or industry because of the sea water intrusion to the aquifer did not affect the land price dramatically.

As it is presented above, in spite of the data shortages, economic studies have been done on different aspects of irrigation water demand and water value. As water become scarcer, the demand and valuation studies on different aspects of that are increasing. Self selectivity is an issue which has been reviewed in few studies but the water market participation decision as an influential factor on WTP did not attract attentions.

\subsection{Methodology}

We define the willingness to pay (WTP) for one unit of additional irrigation water in excess of the the available entitlement from groundwater resources as the price paid by the farmer in the spot water market. A bid function framework is applied to analyse the WTP for irrigation water. WTP in the initial model is defined in the same way as in contingent valuation studies. The bid function is mainly used for analysing the bidding price in auctions in order to define the WTP of bidders. It can be used for different price analysis in different areas. Hofler and List (2004) has used bid function with the stochastic frontier to find the hypothetical bias in stated WTP in CVM studies. They have used sealed-bid prices for baseball cards. Crespi and Sexton (2004) have applied the bid function to analyse the bidding price of beef processing plans in Sealed-bid auctions for live cattle in Texas Panhandle, USA. Alevy et al. (2010) have used the bid function to analyse the WTP of farmers who participated in a spot water market auction in Limari valley of Chile.

Base on CVM studies, the analyst can build a bid function as a result of a utility difference problem which has been solved by respondents. A "Constant Only Bid Function Model" (Bateman et al., 2002) can be parameterised as follows:

$$
\ln \left(y_{i}\right)=\beta \ln X_{i}+u_{i} \quad i=1,2, \ldots, n
$$

where $y_{i}$ is the price paid by person $i, X_{i}$ is a row vector of specific bid determining characteristics for person $i$, and $u_{i}$ is the error term. Typically, the variables are transformed 
in to natural logarithms and the model can be estimated using OLS. Difficulties arise because of the structure of the sample which is divided into two groups, one which has paid for additional units of groundwater in a spot water market and the other group for which no transaction is observed. As a result, the model suffers from self selectivity, which can be solved by applying the Heckman model (Heckman, 1976). Heckman's sample selection model can be defined for bid function as the following structured process:

$$
\begin{aligned}
\ln \left(y_{i}^{*}\right) & =\beta^{\prime} \ln \left(X_{i}\right)+u_{i} \\
Z_{i}^{*} & =\alpha^{\prime} W_{i}+v_{i}
\end{aligned}
$$

where $Z_{i}^{*}$ is the realisation of a latent value of the selection of the individual $i$ (participation in water spot market in this case) and $y_{i}^{*}$ is the latent outcome (price paid for irrigation water to the neighbours). $W_{i}$ and $X_{i}$ are explanatory variables for selection and outcome equations respectively. $W_{i}$ and $X_{i}$ may or may not be equal. In field study results we observe:

$$
\begin{aligned}
& Z_{i}=\left\{\begin{array}{llcc}
0 & \text { if } & Z_{i}^{*}<0 & \text { (no participation) } \\
1 & & & \text { (participation) }
\end{array}\right. \\
& y_{i}=\left\{\begin{array}{ccc}
0 & \text { if } & Z_{i}=0 \\
y_{i}^{*} & & \text { otherwise }
\end{array}\right.
\end{aligned}
$$

We observe the WTP of the farmers when they participated in spot water market $\left(Z_{i}^{*}>0\right)$. The observed dependence between $y_{i}$ and $X_{i}$ can be written as:

$$
E\left(\ln (y) \mid X=X_{i}, W=W_{i}, Z=1\right)=\beta^{\prime} \ln \left(X_{i}\right)+E\left(u \mid v \geq-\alpha^{\prime} W_{i}\right)
$$

(source: Toomet and Henningsen (2008, p.8) and Wooldridge (2004, p.561), with modifications). The model can be alternatively presented by bivariate process (Davidson and 
MacKinnon, 2003, p.478):

$$
\left[\begin{array}{c}
\ln \left(y^{*}\right) \\
Z^{*}
\end{array}\right]=\left[\begin{array}{c}
\ln (X) \beta \\
W \alpha
\end{array}\right]+\left[\begin{array}{l}
u \\
v
\end{array}\right]\left[\begin{array}{l}
u \\
v
\end{array}\right] \sim N\left(0,\left[\begin{array}{cc}
\sigma^{2} & \rho \sigma \\
\rho \sigma & 1
\end{array}\right]\right)
$$

As OLS gives biased estimates for the parameters of the above model when $\rho \neq 0$, the following equation can be defined, as proposed by Heckman (1976):

$$
\ln \left(y_{i}\right)=\beta^{\prime} \ln \left(X_{i}\right)+E\left[u \mid \nu \geq-\alpha^{\prime} W_{i}\right]+\eta_{i}=\beta^{\prime} \ln \left(X_{i}\right)+\rho \sigma \lambda\left(\alpha^{\prime} W_{i}\right)+\eta_{i}
$$

where $\lambda()=.\phi(.) / \Phi($.$) is known as inverse mills ratio, \phi\left(\alpha^{\prime} W_{i}\right)$ and $\Phi\left(\alpha^{\prime} W_{i}\right)$ are standard normal probability density and cumulative distribution function, and $\eta$ is a new disturbance term independent of $X$ and $W$ (Davidson and MacKinnon, 2003, p.480). Each observation contributes a factor to the likelihood function for this model which can be written as:

$$
I\left(Z_{i}=0\right) \operatorname{Pr}\left(Z_{i}=0\right)+I\left(Z_{i}=1\right) \operatorname{Pr}\left(Z_{i}=1\right) f\left(\ln \left(y_{i}^{*}\right) \mid Z_{i}=1\right)
$$

where $f\left(\ln \left(y^{*}\right) \mid Z=1\right)$ denotes the density of $\ln \left(y^{*}\right)$ conditioned on $Z=1$. The likelihood function become:

$$
\sum_{Z_{i}=0} \operatorname{Pr}\left(Z_{i}=0\right)+\sum_{Z_{i}=1} \operatorname{Pr}\left(Z_{i}=1\right) f\left(\ln \left(y_{i}^{*}\right) \mid Z_{i}=1\right)
$$

The first term of equation 4.9, which comes from the observations with $Z_{i}=0$, is exactly the same as the corresponding term in probit model. The second term comes from the observations with $Z_{i}=1$ (Davidson and MacKinnon, 2003, p.479). Thus the likelihood function becomes:

$$
\begin{gathered}
\sum_{Z_{i}=0} \log \Phi\left(-\alpha^{\prime} W_{i}\right)+\sum_{Z_{i}=1} \log \left(\frac{1}{\sigma} \phi\left(\left(\ln \left(y_{i}\right)-\ln \left(X_{i}\right) \beta\right) / \sigma\right)\right)+ \\
\sum_{Z_{i}=1} \log \Phi\left(\frac{\left.\alpha^{\prime} W_{i}+\rho\left(\ln \left(y_{i}\right)-\ln \left(X_{i}\right) \beta\right) / \sigma\right)}{\sqrt{1-\rho^{2}}}\right)
\end{gathered}
$$

If $\rho=0, u$ and $\nu$ are not correlated, and the probit function and regression model could 
Table 4.1.: Pumping unit and farm participation in spot water market

\begin{tabular}{|l|c|c|}
\hline & $\begin{array}{c}\text { Number of pumping } \\
\text { units }\end{array}$ & Number of farms \\
\hline Total number in sample & 52 & 157 \\
Availability of spot water market & 41 & 145 \\
Active participation in spot & - & 28 \\
market & & \\
(during 2008) & & \\
\hline
\end{tabular}

Source: Study findings

be estimated separately (Davidson and MacKinnon, 2003, p.479).

\subsection{Study area and data}

As the same survey data as chapter 2 are used here, the details of the study area and data gathering can be reviewed in section 2.3. The observed spot water market and variables which are used in the model are explained below.

The spot water market of the Rafsanjan aquifer is different from formal water markets, as some countries have set water rights and entitlements are clearly defined (Mukherji, 2008, p.1078). The spot water market in Rafsanjan is more similar to Southeast Asia where groundwater markets means the informal arrangements between the owner of the means of irrigation and others who buy water or rent pumps from them in spite of no water rights are separately specified in these countries (Mukherji, 2008, p.1078). Within the Rafsanjan aquifer, some farmers sell their extra water requirements from the same well or neighbouring wells to other neighbours after meeting their own water requirements.

Description of data As a result of heterogeneous water-land ownership of the area, not all farmers located at the 52 pumping units are aware of the existence of the spot water market $^{1}$. We found that spot water markets were operate among those pumping units with many owners, rather than those with a few owners. Table 4.1 shows the number of farms and wells which are considered in the analysis. Importantly, only 4 farms use modern drip irrigation whilst others still apply traditional furrow irrigation systems.

\footnotetext{
${ }^{1}$ Each pumping unit refers to the number of wells which irrigate a specific farm area. There could be one well or many. Usually, a pumping unit has one management pattern for all wells inside that pumping unit and it's water is mixed for irrigation.
} 

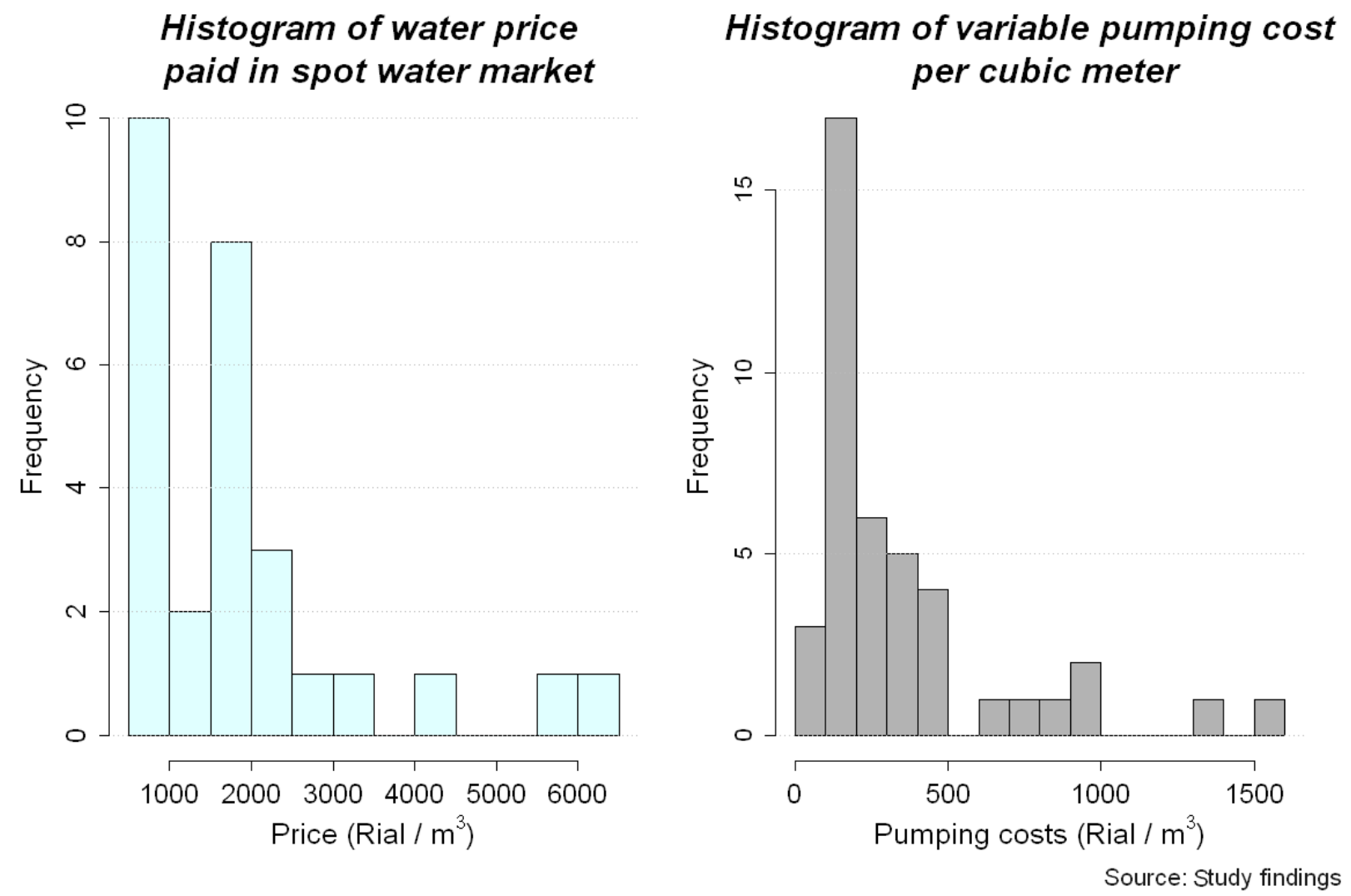

Figure 4.1.: Histogram of the variable pumping costs and the price paid within the spot water market during 2007-2008 agricultural year in the sample of observations

Huge price dispersion is present among those 28 farmers who participate in the spot water market. Figure 4.1 shows the histogram of the variable pumping costs for each cubic meter of extracted groundwater in those pumping units of the participants in the spot water market and the price paid within the spot water market. Figure $4.2^{2}$ shows the spatial distribution of water prices in the aquifer.

Table 4.2 shows a summary of variables used in the establishment of the Heckman model. These variables were selected from many possible variables within the questionnaires based on model selection criteria.

It is worth noting that the water quota of the farm in table 4.2 is calculated as:

WaterFlow $\times 365 \times 24$ Hours $\times 3600$ Second $\times$ FarmerShareFromWell

which is the theoretical volume of water that the framer should receive during one year. The actual water quota is slightly less as there will be a few days during any year when

${ }^{2}$ ggmap and ggplot2 packages in R statistical software have been used to design this plot. 


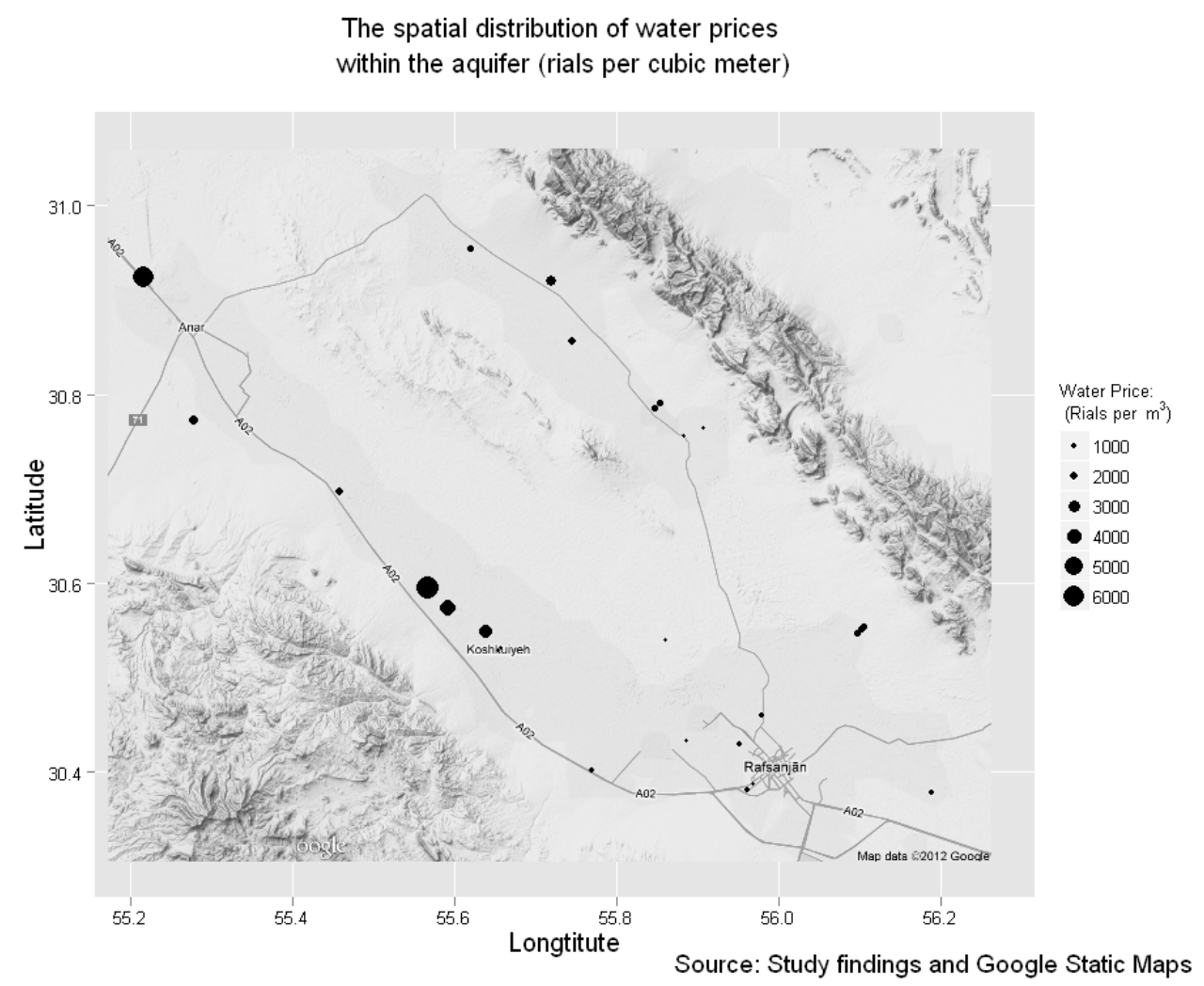

Figure 4.2.: Spatial distribution of water prices (rials $/ \mathrm{m}^{3}$ ) in the aquifer during 2007-2008 agricultural year in the sample of observations

the pump does not work due to faults or rain. The farmer may buy additional water to, or extract surplus water from this amount. Therefore actual water use can differ from the theoretical and actual water quota. However, because farmers consider this theoretical water quota for planning, it explains the model better and is therefore considered as an explanatory variable in the empirical model. 
Table 4.2.: Descriptive summary of variables

\begin{tabular}{lrrrr}
\hline & Means & sd & Max & Min \\
\hline Probit model & & & & \\
\hline Participation in water market (dummy as & 0.19 & 0.40 & 1.00 & 0.00 \\
dependant variable) & & & & \\
Using Other Wells (dummy) & 0.16 & 0.37 & 1.00 & 0.00 \\
Having other jobs (dummy) & 0.38 & 0.49 & 1.00 & 0.00 \\
No of fragmented lands & 3.43 & 2.57 & 15.00 & 1.00 \\
Average age of trees in garden (year) & 25.13 & 8.83 & 65.00 & 4.67 \\
Insuarnce cost (1000 rials) & 2125.52 & 9010.74 & 100000.00 & 0.00 \\
Pistachio production per ha (kg) & 1311.33 & 694.59 & 3453.33 & 0.00 \\
Water quota per ha (cubic meter) & 9902.04 & 4483.32 & 22776.00 & 2463.75 \\
Water level (meter) & 63.05 & 30.50 & 123.47 & 8.11 \\
Share of labor costs from all variable costs & 45.90 & 11.76 & 79.63 & 17.37 \\
EC (mhoS/cm) & 6364.04 & 3753.68 & 17400.00 & 1314.00 \\
pH & 7.58 & 0.39 & 8.60 & 6.70 \\
Number of observations & 145 & & & \\
\hline Regression & & & & \\
\hline Willingness to pay (rials per cubic meter) & 1860.45 & 1417.26 & 6250.00 & 631.31 \\
(dependant variable) & & & & \\
Using Other Wells (dummy) & 0.31 & 0.46 & 1.00 & 0.00 \\
Size of farm (ha) & 4.35 & 5.50 & 21.12 & 0.50 \\
Average age of trees in garden (year) & 21.98 & 9.17 & 35.00 & 4.67 \\
Water quota per ha (cubic meter) & 9487.08 & 4333.62 & 16425.00 & 2737.50 \\
Water level (meter) & 77.19 & 31.39 & 123.47 & 24.23 \\
Pumping cost per cubic meter (rials) & 336.30 & 347.10 & 1502.95 & 75.46 \\
EC (mhoS/cm) & 5458.90 & 2104.17 & 10200.00 & 2480.00 \\
pH & 7.56 & 0.36 & 8.10 & 6.90 \\
Number of observations & 28 & & & \\
\hline & & & & \\
\end{tabular}

Source: Study findings

\subsection{Results}

There are several factors which affect the decision by farmers to buy groundwater and the willingness to pay for extra units of irrigation water. Table 4.3 shows the results of the Heckman regression and probit model. The description and definition of the variables in table 4.3 is given in table 4.2 .

As participation in water markets has been discussed in chapter 3, the focus of this part is the WTP results obtained using the Heckman model. This model can yield much more accurate results due to the availability of more observations (farmers who have partici- 
pated in the water market), but the available results are consistent with the hypothesis. We find a significant $\rho$ in the Heckman model with a negative estimate of -0.73 . This shows that the average WTP of all farmers in the Rafsanjan aquifer is actually much less than those who participated in the spot water market.

The significant and effective variables in the Heckman model are mainly technical. Socioeconomic characteristics of farmers do not affect the model. The variable for pumping costs per cubic meter of water is not significant, but improves the whole model and could not be eliminated. This holds true also for the dummy variable of using other wells. The likelihood ratio test was the model selection criterion.

The results shows that a one percent increase of water quota per hectare reduces the WTP for extra unit of water substantially (-0.7 percent). This is not unexpected because entitlements with water use rights are generally binding for most of the farmers. Results suggest that small-scale farmers who participate in the spot water market tend to pay higher prices than the bigger farms. A one percent water level reduction increases the probability that the farmer will pay higher prices ( 0.4 percent) in the water market, as water is more scarce for them.

As the pumping costs reduces, the farmer participating in water market pays higher prices for extra units. Therefore, if pumping costs stands high because of repairs or bad management, probably the WTP stands at lower level. Increasing in $\mathrm{pH}$ levels of water decreases the WTP for extra water. Although pH level can not change extremely, its change can affect the WTP dramatically.

The unexpected result was the positive elasticity for the older gardens. Based on the probit function, an increase in the average age of the orchards leads to a decreased probability of participating in the water market. However, if the farmer participates, a one percent increase in the average age of garden will increase the WTP elasticity by 0.56 percent.

As pistachio is salt-resistant, an EC up to $8000 \mu \mathrm{S} / \mathrm{cm}$ (Iran Pistachio Association, 2011) does not significantly affect pistachio production. This likely translates also in a highly nonlinear relation between water quality and WTP. Therefore, the EC variable is added to the model in a quadratic way which was found to improve the goodness of fit. It 
is worth noting that these changes in the WTP caused by increased EC levels apply when we have a positive elasticity. It is possible that at lower salinity levels, salinity increases will cause increases in WTP for water.

Moreover, when water is highly saline, farmers have higher WTP, as they require more water to deal with salinity. The results show that WTP elasticity is greater at lower levels of salinity than higher levels. 
Table 4.3.: Heckman model

\begin{tabular}{|c|c|c|c|c|}
\hline & Estimate & Std. Error & Z value & $\operatorname{Pr}(>|z|)$ \\
\hline \multicolumn{5}{|l|}{ Probit model } \\
\hline (Intercept1) & 10.23 & 4.21 & 2.43 & 0.02 \\
\hline Using Other Wells (dummy) & 1.36 & 0.41 & 3.33 & 0.00 \\
\hline Having other jobs (dummy) & 0.64 & 0.29 & 2.22 & 0.03 \\
\hline No of fragmented lands & 0.18 & 0.06 & 3.34 & 0.00 \\
\hline Average age of trees in garden (year) & -0.04 & 0.02 & -2.05 & 0.04 \\
\hline Pistachio production per ha $(\mathrm{kg})$ & 0.0006 & 0.00 & 2.37 & 0.02 \\
\hline Water quota per ha (cubic meter) & -0.0001 & 0.00 & -1.96 & 0.05 \\
\hline Water level (meter) & 0.02 & 0.01 & 3.50 & 0.00 \\
\hline $\begin{array}{l}\text { Share of labor costs from all variable } \\
\text { costs }\end{array}$ & -0.03 & 0.01 & -1.92 & 0.05 \\
\hline $\mathrm{pH}$ & -1.42 & 0.53 & -2.66 & 0.01 \\
\hline$E C / 1000$ & -0.13 & 0.06 & -2.28 & 0.02 \\
\hline Number of observations & 145 & & & \\
\hline \multicolumn{5}{|l|}{ Regression } \\
\hline (Intercept2) & 12.49 & 4.32 & 2.89 & 0.00 \\
\hline Using Other Wells (dummy) & 0.40 & 0.23 & 1.71 & 0.09 \\
\hline $\log ($ Size of farm (ha) $)$ & -0.18 & 0.08 & -2.35 & 0.02 \\
\hline $\begin{array}{l}\log (\text { Average age of trees in garden } \\
\text { (year) ) }\end{array}$ & 0.57 & 0.20 & 2.79 & 0.01 \\
\hline $\log ($ Water quota per ha (cubic meter $)$ ) & -0.72 & 0.29 & -2.49 & 0.01 \\
\hline $\log ($ Water level (meter $))$ & 0.43 & 0.20 & 2.13 & 0.03 \\
\hline $\begin{array}{l}\log (\text { Pumping cost per cubic meter } \\
\text { (Rials)) }\end{array}$ & -0.20 & 0.12 & -1.61 & 0.11 \\
\hline $\log (E C / 1000)$ & 3.55 & 1.64 & 2.17 & 0.03 \\
\hline$(\log (E C / 1000))^{2}$ & -0.76 & 0.50 & -1.53 & 0.13 \\
\hline $\mathrm{pH}$ & -0.59 & 0.31 & -1.88 & 0.06 \\
\hline$\sigma$ & 0.44 & 0.11 & 4.05 & 0.00 \\
\hline$\rho$ & -0.73 & 0.32 & -2.31 & 0.02 \\
\hline Number of observations & 28 & & & \\
\hline Log-Likelihood & & -61.22 & & \\
\hline 145 observations & 117 & censored & 28 & observed \\
\hline
\end{tabular}




\subsection{Discussion and conclusion}

In a scenario where the access to water is regulated by a permanently allocated quota, the WTP of the farmers for additional units of irrigation water varies widely depending on whether farmers are adapted to their quota. In spite of legal restrictions, the availability of spot water market shows that market mechanism is appeared in the study area for groundwater. Although this has happened only among the pumping units with many owners, it shows the potential of water market expansion. The empirical analysis of the decision to participate in a fragmented spot water market and of the price paid in that market showed two distinct groups with totally different WTP for extra water in the study area.

The self selectivity of these two groups could be a methodological issue, neglect of which can affect the results of WTP studies in any direct or indirect approach, and is fundamental to this study. The Heckman selection model shows that the WTP of market participants is much higher than non-participants. This is reflected in the $\rho$ term, which is highly negative and significant in the model. This result confirms Alevy et al. (2010) finding that spot water market participants have higher WTP for irrigation water. Moreover, the price dispersion has been recognised which is consistent with Yoskowitz (2002) findings. Additionally, the high WTP of the participants and the clear difference of that to non-participants shows that in this special case creation of functioning groundwater market can reveal the economic value of water for irrigation activities of water users and may encourage the efficient use of the resource.

The fact that in the Heckman model WTP increases dramatically as water table dropping shows that the scarcity of groundwater become much more sensible issue when market mechanism are available. Using indirect valuation methods can not probably show the scarcity of in situ stock of groundwater in the quota setting condition with the availability of heavy subsidies for pumping energy such as Rafsanjan. It means in a market setting, more clear value is available for water value to users and in situ value of groundwater. The finding show that the higher WTP that small farmers have for extra water can be a signal that the equity and fairness of water market price be a concerning issue. The fact that 
the WTP reduces for larger farmers can be a negative aspect which we have to recognise in the available limited spot water market and in the probable official formal expansion of the groundwater market. It must be added that the possibility of participation in water market is available only among the smallholders at the moment.

The existence of an informal water market reveals that farmers have real WTP for groundwater, and should prompt decision makers to consider legalising water markets for depleting groundwater resources such as in Rafsanjan. The high dispersion of prices paid in this market suggests legalisation of the water market may reduce price dispersion.

In this study we analysed the issue of self selectivity in the farmers' willingness to pay for water in a spot water market, using the real price paid. The significance of the inverse mills ratio coefficient shows that WTP values can not be generalised in settings such as where markets for a resource such as groundwater are poorly developed. The Heckman model helps to find a more realistic picture of willingness to pay values. The low number of observed farmers who are participated in the market is a critical issue for our study as the accuracy of parameters can be questioned. However, this study is one of the rare researches that considers the price in spot water market as WTP and analysed it by self selectivity issue. The study suggests that the promotion of groundwater market could be a way to have a clear picture of the groundwater scarcity in the depleting aquifer such as Rafsanjan.

Further research may focus on the derived demand for water and shadow pricing of the groundwater quota using the Heckman model in the factors analysis when sufficient observations are available. The institutional setting of groundwater market expansion is another potential area for future research. The institutional setting of groundwater market expansion without distorting the available spot water market mechanism can be specifically analysed. Moreover, the change of the WTP of the farmers in the two situation of the availability of official formal groundwater market and informal local spot water market can be of an extra attention. The adoption of new irrigation technology as formal groundwater market expansion can cause, is also an area of research. 


\section{Summary}

Considering water as an "economic good" was a turning point in water management which was proposed by the Dublin Principle in 1992. Water scarcity became recognised as a major problem for living standards of humans and attempts to deal with it from economic and technical points of views became more serious. But past experiences show that surface water received a higher level of attention than groundwater during last years. The fact is that in many arid and semiarid regions, groundwater plays much more important role than surface water. Additionally, agriculture is a major groundwater user in many arid and semiarid areas of the world. Intensive use of groundwater specifically in the agricultural sector has caused the water table to be drawn down worldwide.

However, the economic management of groundwater resources has not been as developed as it has been for surface water or other similar renewable natural resources such as forests or fisheries. The Gisser and Sanchez effect (GSE) is one of the main theoretical and methodological problems for any economic approach of groundwater resources management especially in agriculture. Based on GSE in the long run specifically for large aquifers, the economic gains of optimal control of groundwater resources versus competitive pumping of the resources are negligible. This promotes no economic tool or incentive for controlling the groundwater abstraction. The robustness of the model has been tested in a number of research studies in the last 30 years with the help of numerical methods or mathematical programming and its presence cannot be challenged. Generally speaking, any economic analysis and management of groundwater needs a clear idea of the demand structure. Establishing a demand model that clearly shows the factors affecting groundwater demand is an area of research. The GSE can be tested and analysed in a more advanced manner with the help of identifying the right demand structure. 
This dissertation contributes to the body of literature that defines the empirical demand model for irrigation water from depleting groundwater resources. This research study used field data from the Rafsanjan aquifer in the southeastern part of Iran and used econometric approaches to analyse the demand structure for depleting groundwater resources from different aspects. In order to conduct an effective analysis, the Rafsanjan aquifer was selected for research. This aquifer is an example of large aquifers with depleting characteristics. Rafsanjan is one of the major pistachio production centres of Iran. Pistachio is one of the most highly valued agricultural tree crops and is Iran's major non-oil agricultural export commodity.

In order to achieve the overall research objectives, a rich database has been gathered and aggregated for the study. Two-stage random sampling was conducted for gathering data. For the first stage, the available sample of pumps from the Rafsanjan Irrigation Water Authority was considered since the groundwater quality data was available. For the second stage, some of the water users of each well were selected. A field survey was done during November 2008 - February 2009. Two different questionnaires were used for data gathering. The first stage questionnaire covered the data and information about different technical and economic aspects of the well and pump. The second level questionnaire covered the farm production and cost information of pistachio crop, water ownership, water trade, and household socioeconomic characteristics. 52 pumping unit questionnaires and 157 farmer questionnaires were successfully administered. Additionally, water depth information in observatory wells was gathered from the Rafsanjan Irrigation Water Authority. During the survey, the electricity bill codes of the wells were asked from the respondents, and energy consumption data and costs were found online afterwards. The geographical position of the wells and farms were also defined.

This dissertation poses different questions that were analysed in three different essays. The first essay covered in chapter 2 is a factor demand analysis with the help of a translog cost function. The estimation was done by a seemingly unrelated regression (SUR). As the translog cost function and its Shephard's lemma equation should be estimated 
simultaneously, SUR was applied. In this essay, the water demand elasticity is calculated with the help of a restricted cost function. Additionally, the elasticities were calculated for other variable inputs such as fertilizer-manure-sand, pesticide, labor and machine prices. An aggregated price index was developed for each input category, as many different prices were available for the inputs and farmers were using different brands at the same time. Additionally, shadow prices of water quotas as a quasi-fixed factor was calculated. Moreover, the water depth was considered as a cumulative representative index of an in situ quantity of groundwater stock. The same thing was done with electric conductivity (EC) as an in situ quality index. The number of trees per farm and a well repositioning capital index were considered in the model as quasi-fixed factors.

As a contribution to empirical groundwater demand studies, spatial econometrics was used to correct the presence of spatial autocorrelation in the translog cost equation and water demand equations. In turn, the Kelijan-Prucha GM approach was used. The results show that the groundwater demand is extremely inelastic to changes in water prices due to mainly pumping costs. The water depth as the in situ quantity index variable is insignificant and does not improve the model. The shadow price of water quota estimated by SUR and its spatially corrected model do not show a positive value for the majority of observations. This result was not expected as groundwater is the only source of water in the area. Additionally, the shadow price for the cumulative index of the in situ quality variable of the reservoir (EC) has shown a negative value for a lower level of EC and a positive value for a higher level of EC in the SUR model. This is expected, but when this model is corrected, the positive value disappeared from the model even at higher levels of EC.

The second essay covered in chapter 3 is participatory study with the help of a logit model. In this section, the factors that affect farmers' decision to participate in available spot water markets in Rafsanjan were analysed. In the areas where pumps are owned by many people, 28 farmers among 145 farmers participated in the spot water market during the agricultural year 2007-08. Although a formal water market is not available in Iran and selling water is not legally accepted, neighbouring farms in the pumping units owned by many farmers trade groundwater with each other. The results shows that technical 
factors such as water quota per hectare, tree age, pistachio production per hectare, water depth, number of fragmented pieces of land, share of labor cost from total variable costs are significant factors in decision making with different scales.

The third essay covered in chapter 4 is motivated by the second essay. As the price paid by the farmers in the spot water market was asked during the survey, a Heckman sample selection model was applied to analyse the effect of self-selectivity on willingness to pay for extra units of irrigation water. The results show that the WTP is affected significantly and heavily by the participation decision, and WTP is much lower than those prices found in spot water market. Two distinct groups with totally different WTP were recognised in the sample. Additionally, the sample data had extreme price dispersion.

Data gathering for the groundwater analysis is one of the main barriers for detailed and accurate studies of groundwater economics. Since pumps are dispersed through the aquifer, finding the right person for surveying is costly and time consuming. In this study, we had the advantage that farm and pump level data could be gathered in a field survey. Using farm level data with technical hydrogeological data at the same time provides the opportunity to look deeper into to the issue of water demand of depleting groundwater stock. Also, using different statistical tools allowed us to look into different aspects of data not very common in analyses of groundwater economics. Using spatial econometrics to test and correct the model was a big advantage in this study. The field survey gave us the chance to see the hidden social and economic aspects of groundwater demand not achievable through secondary data analysis or modelling approaches. Although the three essays can be reviewed separately, they may explain some aspects of water demand when reviewed together.

The results of the first essay show that the GSE is present in this aquifer. Its quota setting structure and heavy subsidies given for pumping energy are the main factors for that. The negative shadow prices for water quota found in this study encouraged us to analyse the data to define the reason. One explanation for this is that many farms in the sample actually have enough water from their quota and at times, even more than average. The tragedy of commons for the aquifer and competition to pump water up to the level of 
quota and beyond were also issues. But as many pistachio orchards are old and adapted to their historical water quotas, we could not find the positive shadow price for extra units of water with a restricted cost function. Availability of spot water markets and its participation of minor farmer groups show two distinct groups with different willingness to pay exist in the sample. This can be an explanation for the negative shadow prices we found. Analysis of the price paid in this market shows that the WTP of participants is very high, and factors that should be irrelevant to prices are actually effective. For instance, the insignificance of water depth in the factor demand analysis became an influential factor on WTP in the spot water market. The results of WTP study cannot reject the first essay's major conclusion that the GSE is available but it can explain that with the expansion of the groundwater market, different aspects of groundwater (e.g. in situ value and user shadow prices) would be entirely different.

Although the primary dynamic optimisation models argued that water market expansion would not affect the GSE, an empirical test of an established formal water market may show other results. The availability of a spot water market in spite of common property laws and regulation shows that an area has the potential for a water market to expand.

It must be added that the government's unsuccessful attempt to eliminate heavy subsidies for pumping energy in 2010-2011, shows that large scale changes in energy prices as a groundwater management approach is unrealistic. Also, pistachio producers are strong lobbyists. Therefore, a tax based on shadow prices for groundwater may not be a realistic solution. The inelastic demand for groundwater tells us that even possible implementation of real prices of pumping energy may not help the reduction of water use. Therefore, considering the availability of spot water markets and the pistachio producers' worries about the future of their aquifer can encourage other approaches. Participatory approach for managing the aquifer or the expansion of groundwater market are two possible solutions to the current problem.

One of drawbacks of this study is the data structure. The fact that we do not have many observations of water market participants compared to nonparticipant in the water market has prevented us from doing a switching factor demand analysis to find different 
shadow prices for both groups. The idea of using dynamic factor demand analysis for the investment and capital stock found for repositioning wells could be implemented. This would depend on whether enough observations of repositioned wells in the same year were available. These are two issues that can be considered for further research.

Future research in the area of empirical analyses of groundwater demand can be done by considering the switching model mentioned above and by gathering the data for dynamic factor analysis. Groundwater market expansion while considering the available setting in informal spot water markets is another area of research. In the case of data availability, performing the factor analysis with the help of spatial panel econometrics can be of interest. The GSE is an issue that must be addressed. Empirical studies such as this one have the chance to describe the different aspects of water demand and in turn, the possible solutions for better economic management of water resources. 


\section{Bibliography}

Abdolahi-Ezzatabadi, M. (2008). The role of inconsistent policies in unsustainable pistachio production development base on water resources. Agricultural Economics and Development, (63):117-137. (in Persian).

Abdolahi-Ezzatabadi, M. and Soltani, G. R. (1996). Calculating external costs of groundwater over drafting: A case study of Rafsanjan town. Iranian Journal of Agricultural Sciences, (30):35-44. (in Persian).

Abtahi, S. M. (1998). Rafsanjan Economic History. Tavakol Rafsanjan, 1 edition. (in Persian).

Abtahi, S. M. (2006). Economics of Pistachio. Farzaneh Publication, Tehran with the cooperation of Mafragh Cultural Foundation, Kerman, Iran, 1 edition. (in Persian).

Alevy, J. E., Cristi, O., and Melo, O. (2010). Right-to-choose auctions: A field study of water markets in the limari valley of chile. Agricultural and Resource Economics Review, 39(2).

Almasvandi, A. (2010). 16th provincial sitting of manager and deputies of Iran Water Resources Management Company in Zanjan Water Authority, Zanjan, Iran. accessed September 24, 2010, http://www.wnn.ir/html/index.php?name=News\&file= article\&sid=9030. (in Persian).

Arrow, K., Dasgupta, P., and Mäler, K.-G. (2003). Evaluating projects and assessing sustainable development in imperfect economies. Environmental and Resource Economics, 26:647-685. 10.1023/B:EARE.0000007353.78828.98.

Asadi, H., Soltani, G. R., and Torkamani, J. (2007). Irrigation water pricing in Iran: a case study on land downstream of Taleghan dam. Agricultural Economics and Development, (58):61-90. (in Persian). 
Assadollahi, S. A. (2010). Groundwater resources management in iran. Technical papers, Technical papers included in the special session on groundwater in the 5th Asian Regional Conference of INCID, Vigyan Bhawan, New Delhy, December 9-11, 2009.

Banki (2011). Different interest rates of banks and financial institutions in iran (short run and long run). accessed December 21, 2011, http://banki.ir/sood. (in Persian).

Basarir, A., Sayili, M., and Muhammad, S. (2009). Analyzing producers' willingness to pay for high quality irrigation water. Bulgarian Journal of Agricultural Science, 15(6):566-573.

Bateman, I. J., Carson, R. T., Day, B., Hanemann, M., Hanley, N., Hett, T., Lee, M. J., Loomes, G., Mourato, S., Özdemiroglu, E., Pearce, D. W., Sugden, R., and Swanson, J. (2002). Economic Valuation with Stated Preference Techniques (In Association with the UK Department for Transport). Edward Elgar Pub, Cheltenham, UK and Northampton, MA, USA.

Behzad, M. (2010). Support for agriculture and industry by electricity tariffs announcement. accessed March 15, 2011, http://news.tavanir.org.ir/press/print.php? id=20361. (in Persian).

Berndt, E. R. (1996). The Practice of Econometrics: Classic and Contemporary. Addison Wesley, har/dskt edition.

Birol, E., Karousakis, K., and Koundouri, P. (2006). Using economic valuation techniques to inform water resources management: a survey and critical appraisal of available techniques and an application. Science of The Total Environment, 365(1-3):105 122. Monitoring and modelling the impacts of global change on European freshwater ecosystems.

Bivand, R. (2006). Implementing spatial data analysis software tools in r. Geographical Analysis, 38(1):23-40.

Björklund, G., Burke, J., Foster, S., Rast, W., Vallée, D., van der Hoek, W., Bernardini, F., Cleveringa, R., Cohen, A., Faurés, J.-M., Koo-Oshima, S., Kuonqui, C., Mutandi, R., Stracasto, L., Le-Huu, T., and Winpenny, J. (2009). Impacts of water use on water systems and the environment. In United Nations World Water Assessment Program, editor, The United Nations World Water Development Report 3: Water in a Changing 
World, chapter 8, pages 127-149. Earthscan Publications Ltd., pap/cdr edition.

Boggess, W., Lacewell, R., and Zilberman, D. (1993). The economics of water use in agriculture. In Carlson, G. A., Zilberman, D., and Miranowski, J. A., editors, Agricultural and Environmental Resource Economics (Biological Resource Management). Oxford University Press, New York, USA.

Boland, M. A. and Marsh, T. L. (2006). Input quality in the sugar beet industry. Journal of Agricultural and Resource Economics, 31(01):114-128.

Booker, J. F., Howitt, R. E., Michelsen, A. M., and Young, R. A. (2012). Economics and the modeling of water resources and policies. Natural Resource Modeling, 25(1):168-218.

Brennan, D. (2008). Missing markets for storage and the potential economic cost of expanding the spatial scope of water trade. Australian Journal of Agricultural and Resource Economics, 52(4):471-485.

Brooks, D. B. (2006). An operational definition of water demand management. International Journal of Water Resources Development, 22:521-528(8).

Brookshire, D. S., Colby, B., Ewers, M., and Ganderton, P. T. (2004). Market prices for water in the semiarid west of the united states. Water Resources Research, 40:W09S04.

Brown, G. M. (2000). Renewable natural resource management and use without markets. Journal of Economic Literature, 38(4):875-914.

Brozovic, N., Sunding, D., and Zilberman, D. (2006). Optimal management of groundwater over space and time. In Zilberman, D., Goetz, R.-U., and Berga, D., editors, Frontiers in Water Resource Economics, volume 29 of Natural resource management and policy, pages 109-135. Springer US.

Bureau of Technical Execution System (2011). The guideline for economic analysis of water resources development projects (first revision). Guideline 365-A, Islamic Republic of Iran, Vice Presidency For Strategic Planning and Supervision. (in persin).

Burke, J. (2003). Groundwater for irrigation: productivity gains and the need to manage hydro-environmental risk. In Llamas, M. R. and Custodio, E., editors, Intensive Use of Groundwater:Challenges and Opportunities, chapter 3, pages 59-80. Taylor \& Francis.

Calatrava, J. and Garrido, A. (2005). Spot water markets and risk in water supply. Agricultural Economics, 33(2):131-143. 
Central Bank of the Iran (2011). Consumer price index for all urban consumers (base year 2004). accessed November 4, 2011, http://www.cbi.ir/page/8110.aspx. (in Persian)

Cohen, J. P. and Paul, C. M. (2007). The impacts of transportation infrastructure on property values: A higher-order spatial econometrics approach. Journal of Regional Science, 47(3):457-478.

Crespi, J. M. and Sexton, R. J. (2004). Bidding for cattle in the texas panhandle. American Journal of Agricultural Economics, 86(3):660-674.

Davidson, R. and MacKinnon, J. G. (2003). Econometric Theory and Methods International Edition. Oxford University Press, USA, international ed edition.

Deepak, S., Chandrakanth, M., and Nagaraj, N. (2005). Groundwater markets and water use efficiency: The case of karnataka. Water Policy Research Highlights 43633, International Water Management Institute.

Department of the Treasury (1990). Depreciation of fruit and nut trees. Report to congress, Department of the Treasury.

Diewert, W. and Lawrence, D. (2001). Progress in measuring the price and quantity of capital. In Lawrence, J. L., editor, Econometrics and the Cost of Capital: Essays in Honor of Dale W. Jorgenson, volume 2, pages 273-326. Cambridge MA: The MIT Press.

Diewert, W. E. (1981). The economic theory of index numbers: A survey. In Deaton, A., editor, Essays in the theory and measurement of consumer behaviour. Cambridge University Press.

Diewert, W. E. and Wales, T. J. (1987). Flexible functional forms and global curvature conditions. Econometrica, 55(1):43-68.

Dinar, A. and Letey, J. (1991). Agricultural water marketing, allocative efficiency, and drainage reduction. Journal of Environmental Economics and Management, 20(3):210223.

Directive 2000/60/EC of the European Parliament and of the Council (2000). Water framework directive (wfd). Act L 327/1, European Parliament and Council.

Dobson, A. J. (2001). An Introduction to Generalized Linear Models, Second Edition. 
Chapman and Hall/CRC, 2 edition.

Donohew, Z. (2009). Property rights and western united states water markets*. Australian Journal of Agricultural and Resource Economics, 53(1):85-103.

Economic Research Service (ERS), USDA (2011). Fruit and tree nuts outlook (newsletter). Online. FTS-349.

Faux, J. and Perry, G. M. (1999). Estimating irrigation water value using hedonic price analysis: A case study in malheur county, oregon. Land Economics, 75(3):440-452.

Ferguson, L., Polito, V., and Kallsen, C. (2005). The pistachio tree; botany and physiology and factors that affect yield. In Ferguson, L., editor, Pistachio Production Manual, pages 31-39. University California Cooperative Extension, 4 edition.

Fraiture, C. d. and Perry, C. (2007). Why is agricultural water demand unresponsive at low price ranges? In Molle, F. and Berkoff, J., editors, Irrigation Water Pricing: The Gap Between Theory and Practice, 4, chapter 3, pages 94-107. CABI, 1 edition.

Fujita, K. and Hossain, F. (1995). Role of the groundwater market in agricultural development and income distribution: A case study in a northwest bangladesh village. The Developing Economies, 33(4):460-463.

Garrido, A. and Livingston, M. L. (2003). Economic and financial perspectives on intensive groundwater use. In Llamas, M. R. and Custodio, E., editors, Intensive Use of Groundwater:Challenges and Opportunities, chapter 10, pages 207-225. Taylor \& Francis.

Gisser, M. (1983). Groundwater: Focusing on the real issue. Journal of Political Economy, 91(6):1001-27.

Gisser, M. and Sánchez, D. A. (1980). Competition versus optimal control in groundwater pumping. Water Resour. Res., 16(4):638-642.

Guyomard, H. and Vermersch, D. (1989). Derivation of long-run factor demands from short-run responses. Agricultural Economics, 3(3):213 - 230.

Hadjigeorgalis, E. (2008). Managing drought through water markets: Farmer preferences in the rio grande basin1. JAWRA Journal of the American Water Resources Association, 44(3):594-605.

Halvorsen, R. and Smith, T. R. (1991). A test of the theory of exhaustible resources. The 
Quarterly Journal of Economics, 106(1):123-40.

Hanemann, W. M. (2006). The economic conception of water. In Rogers, P. P., Llamas, M. R., and Cortina, L. M., editors, Water Crisis: Myth or Reality? (Balkema: Proceedings and Monographs in Engineering, Water and Earth Sciences), pages 61-91. Taylor \& Francis, London, UK, 1 edition.

Heckman, J. J. (1976). The common structure of statistical models of truncation, sample selection and limited dependent variables and a simple estimator for such models. In Annals of Economic and Social Measurement, Volume 5, number 4, pages 120-137. National Bureau of Economic Research, Inc.

Hellegers, P., Perry, C., and Berkoff, J. (2007). Water pricing in haryana, india. In Molle, F. and Berkoff, J., editors, Irrigation Water Pricing: The Gap Between Theory and Practice, 4, chapter 8, pages 262-276. CABI, 1 edition.

Hellegers, P., Zilberman, D., and van Ierland, E. (2001). Dynamics of agricultural groundwater extraction. Ecological Economics, 37(2):303 - 311.

Henningsen, A. and Hamann, J. D. (2007). systemfit: A package for estimating systems of simultaneous equations in r. Journal of Statistical Software, 23(4):1-40.

Hofler, R. A. and List, J. A. (2004). Valuation on the frontier: calibrating actual and hypothetical statements of value. American Journal of Agricultural Economics, 86(1):213 $-221$.

Howe, C. W. (2002). Policy issues and institutional impediments in the management of groundwater: Lessons from case studies. Environment and Development Economics, $7(04): 625-641$.

ICWE (1992). The dublin statement and report of the conference. accessed November 27, 2011, http://www.wmo. int/pages/prog/hwrp/documents/english/icwedece.html. International Conference on Water and the Environment: Development Issues for the 21st century.

Iran Pistachio Association (2011). Pistachio Plantation and Production Guideline. accessed November 04 2011, http://www.pistachioassociation.com/fa/documents/ 0.global/0.rahnama-dasht-negahdari.pdf. (in Persian).

Jaghdani, T. J., Brümmer, B., and Barkmann, J. (2012). Comparison of methods for the 
valuation of irrigation water: Case study from qazvin, iran. Irrigation and Drainage, $61(3): 375-385$.

Jamab (2004). Compatibility to arid and semi arid climate studies. Report, Jamab Consulting Engineers Company. (in Persian).

Jaroslav, V. and Annukka, L. (2007). Groundwater resources sustainability indicators. IHP-VI Series on Groundwater 14, UNESCO.

Johansson, R. C. (2000). Pricing irrigation water : a literature survey. Policy Research Working Paper Series 2449, The World Bank.

Johansson, R. C. (2005). Micro and macro-level approaches for assessing the value of irrigation water. Policy Research Working Paper Series 3778, The World Bank, Washington, DC, USA.

Johansson, R. C., Tsur, Y., Roe, T. L., Doukkali, R., and Dinar, A. (2002). Pricing irrigation water: a review of theory and practice. Water Policy, 4(2):173 - 199.

Kan, I., Schwabe, K. A., and Knapp, K. C. (2002). Microeconomics of irrigation with saline water. Journal of Agricultural and Resource Economics, 27(01).

Kanazawa, M. T. (1992). Econometric estimation of groundwater pumping costs: a simultaneous equations approach. Water Resources Research, 28(6):1507-1516.

Karakaya, M. (2009). An overview to accounting applications on agricultural activities in turkey within historical progress. African Journal of Business Management, 3(7):294304.

Kawab (2002). Rafsanjan water balance studies. Report, Kawab Consulting Engineers Company. (in Persian).

Kelejian, H. H. and Prucha, I. R. (1999). A generalized moments estimator for the autoregressive parameter in a spatial model. International Economic Review, 40(2):50933.

Kelejian, H. H. and Prucha, I. R. (2004). Estimation of simultaneous systems of spatially interrelated cross sectional equations. Journal of Econometrics, 118(1-2):27 - 50. Contributions to econometrics, time series analysis, and systems identification: a Festschrift in honor of Manfred Deistler.

Kelejian, H. H. and Robinson, D. P. (1992). Spatial autocorrelation : A new computation- 
ally simple test with an application to per capita county police expenditures. Regional Science and Urban Economics, 22(3):317-331.

Kerman Agrijahad Organization (2012). Statistics. accessed November 16, 2012, http: //www.agrijahad.kr.ir/. (in Persian).

Khalilian, S. (2011). Good news of agricultural ministry. accessed November 8, 2011, http://www.javanonline.ir/vdcenp8evjh8e7i.b9bj.html. (in Persian).

Khalilian, S. and Mehrjardi, Z. (2005). Groundwater Valuation in Agriculture (A case study of Kerman County Wheat Producers). Agricultural Economics and Development, (51):1-14. (in Persian).

Knapp, K. C. and Baerenklau, K. A. (2006). Groundwater quantity and quality management: agricultural production and aquifer salinization over long time scales. Journal of Agricultural and Resource Economics, 31(03):616-641.

Knapp, K. C. and Dinar, A. (1988). Production with optimum irrigation management under saline conditions. Engineering Costs and Production Economics, 14(1):41-46.

Koundouri, P. (2004a). Potential for groundwater management: Gisser-Sanchez effect reconsidered. Water Resources Research, 40(6):W06S16.

Koundouri, P. (2004b). Current issues in the economics of groundwater resource management. Journal of Economic Surveys, 18(5):703-740.

Koundouri, P. and Pashardes, P. (2003). Hedonic price analysis and selectivity bias. Environmental and Resource Economics, 26(1):45-56.

Koundouri, P. and Xepapadeas, A. (2004). Estimating accounting prices for common pool natural resources: a distance function approach. Water Resources Research, 40(6):W06S17.

KRW (2009). Kerman Provincial Rainfal Report 2009. accessed November 4, 2011, http://krrw.kr.ir/images/upload/barandegi.doc. (in Persian).

Lapp, J. S. and Smith, V. H. (1992). Aggregate Sources of Relative Price Variability Among Agricultural Commodities. American Journal of Agricultural Economics, 74:19.

Libecap, G. D. (2009). The tragedy of the commons: property rights and markets as solutions to resource and environmental problems. Australian Journal of Agricultural 
and Resource Economics, 53(1):129-144.

Libecap, G. D. (2010). Water rights and markets in the u.s. semi arid west: Efficiency and equity issues. ICER Working Papers 30-2010, ICER - International Centre for Economic Research.

Majlis of Iran (1983). Fair distribution of water. Act 22/17335, Approved by Islamic Consultative Assembely, Ratified by Gurdian Council of Constitution of Iran. (in Persian).

Majlis of Iran (1988). The direct tax act. Act 12583, Approved by Islamic Consultative Assembely, Ratified by Gurdian Council of Constitution of Iran. (in Persian).

Manjunatha, A., Speelman, S., Van Huylenbroeck, G., and Chandrakanth, M. (2009). Impact of groundwater markets in peninsular india on water use efficiency: A data envelopment analysis approach. Contributed Paper 242, International Association of Agricultural Economists Conference, Beijing, China.

Michelsen, A. M. and Young, R. A. (1993). Optioning agricultural water rights for urban water supplies during drought. American Journal of Agricultural Economics, 75(4):1010-1020.

Mirzaei-Khallilabadi, H. and Chizari, A. H. (2004). Determination of irrigation water consumption in pistachio production (a case study of rafsanjan province). Pajouhesh E Sazandegi, (62):43-49. (in Persian).

Molle, F. and Berkoff, J. (2007). Irrigation Water Pricing: The Gap Between Theory and Practice: Comprehensive Assessment of Water Management in Agriculture. 4. CABI, 1st edition.

Moore, M. R., Gollehon, N. R., and Carey, M. B. (1994). Alternative models of input allocation in multicrop systems: irrigation water in the central plains, United States. Agricultural Economics, 11(2-3):143-158.

Moore, M. R., Gollehon, N. R., and Hellerstein, D. (2000). Estimating producer's surplus with the censored regression model: An application to producers affected by columbia river basin salmon recovery. Journal of Agricultural and Resource Economics, 25(02).

Morrison, C. (1988). Quasi-fixed inputs in u.s. and japanese manufacturing: a generalized leontief restricted cost function approach. The Review of Economics and Statistics, $70(2): 275-287$. 
Morrison, C. J. and Siegel, D. (1997). External capital factors and increasing returns in u.s. manufacturing. The Review of Economics and Statistics, 79(4):647-654.

Motagh, M., Thomas Walter, R., Sharifi, M. A., Fielding, E., Schenk, A., Anderssohn, J., and Zschau, J. (2008). Land subsidence in Iran caused by widespread water reservoir overexploitation. Geophysical Research Letters, 35(L16403).

Mukherji, A. (2008). Spatio-temporal analysis of markets for groundwater irrigation services in india: 1976 -1977 to 1997-1998. Hydrogeology Journal, 16:1077-1087. 10.1007/s10040-008-0287-0.

Mullen, J. D., Yu, Y., and Hoogenboom, G. (2009). Estimating the demand for irrigation water in a humid climate: A case study from the southeastern united states. Agricultural Water Management, 96(10):1421-1428.

Nieswiadomy, M. (1985). The demand for irrigation water in the high plains of Texas, 1957-80. American Journal of Agricultural Economics, 67(3):619-626.

Nieswiadomy, M. L. (1988). Input substitution in irrigation agriculture in the high plains of Texas, 1970-80. Western Journal of Agricultural Economics, 13(01).

Nikbakht, M. A. (2011). Agricultural electricity tariffs announcement. accessed March 15, 2011, http://www.rajanews.com/PrintFriendly.asp?id=77342. (in Persian).

NKEPD Co. (2011). North kerman electrical power distribution company electricity tariffs. accessed November 4, 2011, http://www.nked.co.ir/index.php?option=com_ content\&view=article\&id=13\&Itemid=17\&lang=fa. (in Persian).

Ogg, C. W. and Gollehon, N. R. (1989). Western irrigation response to pumping costs: a water demand analysis using climatic regions. Water Resources Research, 25:767-773.

Pindyck, R. S. and Rotemberg, J. J. (1983). Dynamic factor demands and the effects of energy price shocks. American Economic Review, 73(5):1066-79.

Plummer, J. (2008). Introducing water and corruption. In International, T., editor, In Global Corruption Report 2008. Corruption in the Water Sector, chapter 1, pages 3-15. New York: Cambridge University Press.

Pope, R. D. and Chambers, R. G. (1989). Price aggregation when price-taking firms' prices vary. Review of Economic Studies, 56(2):297-309.

Pritchett, J., Thorvaldson, J., and Frasier, M. (2008). Water as a crop: Limited irrigation 
and water leasing in colorado. Review of Agricultural Economics, 30(3):435-444.

Provencher, B. and Burt, O. (1994). A private property rights regime for the commons: The case for groundwater. American Journal of Agricultural Economics, 76(4):875-888.

Ranjan, R., Gollehon, N. R., and Aillery, M. P. (2004). Explaining participation in spot and options markets for water. Working Papers 15650, University of Florida, International Agricultural Trade and Policy Center.

Rauscher, M. (2007). Dynamics of agricultural groundwater extraction: Comment and correction. Ecological Economics, 61(1):11 - 14 .

Renzetti, S. (1992). Estimating the structure of industrial water demands: the case of canadian manufacturing. Land Economics, 68(4):pp. 396-404.

Rey, S. J. and Boarnet, M. G. (2004). A taxonomy of spatial econometric models for simultaneous equations systems. In Anselin, L., Florax, R. J., and Rey, S. J., editors, Advances in Spatial Econometrics: Methodology, Tools and Applications. Springer, 1 edition.

Rigby, D., Alcon, F., and Burton, M. (2010). Supply uncertainty and the economic value of irrigation water. European Review of Agricultural Economics, 37(1):97-117.

Rogers, P., Silva, R. D., and Bhatia, R. (2002). Water is an economic good: How to use prices to promote equity, efficiency, and sustainability. Water Policy, 4(1):1-17.

Roseta-Palma, C. (2002). Groundwater management when water quality is endogenous. Journal of Environmental Economics and Management, 44(1):93 - 105.

Sabohi, M., Soltani, G. R., and Zibaie, M. (2007). Evaluation of the strategies for groundwater resources management: a case study in Narimani plain, Khorasan Province. The Journal of Science and Technology of Agriculture and Natural Resources, 11(1):475-484. [in Persian].

Sampath, R. K. (1992). Issues in irrigation pricing in developing countries. World Development, 20(7):967-977.

Savenije, H. and van der Zaag, P. (2002). Water as an economic good and demand management paradigms with pitfalls. Water International, 27(1):98-104.

Schlager, E. and Ostrom, E. (1992). Property-Rights Regimes and Natural Resources: A Conceptual Analysis. Land Economics, 68(3). 
Schoengold, K., Sunding, D. L., and Moreno, G. (2006). Price elasticity reconsidered: Panel estimation of an agricultural water demand function. Water Resources Research, 42(9):W09411.

Shah, T., Bhatt, S., Shah, R., and Talati, J. (2008). Groundwater governance through electricity supply management: Assessing an innovative intervention in gujarat, western india. Agricultural Water Management, 95(11):1233-1242.

Shah, T., Burke, J., Villholth, K., Angelica, M., Custodio, E., Daibes, F., Hoogesteger, J., Giordano, M., Girman, J., van der Gun, J., Kendy, E., Kijne, J., Llamas, R., Masiyandama, M., Margat, J., Marin, L., Peck, J., Rozelle, S., Sharma, B., Vincent, L., and Wang, J. (2007). Groundwater: a global assessment of scale and significance. In Molden, D., editor, Water for Food, Water for Life, chapter 10, pages 395-423. Earthscan Publications Ltd., illustrated edition.

Shajari, S., Barikani, E., and Amjadi, A. (2009). Management of water demand by water pricing in date groves of Jahrom County. Agricultural Economics and Development, (65). (in Persian).

Sharma, P. and Sharma, R. (2006). Factors determining farmers' decision for buying irrigation water: Study of groundwater markets in rajasthan. Agricultural Economics Research Review, 19(1):39-56.

Shaw, W. D. (2005). Water Resource Economics And Policy: An Introduction. Edward Elgar Publishing.

Siebert, S., Burke, J., Faures, J. M., Frenken, K., Hoogeveen, J., Döll, P., and Portmann, F. T. (2010). Groundwater use for irrigation - a global inventory. Hydrology and Earth System Sciences, 14(10):1863-1880.

Statistical Center of Iran (2008). Kerman annual statistical book 2008. accessed November 16, 2012, http: //amar.org.ir/Default. aspx?tabid=667\&fid=7666. (in Persian).

Tardieu, H. and Prefol, B. (2002). Full cost or sustainability cost pricing in irrigated agriculture. Charging for water can be effective but is it sufficient? Irrigation and Drainage, 51(2):97-107.

Theesfeld, I. (2010). Institutional challenges for national groundwater governance: policies and issues. Ground Water, 48(1):131-142. 
Tisdell, J. G. (2001). The environmental impact of water markets: An australian casestudy. Journal of Environmental Management, 62(1):113 - 120.

Toomet, O. and Henningsen, A. (2008). Sample selection models in r: Package sampleselection. Journal of Statistical Software, 27(7):1-23.

Tsur, Y. (2005). Economic aspects of irrigation water pricing. Canadian Water Resources Journal, 30(1):31-46.

Tsur, Y. and Dinar, A. (1997). The relative efficiency and implementation costs of alternative methods for pricing irrigation water. World Bank Economic Review, 11(2):243-62.

Tsur, Y., Dinar, A., Doukkali, R. M., and Roe, T. (2004). Irrigation water pricing: policy implications based on international comparison. Environment and Development Economics, 9(06):735-755.

Turner, K., Georgiou, S., Clark, R., Brouwer, R., and Burke, J. (2004). Economic valuation of water resources in agriculture : from the sectoral to a functional perspective of natural resource management / by Kerry Turner ... [et al.]. Food and Agriculture Organization of the United Nations, Rome.

UNICEF (1998). The Sixth Annual World Water Day. accessed September 24, 2010, http://www . worldwaterday . org/wwday/1998.

UNWWAP (2009). The United Nations World Water Development Report 3: Water in a Changing World. Earthscan Publications Ltd., pap/cdr edition.

Verba, J. (2003). The impact of aquifer intensive use on groundwater quality. In Llamas, M. R. and Custodio, E., editors, Intensive Use of Groundwater:Challenges and Opportunities, pages 113-132. Taylor \& Francis.

Wheeler, S., Bjornlund, H., Shanahan, M., and Zuo, A. (2009). Who trades water allocations? evidence of the characteristics of early adopters in the goulburn-murray irrigation district, australia 1998-1999*. Agricultural Economics, 40(6):631-643.

Wilson, P. N. (1997). Economic discovery in federally supported irrigation districts: a tribute to William E. Martin and friends. Journal of Agricultural and Resource Economics, 22(01):61-77.

Wooldridge, J. M. (2004). Introductory Econometrics: A Modern Approach (International Edition). Thomson Learning, 2nd edition. 
WRS (2011). Summary of kerman province groundwater resources 2011. accessed November 16, 2012, http://wrs.wrm.ir/tolidat/ab-zirzamini-4.asp. (in Persian).

Xepapadeas, A. and Koundouri, P. (2004). Introduction to special section on groundwater economics and policy. Water Resources Research, 40(6):W06S15.

Yoskowitz, D. (2002). Price dispersion and price discrimination: Empirical evidence from a spot market for water. Review of Industrial Organization, 20(3):283-289.

Young, R. A. (1986). Why are there so few transactions among water users? American Journal of Agricultural Economics, 68(5):1143-1151.

Young, R. A. (2005). Determining the Economic Value of Water: Concepts and Methods. RFF Press, Washington, DC, USA, illustrated edition. 
A. Appendix 


\section{Appendix 1:}

\section{Costs of Water Abstraction Questionnaire}

1) Questionnaire code:

3) Name of the village:

5) Name of the respondent:

6) Well code:

9) Role of respondent at home:

10) Respondents occupation:

11) Well ownership:

12) Well operational condition:
2) Name of the interviewer:

4) Name of the county:

Mobile:

TEL:

7) Well name: 8 ) Date:

$\square$ Head of household $\quad \square$ Member of household

$\square$ Well technical observer $\square$ Farmer $\square$ Both

$\square$ Other

$\square$ Smallholders

$\square$ Big holders

$\square$ Rented

$\square$ Own Used

Number of DONG: Number of HABEH: Number of HABEH owner:

13) If smallholder:

Name and share of 2 main owners:

Name and share of 2 minor owners:

14) If big holder, name and share of the owners:

1)

2)

3)

4)

\section{Well structure}

\begin{tabular}{|c|c|c|c|c|}
\hline 15 & Depth of the well: & 2008: & ------: & $----:$ \\
\hline 16 & Digging year: & & & \\
\hline \multirow[t]{2}{*}{17} & Last well deepening year: & & & \\
\hline & Number of well deepening: & & & \\
\hline \multirow[t]{3}{*}{18} & Last well movement (date): & & $\begin{array}{l}\text { Distance from } \\
\text { Last well: }\end{array}$ & \\
\hline & Number of well movement:: & & & \\
\hline & Buying land for well movement: & Size: & Value: & \\
\hline 19 & Water depth $(\mathrm{m}):$ & 2008: & -----: & -----: \\
\hline 20: & $\mathrm{EC}$ & 2008: & -----: & -----: \\
\hline 21 & Salinity: & Fresh $\square$ & Half $\square$ & Saline $\square$ \\
\hline 22 & Well-pump annual off days: & & & \\
\hline 23 & Well-pump facilities: & & & \\
\hline 24 & $\begin{array}{l}\text { Facilities to transfer water from well } \\
\text { to farms }\end{array}$ & & & \\
\hline \multirow[t]{2}{*}{25} & Size of the well jacket (inch): & & Size of pipe & (inch): \\
\hline & Size of the pipe jacket: & & & \\
\hline \multirow[t]{2}{*}{26} & Real water pumping rate (lit/s) & 2008: & -----: & ----: \\
\hline & Permitted water pumping rate (lit/s) & & & \\
\hline \multirow[t]{2}{*}{27} & Type of the engine & Electric $\square$ & Diesel $\square$ & \\
\hline & & Horizontal $\square$ & Vertical $\square$ & \\
\hline \multirow[t]{2}{*}{28} & Real power of the engine: & & & \\
\hline & Permitted power of engine: & & & \\
\hline \multirow[t]{3}{*}{29} & Brand of pump: & Pump floors: & & \\
\hline & Electricity subscription number: & & File code: & \\
\hline & Issued to: & & & \\
\hline
\end{tabular}




\begin{tabular}{|c|c|c|c|c|}
\hline & $\begin{array}{l}\text { The cost of labor for guarding the } \\
\text { garden in summer (common): }\end{array}$ & 2008: & 2007: & \\
\hline & The cost of water transfer repairing: & 2008: & 2007: & \\
\hline \multirow[t]{2}{*}{30} & Labor & No: & Salary: & Insurance: \\
\hline & Well representative: & & Salary: & \\
\hline \multirow[t]{16}{*}{31} & Cost of Repair & & & \\
\hline & New shaft and jacket: & -----: & Price: & Price $(\mathrm{m})$ : \\
\hline & Oil: $\quad$ brand: & No of barrels: & & \\
\hline & Weight of barrels: & & Price: & \\
\hline & Engine (buying / repair): & & & \\
\hline & Turbine (buying / repair): & & & \\
\hline & Cardan shaft (buying / repair): & & & \\
\hline & Gearbox (buying / repair): & & & \\
\hline & Shaft and jacket repair: & & No: & \\
\hline & $\begin{array}{ll}\text { Depth: } & \text { Crane } \\
\text { working hours: } & \end{array}$ & & Price: & \\
\hline & $\begin{array}{ll}\text { Depth: } & \text { Crane } \\
\text { working hours: } & \end{array}$ & & Price: & \\
\hline & $\begin{array}{ll}\text { Depth: } & \text { Crane } \\
\text { working hours: } & \\
\end{array}$ & & Price: & \\
\hline & & & & \\
\hline & Crane cost & Transport cost? & & \\
\hline & Labor & Crane work & Hour: & \\
\hline & Labor price & Crane work & Price: & \\
\hline 32 & Missiling? & & & \\
\hline 33 & Robbery costs: & & & \\
\hline \multirow[t]{5}{*}{34} & Cost of energy & Electricity & & Gasoline \\
\hline & & This year & & Last year \\
\hline & & Quantity: & & \\
\hline & & Price: & & \\
\hline & $\begin{array}{l}\text { Cost of well digging } \\
\text { (if available): }\end{array}$ & & & \\
\hline \multirow[t]{3}{*}{35} & Water selling price (per hour): & 2008: & 2007: & \\
\hline & Annual cost of each HABEH: & 2008: & 2007: & \\
\hline & The share of each HABEH from water & & & \\
\hline 37 & Value of each HABEH: & 2008: & 2007: & \\
\hline 38 & Renting cost of each HABEH: & 2008: & 2007: & \\
\hline 39 & Value of land irrigated by this well & (ha): & 2008: & 2007: \\
\hline 40 & Covering area by this well: & & & \\
\hline 41 & Area which left dry by farmers: & & & \\
\hline
\end{tabular}

How do you manage the well generally? 


\section{Appendix 2:}

\section{Operator Questionnaire}

1) Questionnaire code:

4) Name of the county:

6) Well code:
2) Name of the interviewer:

5) Name of the respondent:

7) Well local name:
3) Name of the village:

Mobile:

Tel:

8) Date:

9) Role of the respondent at home:

Head of household $\square$

Member of household $\square$

\section{Cropping Pattern and Agricultural Crops}

1) Does household own share from well?

O Yes

O No

\begin{tabular}{|l|l|l|c|}
\hline Well name & Share from the well & Number of operators & $\begin{array}{c}\text { Pump charge level } \\
(\text { lit/s) }\end{array}$ \\
\hline & & & \\
& & & \\
\hline
\end{tabular}

2) Does household own land?

A) Yes (if yes, size

B) No

\begin{tabular}{|l|r|r|}
\hline Well name & Land size & Soil quality: \\
\hline & $\mathrm{Ha} /$ Qasab & $\mathrm{Ha} /$ Qasab \\
$\mathrm{Ha} /$ Qasab & $\mathrm{Ha} /$ Qasab \\
$\mathrm{Ha} /$ Qasab & \\
\hline
\end{tabular}

Slope of land:

How many ha/qasabs are not planned anymore because of water shortages?

3) Does household rent land?
A) Yes (if yes, size
B) No
4) Number of pieces
size of each piece

Quality of soil:

Slope of land:

5) Type of produced pistachio?

Akbari, Kalehghuchi, Ahmadaghai, Ohadi, Badami, Zarand Momtaz, Khanjari Damghan,

Shahpasand sefid, Pesteh Nogh, Ghazvini, Fandoghi, Cheruki

6) Targeting Markets:
A) Domestic Markets
B) Exports
C) Both 
7) Price of products:

\begin{tabular}{|l|c|c|c|c|c|c|}
\hline \multirow{2}{*}{ Pistachio types } & \multicolumn{3}{|c|}{2007 price (rials /kg) } & \multicolumn{3}{c|}{2008 price (rials /kg) } \\
\cline { 2 - 7 } & $\begin{array}{c}\text { Fresh / } \\
\text { small }\end{array}$ & Open & Close & $\begin{array}{c}\text { Fresh / } \\
\text { small }\end{array}$ & Open & Close \\
\hline & & & & & & \\
& & & & & & \\
\end{tabular}

8) Garden structure:

\begin{tabular}{|l|l|l|l|l|l|l|l|l|l|}
\hline $\begin{array}{l}\text { Size of } \\
\text { the land }\end{array}$ & $\begin{array}{l}\text { Type of } \\
\text { pistachio }\end{array}$ & $\begin{array}{l}\text { Age of } \\
\text { trees }\end{array}$ & $\begin{array}{l}\text { Number } \\
\text { of male } \\
\text { trees }\end{array}$ & $\begin{array}{l}\text { Number } \\
\text { of rows }\end{array}$ & $\begin{array}{l}\text { Number } \\
\text { of trees } \\
\text { in each } \\
\text { row }\end{array}$ & $\begin{array}{l}\text { Distance } \\
\text { between } \\
\text { 2 rows }\end{array}$ & $\begin{array}{l}\text { Distance } \\
\text { between } \\
\text { 2 trees in } \\
\text { one row }\end{array}$ & $\begin{array}{l}\text { Soil } \\
\text { type }\end{array}$ & $\begin{array}{l}\text { Irrigation } \\
\text { method }\end{array}$ \\
\hline & & & & & & & & & \\
\hline
\end{tabular}

9) Production level:

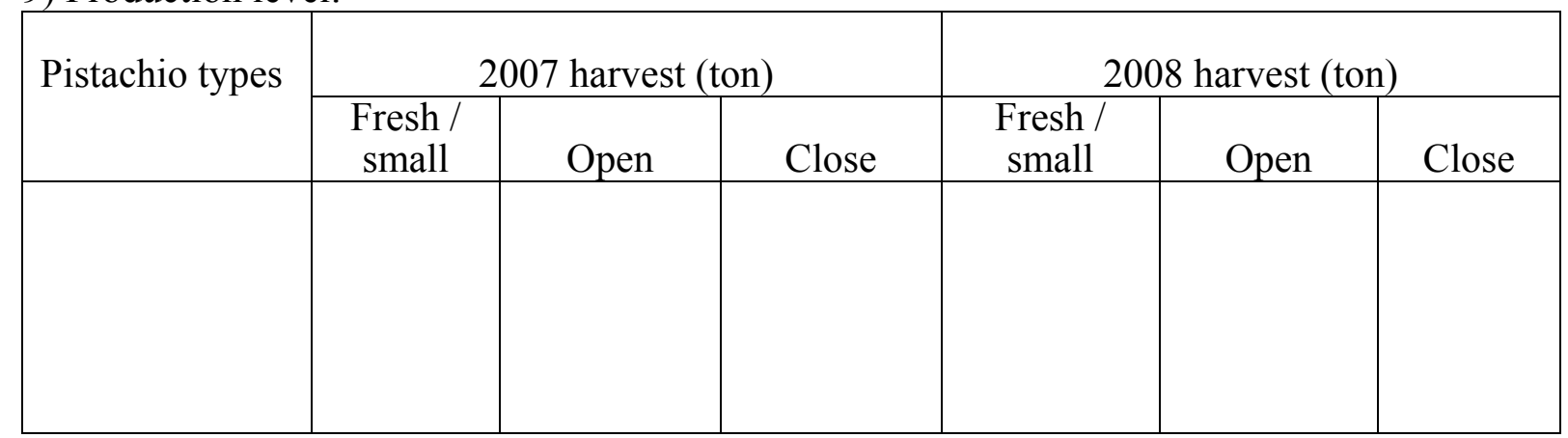

The ratio of fresh to dry harvest?

10) How many trees are dried out last year?

11) How many trees are replanted?

12) Do you have a fix plantation area? O Yes O No

What were your annual changes? 2005 $2006 \quad 2007$

Why?

13) Did you have a fix production level? O Yes O No

What were your annual changes? 2005 $2006 \quad 2007$

Why?

14) Did you have bearing year this agricultural year? O Yes O No

Which year did you have higher production?

- How different from low production?

Which year did you have lower production?

- How different from high production?

15) Do you have by-products / secondary crops?

Size:

Production level:

Price: 
16) Selling system:

- Exporter:

- Direct exporting:

- Middle Man:

- Pistachio Producers Co.:

- Pistachio Producers Cooperative:

\section{Cost of Crop Production?}

\section{Cost of production (without irrigation)}

1) The daily labor price at the village level:

$\begin{array}{llll}2007 & \text { Normal } & \text { Daily working hours: } & \text { Price (rials /day): } \\ 2007 & \text { Harvest time } & & \text { Price (rials /day): } \\ 2008 & \text { Normal } & \text { Daily working hours: } & \text { Price (rials /day): } \\ 2008 & \text { Harvest time } & & \text { Price (rials /day): }\end{array}$

2) Do you have permanent labor? O Yes O No

Permanent labor salary (2008):

Permanent labor salary (2009):

3) Guarding costs?

Summer 2008

Summer 2009

4) Cost of engineers?

5) Cost of laboratory?

\section{Garden construction costs?}

1) Have you newly established a pistachio garden? Yes $\square \quad$ No $\square$

2) When did you establish your garden?

3) Size of the established garden? $\mathrm{Ha} /$ Qasab

4) No of rows:

5) Distance between row:

6) Length of the row:

7) Land preparation:

\begin{tabular}{|l|c|c|c|}
\hline No: & $\begin{array}{c}\text { Excavation machine: } \\
\text { (tractor, loader, ...) }\end{array}$ & $\begin{array}{c}\text { Number of hours } \\
\text { work }\end{array}$ & $\begin{array}{c}\text { Price per hour } \\
\text { (rials / hours) }\end{array}$ \\
\hline & & & \\
\hline
\end{tabular}

8) Hole digging labor

10) Number of sibling

12) Grafting year

14) Price of graft:

16) Price of grafting labor:

17) Sand and manure distribution:

\begin{tabular}{|l|c|c|c|c|}
\hline & No of units & $\begin{array}{c}\text { Size of unit } \\
\text { (ton) }\end{array}$ & $\begin{array}{c}\text { Price of unit } \\
(1000 \text { rials / unit })\end{array}$ & Distribution cost \\
\hline Sand & & & & \\
\hline Manuare & & & & \\
\hline
\end{tabular}

18) Fertilizing year

21) Size of irrigation water
19) Pesticide year

22) Round days
9) Number of digged holes

11) Plantation labor

13) Number of grafts

15) Number of grafting labor:
20) Irrigation year

23) Hours 


\section{1) Inputs}

Sibling price in the region:

1)

2)

3)

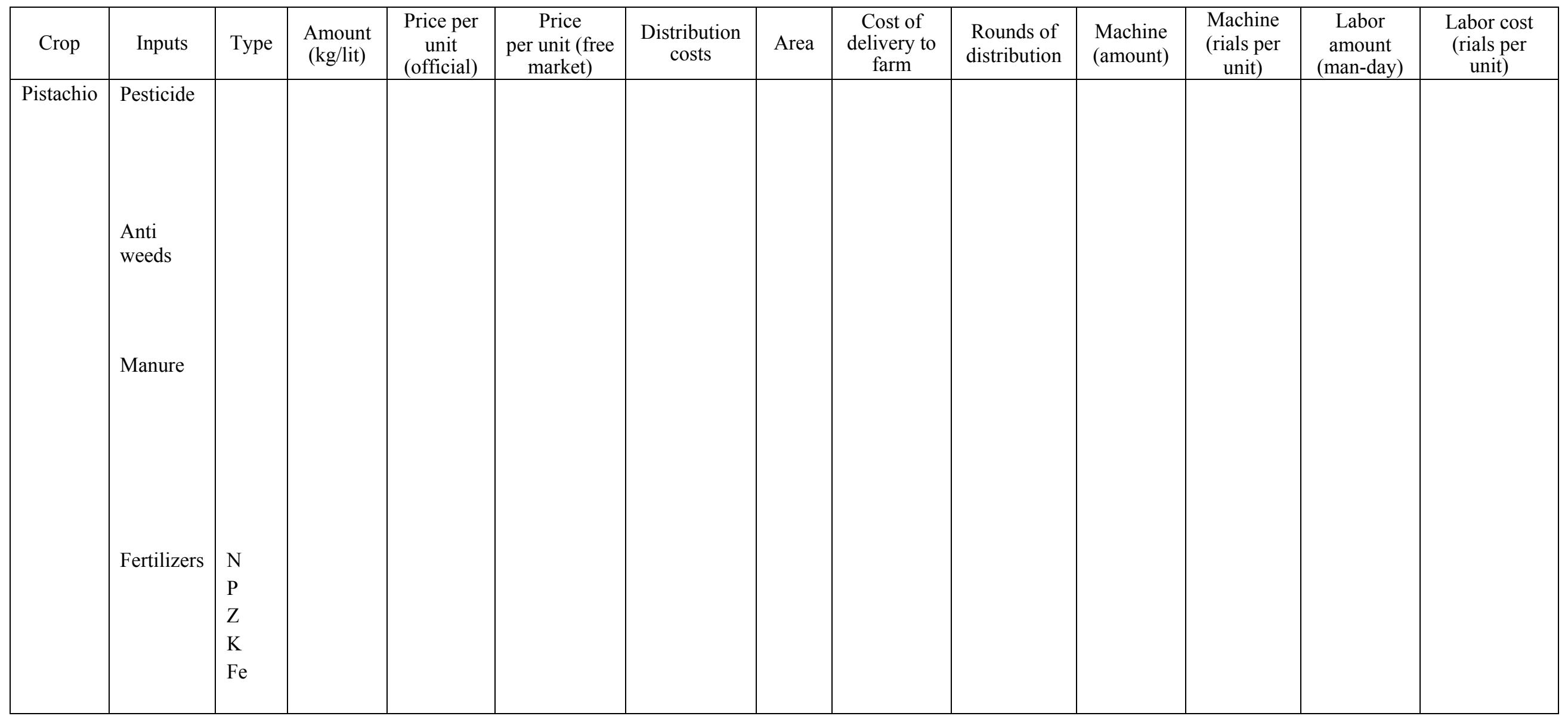


2) Machines

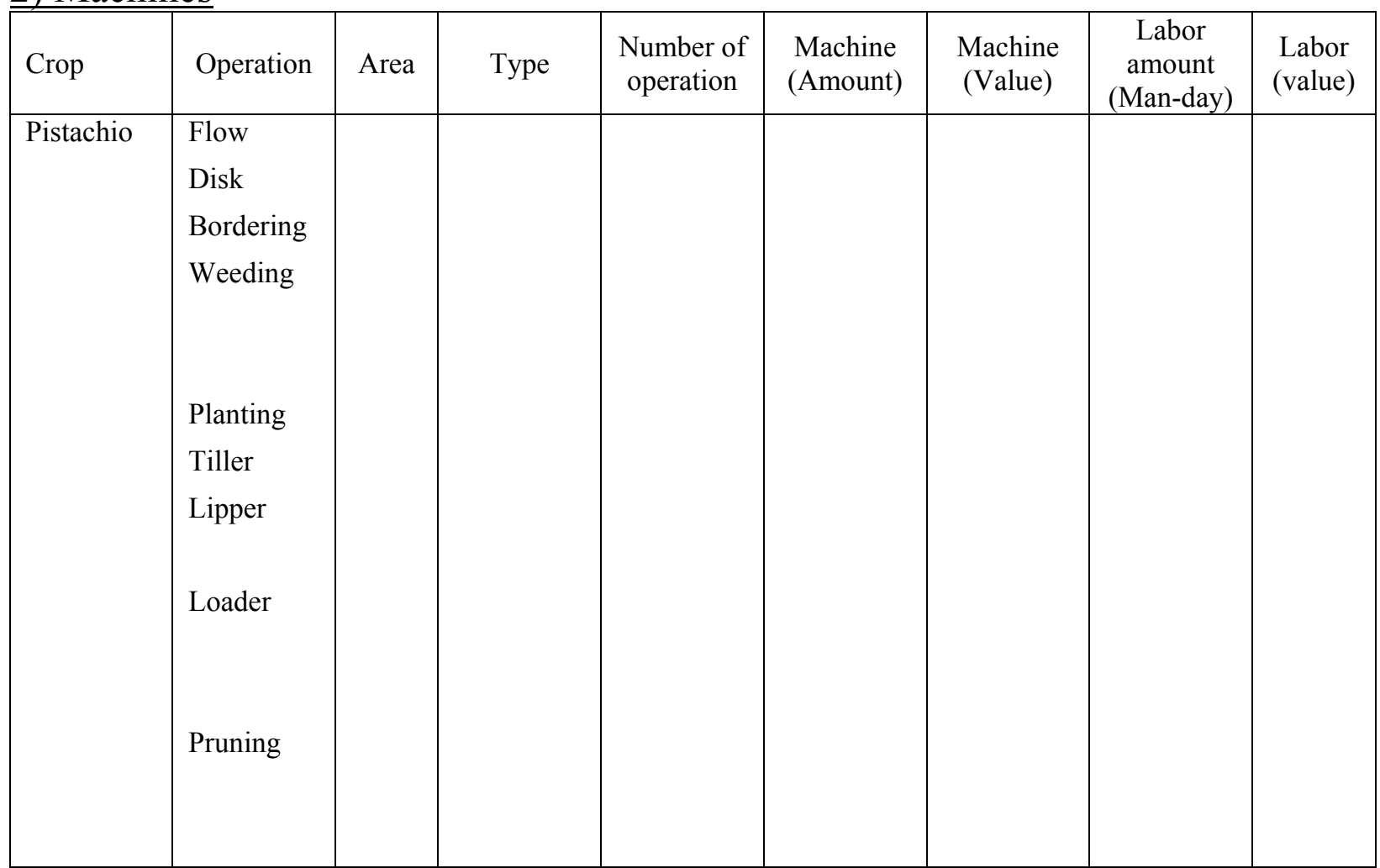

3) Harvest

\begin{tabular}{|c|c|c|c|c|c|c|c|c|c|c|c|c|c|}
\hline \multirow[b]{2}{*}{ 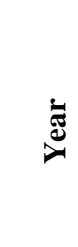 } & \multirow[b]{2}{*}{$\begin{array}{c}\text { Covering } \\
\text { Area } \\
\text { (ha) }\end{array}$} & \multicolumn{3}{|c|}{ Harvest } & \multicolumn{4}{|c|}{$\begin{array}{l}\text { Packing and } \\
\text { loading }\end{array}$} & \multicolumn{5}{|c|}{ Process Costs } \\
\hline & & 䓂 & 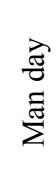 & $\begin{array}{l}\text { Daily } \\
\text { wages } \\
\text { (rials) }\end{array}$ & 䓂 & 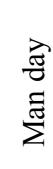 & $\begin{array}{l}\text { Daily } \\
\text { wages } \\
\text { (rials) }\end{array}$ & $\begin{array}{c}\text { Cost of } \\
\text { delivery } \\
\text { to } \\
\text { warehouse }\end{array}$ & 葛 & Machine & $\begin{array}{l}\text { Labor } \\
\text { type }\end{array}$ & $\begin{array}{c}\text { Amount } \\
\text { (man - } \\
\text { day) }\end{array}$ & $\begin{array}{l}\text { Daily } \\
\text { wages } \\
\text { (rials) }\end{array}$ \\
\hline \multirow[t]{2}{*}{2008} & & & & & & & & & & & Male & & \\
\hline & & & & & & & & & & & Female & & \\
\hline \multirow[t]{2}{*}{2009} & & & & & & & & & & & Male & & \\
\hline & & & & & & & & & & & Female & & \\
\hline
\end{tabular}

4) Number of packing (box or package)?

Unit price

\section{$\underline{\text { Water and Irrigation }}$}

1) Water resources

During last year, did you?

Rent water resources: O Yes $\quad \mathrm{O}$ No

If yes, how much?

Buy water resources: O Yes O No

If yes, how much?

2) Irrigation water system
Type:
A) Drop
B) Bubbler
C) Furrow
D) Plot irrigation
Area:
A) $\ldots .$.
B) $\ldots$.
C) $\ldots$
D) $\ldots$.

Cost of establishing the irrigation systems? 
3) Rent or selling price of agricultural land and water resources during one agricultural season?

\begin{tabular}{|l|l|l|l|l|l|}
\hline Description & $\begin{array}{l}\text { Land with water } \\
\text { resources }\end{array}$ & $\begin{array}{l}\text { Land without water } \\
\text { resources }\end{array}$ & $\begin{array}{l}\text { Water without } \\
\text { land }\end{array}$ & Well & $\begin{array}{l}\text { Volume } \\
\text { of well }\end{array}$ \\
\hline Rent (2007) & & & & & \\
\hline 2007 & & & & & \\
\hline Sell $(2008)$ & & & & & \\
\hline 2008 & & & & & \\
\hline
\end{tabular}

3) Water price

\begin{tabular}{|l|l|l|l|l|}
\hline Source: & Year & Price & Value & Costs \\
\hline & 2007 & & & \\
& 2008 & & & \\
\hline & 2007 & & & \\
& 2008 & & & \\
\hline & 2007 & & & \\
& 2008 & & & \\
\hline
\end{tabular}

5) Characters of each round of irrigation?

\begin{tabular}{|l|l|l|l|l|l|l|}
\hline Crops & Area & $\begin{array}{l}\text { Amount of } \\
\text { purchased } \\
\text { water }\end{array}$ & $\begin{array}{l}\text { Amount of } \\
\text { received } \\
\text { water }\end{array}$ & $\begin{array}{l}\text { Number of } \\
\text { irrigation } \\
\text { rounds }\end{array}$ & $\begin{array}{l}\text { Length of } \\
\text { each irrigation } \\
\text { round }\end{array}$ & $\begin{array}{l}\text { Seasonal } \\
\text { period of } \\
\text { Irrigation }\end{array}$ \\
\hline $\begin{array}{l}\text { Old } \\
\text { orchards }\end{array}$ & & & & & \\
$\begin{array}{l}\text { New } \\
\text { orchards }\end{array}$ & & & & & & \\
\hline
\end{tabular}

6) Man-day required for irrigation and its costs

7) Last well deepening: How deep?

Change of plantation area? O Yes O No How much?

Increases in pumped water compared to the past? O Yes O No

How much?

8) Last movement of well: How far? How deep?

Change of plantation area? O Yes O No How much?

Increases in pumped water compared to the past? O Yes O No

How much?

9) Quality of well water?

O Suitable O Low salty O Middle salty O High salty

\section{$\underline{\text { Water Market }}$}

10) Have you ever given water to your neighbours? O Yes O No If yes

\begin{tabular}{|l|l|l|l|l|}
\hline For which crops & At which level & For which season & How many times & How? \\
\hline & & & & \\
\hline
\end{tabular}


How?
A) Free
B) For commodities
C) For the same round
D) For money-price

11) How the water price can be determined?

$\mathrm{O}$ By middle man $\mathrm{O}$ Bargaining $\mathrm{O}$ Determined from beginning O Other (please describe)

12) How do they measure the size of water?

O Volumetrically O Hourly O Other

13) How can you transfer water to the field?

$\begin{array}{lll}\text { O PVC pipeline } & \text { O Cement pipeline } & \text { O Tank }\end{array}$

14) What is the share of different water resource on your usages last year?

\begin{tabular}{|c|c|c|c|c|}
\hline Source & Type of provision & Time and operation & $\begin{array}{c}\text { No of } \\
\text { irrigations }\end{array}$ & Percentage \\
\hline \multirow{3}{*}{ Official quota/ Free } & & & & \\
& Oficial quota /Free & & & \\
\hline
\end{tabular}

\section{Household Characters}

1) Credit from bank? O Yes O No

\begin{tabular}{|l|l|l|l|l|}
\hline $\begin{array}{l}\text { Bank name / (money } \\
\text { lender) }\end{array}$ & Amount & Interest Rate & $\begin{array}{l}\text { Annual } \\
\text { repayment }\end{array}$ & $\begin{array}{l}\text { Period of } \\
\text { repayment }\end{array}$ \\
\hline & & & & \\
& & & \\
\hline
\end{tabular}

2) Membership of any organization? O Yes O No

\begin{tabular}{|l|l|l|l|l|}
\hline Name & Annual charge & Services & Supports & Buying crops \\
\hline & & & & \\
& & & & \\
\hline
\end{tabular}

3) Family Members

\begin{tabular}{|l|l|l|l|l|l|}
\hline Relation to head & Age & Education level & Job & Help in the field & How much \\
\hline & & & & & \\
& & & & & \\
\end{tabular}

Household children who have left the family:

\begin{tabular}{|l|l|l|}
\hline Gender & Job & Education \\
\hline & & \\
& & \\
\hline
\end{tabular}

4) Does the head of household has another job? What? Where? 
5) Where is the residence of household?
O Village
O County centre
O City
O Out of province

6) Household machine and transport facilities:

\begin{tabular}{|l|l|l|c|c|}
\hline Type & Number & Model & Activity out of field & How much \\
\hline Car & & & Yes / No & \\
Tractor & & & Yes / No & \\
Truck & & & Yes / No & \\
Motorcycle & & & Yes / No & \\
& & & & \\
\hline
\end{tabular}

7) Animal husbandry?

\begin{tabular}{|l|l|l|l|l|l|}
\hline \multicolumn{1}{|c|}{ Type } & Number & Source of water & Size of water & Costs & Benefits \\
\hline Cow & & & & & \\
Sheep & & & & & \\
Goat & & & & & \\
Chicken & & & & & \\
\hline
\end{tabular}

8) Farm insurance

\begin{tabular}{|l|l|l|}
\hline & 2007 & 2008 \\
\hline Type of insurance: & & \\
\hline Insurance costs: & & \\
\hline Repaid casualty costs: & & \\
\hline
\end{tabular}

9) Do you do agricultural activities in another place? O Yes O No

Planted area?

Crop?

Which region? 